\author{
UNIVERSIDADE DE SÃO PAULO \\ Faculdade de Filosofia, Ciências e Letras de Ribeirão Preto \\ Departamento de Física
}

Kaio Felippe Secchinato

Mapeamento da vasorreatividade cerebral sem estímulo vasoativo: Um estudo de imagens em estado de repouso

Ribeirão Preto, São Paulo, Brasil 

Kaio Felippe Secchinato

\title{
Mapeamento da vasorreatividade cerebral sem estímulo vasoativo: Um estudo de imagens em estado de repouso
}

\begin{abstract}
Dissertação apresentada ao Programa de PósGraduação em Física Aplicada à Medicina e Biologia do Departamento de Física da Faculdade de Filosofia, Ciências e Letras de Ribeirão Preto da Universidade de São Paulo, para a obtenção do título de Mestre em Ciências.
\end{abstract}

\begin{abstract}
Universidade de São Paulo - USP
Faculdade de Filosofia, Ciências e Letras de Ribeirão Preto - FFCLRP

Programa de Pós-Graduação em Física Aplicada à Medicina e Biologia

Versão Corrigida
\end{abstract}

Orientador: Dra. Renata Ferranti Leoni

Ribeirão Preto, São Paulo, Brasil 
Autorizo a reprodução e divulgação total ou parcial deste trabalho, por qualquer meio convencional ou eletrônico, para fins de estudo e pesquisa, desde que citada a fonte.

Secchinato, Kaio Felippe

Mapeamento da vasorreatividade cerebral sem estímulo vasoativo: um estudo de imagens em estado de repouso / Kaio Felippe Secchinato. - Ribeirão Preto, São Paulo, Brasil, 2021-

87 p. : il. ; $30 \mathrm{~cm}$.

Dissertação apresentada ao Programa de Pós-Graduação em Física Aplicada à Medicina e Biologia do Departamento de Física da Faculdade de Filosofia, Ciências e Letras de Ribeirão Preto da Universidade de São Paulo Orientador: Dra ${ }^{a}$. Renata Ferranti Leoni

1. Vasorreatividade cerebral. 2. Imagem por Ressonância Magnética. 3. Imagem funcional em respouso. 4. Estenose de carótidas. 5. Estenose carotídea assintomática. 6. Hemodinâmica cerebral. 
Kaio Felippe Secchinato

\section{Mapeamento da vasorreatividade cerebral sem estímulo vasoativo: Um estudo de imagens em estado de repouso}

Dissertação apresentada ao Programa de Pós-Graduação em Física Aplicada à Medicina e Biologia do Departamento de Física da Faculdade de Filosofia, Ciências e Letras de Ribeirão Preto da Universidade de São Paulo, para a obtenção do título de Mestre em Ciências.

Ribeirão Preto, São Paulo, Brasil,

Aprovado em:

Banca Avaliadora

Prof. Dr.: Instituição:

Julgamento: Assinatura:

Prof. Dr.: Instituição:

Julgamento: Assinatura:

Prof. Dr.: Instituição:

Julgamento: Assinatura:

Ribeirão Preto, São Paulo, Brasil 

Dedico esse trabalho a Deus. Tenho certeza que teus planos para minha vida são maiores do que eu posso imaginar. 



\section{Agradecimentos}

Antes de mais nada, parece clichê, mas gostaria de agradecer a Deus pela força que me deu ao longo de todo esse trabalho. Também agradeço à minha mãe, meu pai, meus irmãos e aos meus cachorros pelo carinho de sempre. Vou tentar fazer a partir daqui de forma cronológica.

Agradeço ao meu professor de matemática do ensino médio, professor Lauro. Agradeço também algumas pessoas que não tenho mais o contato, mas que foram de fundamental importância para eu entrasse na USP, e o mais importante: não desistir nos momentos difíceis, principalmente no começo.

Agora já na USP, agradeço aos veteranos que me acolheram de uma maneira que eu não sabia que seria próximo do possível: Cueca, Três Pontas e Didi.

Á amizade da turma XV de física médica no começo de tudo, em especial, Tricô, Xitara, Sardinha e Kurumim. Às inúmeras idas ao direito passar praticamente o dia todo estudando e realmente me carregando no colo o curso todo: Gustavo, Kurumim, Coroinha e Chucrute. Também mostro minhas sinceras homenagens ao professor de Cálculo 1 que disse, com essas palavras, que eu não conseguiria terminar o curso por ter tirado 0,25 em sua primeira prova.

No terceiro ano, ano bastante difícil, e não menos divertido, agradeço (além de fazer menção honrosa) ao Gilberto, que foi monitor de eletromagnetismo, matéria mais temida do curso e ao professor Garrido, que nem imagina o quão legal eram as aulas de terça e quinta a noite, apesar de eu não ter forças de pegar no lápis para fazer anotações durante a aula, por ter ficado o dia todo estudando exaustivamente ("Gustavo: 8 horas no proá da filô e 14hrs no direito?").

À República Budega que me proporcionaram inúmeras noites de quinta de muita água de malte, música e risadas. B1, B2, Leôncio (papi), Nosferatu, Perônio, Pippen e mais recentemente: Pariu, Temer, Lost, Molejo, Suri, Bolt.

Ao laboratório INBRAINLAB pelo crescimento profissional (e intelectual) que me proporcionou. Cera, Ícaro, Maíra, Jean, Bruninho, André, Pedro, Fábio, Hohana, Erick e Carlo. O Pedro merece uma menção honrosa pelas idas aos domingos e feriados ao laboratório para me acompanhar na minha iniciação científica. Também agradeço ao pessoal do Hospital das Clínicas de Ribeirão Preto, Octávio, Guilherme e Ana Paula pelas sugestões que só enriqueceram o trabalho. Ao professor Martin, que apesar de não ser da área desse trabalho, é o Google humano, agradeço pelos conselhos de amigo que me passou.

A Renata merece um parágrafo individual. A única expressão que me vem à cabeça é

"ela nem imagina o quanto legal ela é". É impressionante a leveza que essa pessoa tem de 
orientar seus alunos e dar aulas de assuntos extremamente complicados. Eu não tenho nem dúvidas que você nasceu pra isso, Renata. Obrigado pela orientação no tempo de iniciação científica e no mestrado. Quando eu ouvir a expressão, "qualidade profissional", você é a primeira pessoa que virá em minha cabeça.

Por fim, nesses últimos 2 anos as novas amizades que fiz, que sem dúvidas serão amizades que lavarei pelo resto da vida: Toco's - Caio, Paulinho, Dadalt, Natasha e Vivian. Foi muito divertido dividir esses 2 anos com vocês, e o mais importante: ter pra quem correr quando tudo estava dando errado. 


\section{Resumo}

A reatividade cerebrovascular (CVR) representa a habilidade da musculatura lisa vascular de dilatar-se ou contrair-se em resposta às alterações de demanda metabólica ou a estímulos vasoativos para regular o fluxo sanguíneo cerebral quando necessário. Essa resposta pode ser afetada em diversas doenças neurológicas, principalmente em doenças cerebrovasculares, tanto em magnitude quanto em atraso temporal. Esse último sendo observado como um deslocamento temporal (time shift, TS) da resposta. Tais grandezas são importantes para reportar o estado hemodinâmico cerebral, e tem despertado interesse em diversos estudos que podem prever o risco de acidente vascular cerebral em pacientes com estenose de carótidas. No entanto, os métodos de medições requerem condições específicas, como por exemplo, administração de acetazolamida ou inalação de $\mathrm{CO}_{2}$ enquanto são adquiridas imagens de ressonância magnética (IRM). Nesse trabalho, avaliamos CVR e TS a partir das flutuações do sinal de IRM baseadas no contraste dependente da oxigenação sanguínea (BOLD) em estado de repouso, sem a realização de desafios de hipercapnia. Na primeira parte do estudo, identificamos a faixa de frequência adequada de filtragem temporal do sinal de repouso para obtenção de mapas de CVR, com base na correlação espacial com mapas de CVR padrão obtidos com a inalação de $\mathrm{CO}_{2}$ e pausa respiratória. Cinco pacientes com estenose de carotídea assintomática unilateral severa (70 \pm 3 anos) e cinco sujeitos controles ( $65 \pm 3$ anos) realizaram o experimento com inalação de $\mathrm{CO}_{2}$; e 23 indivíduos idosos saudáveis (67 \pm 6 anos) realizaram o experimento com pausa respiratória. Mapas de CVR obtidos através do modelo de regressão linear geral mostraram maior correlação espacial quando usado o regressor do sinal global filtrado em 0,02 a 0,04 Hz, quando comparados com mapas de referência. Assim, essa banda de frequências foi utilizada para a segunda parte do estudo, em que avaliamos CVR e TS em 20 pacientes com estenose de carotídea assintomática unilateral severa (12 mulheres; 8 homens; idade média $=67 \pm 10$ anos) comparando com um grupo controle saudável (8 mulheres; 12 homens; idade média $=68 \pm 7$ anos), nas principais regiões de irrigação arterial. Nos pacientes, valores de CVR reduzidos foram observados bilateralmente em regiões irrigadas pela porção intermediário da artéria cerebral anterior (ACA) quando comparada à porção proximal, e para a artéria cerebral média (ACM) proximal quando comparada à distal $(\mathrm{p}<0,05)$. Os valores de TS foram maiores nos pacientes nas três porções do território do ACM e na porção distal do território da artéria cerebral posterior (ACP), no hemisfério ipsilateral à estenose, quando comparados às regiões correspondentes do grupo controle $(p<0,04)$. Além disso, nos pacientes, TS foi maior na ACM distal ipsilateral à estenose em comparação com a mesma região do hemisfério contralateral $(p=0,0025)$. Alterações regionais semelhantes de CVR e TS foram observadas ao analisar visualmente mapas individuais sugerindo que as metodologias são complementares. Os resultados sugerem que esses parâmetros podem refletir alterações hemodinâmicas subclínicas e são úteis para investigar áreas com maior risco de dano neuronal ou acidente vascular cerebral isquêmico em um nível individual. Portanto, o 
estudo da hemodinâmica cerebral por meio de IRM em estado de repouso pode se tornar uma ferramenta não invasiva para ajudar na estratificação de pacientes com estenose carotídea assintomática quanto à probabilidade de evolução para um acidente vascular cerebral.

Palavras-chave: Vasorreatividade cerebral, Imagem por Ressonância Magnética, Imagem funcional em respouso, Estenose de carótidas, Estenose carotídea assintomática, Hemodinâmica cerebral. 


\section{Abstract}

Cerebrovascular reactivity (CVR) represents the ability of the vascular smooth muscle to dilate or contract in response to changes in metabolic demand changes or vasoactive stimuli to regulate cerebral blood flow when necessary. This response can be affected in several neurological diseases, mainly cerebrovascular diseases, both in magnitude and in time delay. The latter is observed as a temporal shift (TS) of the response. Such measures are valuable to report the hemodynamic state of the brain and are of interest in several studies trying to predict the risk of stroke, such as in patients with carotid artery stenosis. However, standard methods require specific conditions, such as administering acetazolamide or inhalation of $\mathrm{CO}_{2}$ while magnetic resonance images (MRI) are acquired. In the present study, we evaluated CVR and TS from fluctuations in the MRI signal based on the blood oxygenation-dependent contrast (BOLD) at rest, without performing hypercapnia challenges. In the first part of the study, we identified an adequate frequency range for temporal filtering of the resting-state signal to obtain CVR maps, based on the spatial correlation with standard CVR maps obtained with $\mathrm{CO}_{2}$ inhalation and breath-holding. Five patients with unilateral severe asymptomatic carotid stenosis (70 \pm 3 years) and five controls (65 \pm 3 years) performed the experiment with $\mathrm{CO}_{2}$ inhalation, and 23 healthy elderly (67 \pm 6 years) performed the experiment with breath-holding. CVR maps obtained through the general linear regression model showed a more significant spatial correlation when using the regressor of the global signal filtered at 0.02 to $0.04 \mathrm{~Hz}$ when compared with reference maps. Thus, this frequency band was used for the second part of the study, in which we evaluated CVR and TS in 20 patients with unilateral severe asymptomatic carotid stenosis ( 12 women; 8 men; mean age $=67 \pm 10$ years) comparing with a group of healthy control ( 8 women; 12 men; mean age $=68 \pm$ seven years). In patients, reduced CVR values were observed bilaterally in regions irrigated by the intermediary portion of the anterior cerebral artery (ACA) when compared to the proximal portion and for the proximal, middle cerebral artery (MCA) when compared to the distal $(p<0.05)$. TS values were higher in patients in the three portions of the MCA territory and the distal portion of the posterior cerebral artery (PCA) territory, in the hemisphere ipsilateral to the stenosis, when compared to the corresponding regions of the control group $(\mathrm{p}<0.04)$. In addition, in patients, TS was higher in the distal MCA ipsilateral to the stenosis compared to the same region in the contralateral hemisphere $(\mathrm{p}=0.0025)$. Similar regional changes in CVR and TS were observed when visually analyzing individual maps suggesting that the methodologies are complementary. These parameters may reflect subclinical hemodynamic changes and help investigate areas with a higher risk of neuronal damage or ischemic stroke at an individual level. Therefore, the study of cerebral hemodynamics through MRI at rest can become a non-invasive tool to help stratify patients with asymptomatic carotid stenosis regarding the 
likelihood of a stroke.

Keywords: Cerebral vasoreactivity, Magnetic resonance imaging, functional imaging at rest, carotid stenosis, asymptomatic carotid stenosis, cerebral hemodynamics. 


\section{Lista de ilustrações}

Figura 1 - Suprimento sanguíneo arterial cerebral. Figura adaptada de Manual MSD Versão para profissionais de saúde (MANUAL-MSD, 2021) e Fisher e colaboradores (FISHER; MIKULIS, 2021). São representados: ACI = artéria carótida interna, $\mathrm{AB}=$ artéria basilar, $\mathrm{AV}$ = artéria vertebral, $\mathrm{ACA}$ = artéria cerebral anterior, $\mathrm{ACM}=$ artéria cerebral média e $\mathrm{ACP}=$ artéria cerebral posterior. . 22

Figura 2 - Artéria cerebral Anterior (ACA) em verde, artéria cerebral média (ACM) em vermelho e artéria cerebral psoterior (ACP) em azul referem-se aos territórios de fluxo padrão perfundidos pelas artérias cerebrais bilaterais anterior, média e posterior, respectivamente, enquanto os sombreamentos representam sua subdivisão em territórios de fluxo proximal, intermediário e distal, com base em tempos de trânsito arterial. Figura adaptada de Mutsaerts e colaboradores (MUTSAERTS et al., 2015) . . . . . . . . . . . . . . . . 23

Figura 3 - Relação entre a pressão parcial de CO2 arterial e fluxo sanguíneo cerebral. Figura adaptada de Guyton e coladoradores (GUYTON, 2006) . . . . . . . .

Figura 4 - Esquema do efeito BOLD em atividade neuronal (A) e em desafios de hiper-

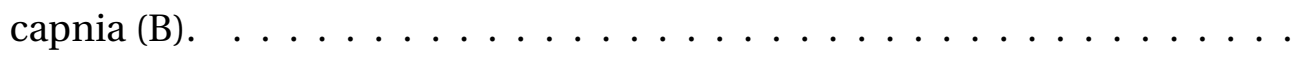

Figura 5 - Esquema dos equipamentos necessários para desafio de hipercapnia. Adaptada de Lu e colaboradores (LU et al., 2014). . . . . . . . . . . . . . . . . . 36

Figura 6 - O diagrama mostra as etapas do procedimento da metodologia de mapeamento de reatividade cerebrovascular em estado de repouso. . . . . . . . . 39

Figura 7 - Metodologia de correlação entre todos os voxels com alguma curva de referência (em vermelho), fazendo adiantamento (em em cinza) e atrasando (em vermelho), para obtenção do mapa de deslocamento temporal. . . . . .

Figura 8 - Metodologia para mapeamento de CVR com inalação de CO2 e em estado de repouso. $(*)$ Indica todas as 5 bandas de frequências utilizadas. . . . . . .

Figura 9 - Esquema ilustrativo do método iterativo para o mapeamento do deslocamento temporal (TS). . . . . . . . . . . . . . . . .

Figura 10 - Coeficientes de correlação de Pearson entre os valores de reatividade cerebrovascular obtidos para o estado de repouso (cerebrovascular reactivity em estado de repouso (rs-CVR)), filtrados para diferentes bandas de frequências, comparados com aqueles obtidos durante a inalação de $\mathrm{CO}_{2} \cdot\left({ }^{*} \mathrm{p}<0.05\right.$; $\left.{ }^{* *} \mathrm{p}<0.01 ;{ }^{* * *} \mathrm{p}<0.001\right)$. Figura adaptada de Secchinato e colaboradores (SECCHINATO et al., 2019) . . . . . . . . . . . . . . . . . . . . 53 
Figura 11 - Mapas de CVR obtidos com BOLD-MRI adquiridos durante o estado de repouso (rs-CVR, primeira linha) e durante a hipercapnia (CVR $\operatorname{com~} \mathrm{CO}_{2}$, segunda linha). Foi observada boa correlação entre os valores de CVR obtidos pelos dois métodos (terceira linha; r: coeficiente de correlação de Pearson; com todos os valores sendo $\mathrm{p}<0,05)$. Uma fatia de cada paciente é mostrada em orientação radiológica. D: direita; E: esquerda. . . . . . . . . . 54

Figura 12 - Comparação entre o mapa médio de CVR do grupo obtido a partir desafio de pausa respiratória e em estado de repouso. Na minha linha é apresentado o mapa de CVR em pausa respiratória; na segunda linha o mapa de CVR em estado de repouso obtidos com determinadas frequência; e na terceira linha os histogramas dos valores de CVR de ambas metodologias comparado com CVR em pausa respiratória. . . . . . . . . . . . . . . . . 57

Figura 13 - Mapas de reatividade cerebrovascular em estado de repouso (rs-CVR) para pacientes (à esquerda) e para controle saudáveis (à direita). Os mapas estão em unidades relativas. $\mathrm{D}=$ direita; $\mathrm{E}=$ esquerda. . . . . . . . . . . . . 58

Figura 14 - Reatividade cerebrovascular em repouso (rs-CVR) para os territórios das artérias cerebrais dos pacientes, ambos os hemisférios (ipsi e contralateral ao lado da estenose severa) e controles. São apresentadas diferenças estatísticas significantes dentro dos grupos ( ${ }^{*} \mathrm{p}<0,05$; ${ }^{* *} \mathrm{p}<0,01$; $\left.{ }^{* * *} \mathrm{p}<0,001\right) \mathrm{e}$ entre os grupos $(++\mathrm{p}<0,01 ;+++\mathrm{p}<0,001) \ldots \ldots \ldots 59$

Figura 15 - Mapas de reatividade cerebrovascular em estado de repouso (rs-CVR) usando o sinal global atrasado para regressão linear. A série temporal do sinal global foi atrasada em deslocamentos de 1 segundo até 4 segundos (deslocamentos temporais (TS) de 0, 1, 2, 3 e 4 segundos). Uma fatia é mostrada para cada atraso e cada paciente. . . . . . . . . . . . . . . . .

Figura 16 - Mapas de deslocamento temporal (BOLD-TS) para pacientes (esquerda) e controles (direita). Os mapas estão em segundos. $\mathrm{E}=$ esquerda; $\mathrm{D}=$ Direita. 61

Figura 17 - Índice de deslocamento de tempo (TS BOLD) para os territórios da artéria cerebral dos pacientes, ambos os hemisférios (ipsi e contralateral ao lado da estenose) e controles. São apresentadas diferenças estatísticas significativas dentro dos grupos $\left({ }^{*} \mathrm{p}<0,05 ;{ }^{* *} \mathrm{p}<0,01 ;{ }^{* * *} \mathrm{p}<0,001\right)$ e entre os grupos $(+\mathrm{p}$ $<0,05 ;++\mathrm{p}<0,01 ;+++\mathrm{p}<0,001) \ldots \ldots \ldots 2$

Figura 18 - Regressão linear entre destolamento temporal (valores de TS BOLD) e o reatividade cerebrovascular (CVR), mostrando uma correlação negativa significativa entre (A) pacientes e (B) controles. O teste de normalidade Kolmogorov-Smirnov foi realizada e os coeficientes de correlação de Pearson (r) e de determinação ( $\mathrm{R}^{2}$ ajustado) foram apresentados. . . . . . . . . 62 


\section{Lista de tabelas}

Tabela 1 - Dados demográficos dos pacientes para o estudo da correlação entre rsCVR e CVR em hipercapnia em ECa. . . . . . . . . . . . . . . . . . . . 48

Tabela 2 - Dados demográficos dos pacientes com ECa unitaleral severa para avaliação da rs-CVR. . . . . . . . . . . . . . . . . . . . . . . . . 51 



\section{Lista de Abreviações}

ACA artéria cerebral anterior 21, 55, 56, 64

ACE artéria carótida externa 21

ACI artéria carótida interna 21, 53, 64, 66

ACM artéria cerebral média 21, 53, 55, 56, 63-65

ACP artéria cerebral posterior 21, 55, 56

AIT ataque isquêmico transitório 24, 50

angio-MR angiografia por ressonância magnética 65

ASL arterial spin labeling 33, 41, 65

ATP trifosfato de adenosina 34

AVC acidente vascular cerebral 22-24, 39-41, 50, 69

BOLD blood oxygen level-dependent 26, 34, 35, 37-40, 45, 48, 50, 53, 63, 66, 67, 69

$\mathbf{C M R O}_{2}$ cerebral metabolic rate of oxygen 28,34

CVR cerebrovascular reactivity 24, 26-28, 30, 33, 35-39, 41, 43, 45, 49-51, 53-56, 63-67, 69

deoxi-Hb desoxihemoglobina 32, 34, 35

ECa estenose de carótida assintomática 43, 45, 47, 50, 63-65, 69

EPI Echo planar imaging 47, 48

FSC fluxo sanguíneo cerebral 21-28, 30, 32, 33, 35, 65

FSCr fluxo sanguíneo cerebral regional 34

GRE gradiente eco 47,48

Hb hemoglobina 34

IRM imagens de ressonância magnética 26, 32, 36, 37

IRMf imagens por ressonância magnética funcional 34-36, 38, 45, 47, 66 
MTT mean transit time 25, 26, 41, 64

NIRS near-infrared spectroscopy 32

oxi-Hb oxihemoglobina 32, 34, 35

$\mathbf{P a C O}_{2}$ pressão parcial de $\mathrm{CO}_{2}$ no sangue arterial 26-30, 35

$\mathbf{P a O}_{2}$ pressão parcial de $\mathrm{O}_{2}$ no sangue arterial 28-30

PET positron emission tomography 31, 32, 34

PETCO $_{2}$ pressão parcial de $\mathrm{CO}_{2}$ ao final da expiração 27-30, 36-39, 43, 49, 53, 63, 64, 66, 71

RM ressonância magnética 34, 35, 37, 38, 50, 65, 69

RM-PC ressonância magnética com contraste de fase 33

ROI region of interest 37

rs-CVR cerebrovascular reactivity em estado de repouso 13-15, 45, 48, 50, 51, 53-55, 58-60, $63-67$

rs-fMRI resting-state functional magnetic resonance imaging 38, 40, 47, 49, 50

sLFOs systemic low-frequency oscillations 66

SPECT single photon emission computed tomography 32

TR time repetition 37

TS time shift 40, 43, 45, 51, 56, 63-66, 69

TTP tempo ao pico 41, 64

UDTC ultrassom com doppler transcraniano 30

VSC volume sanguíneo cerebral 25 


\section{Sumário}

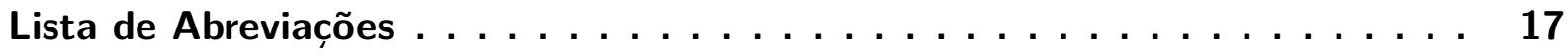

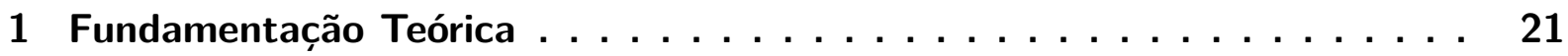

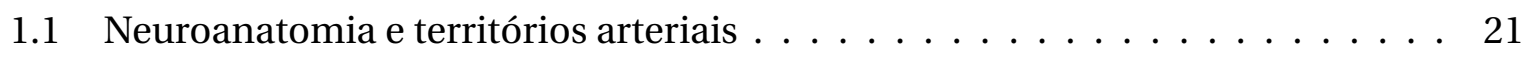

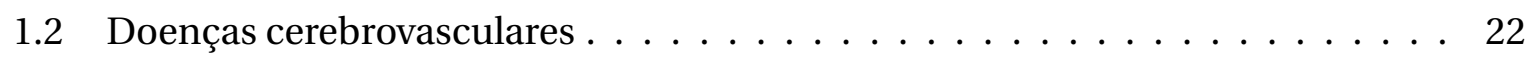

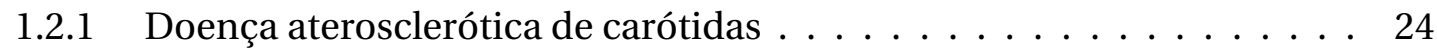

1.3 Reatividade Cerebrovascular . . . . . . . . . . . . . . . . . . . 24

1.3.1 Efeito vasoativo da $\mathrm{PaCO}_{2} \ldots \ldots \ldots \ldots \ldots \ldots \ldots \ldots$

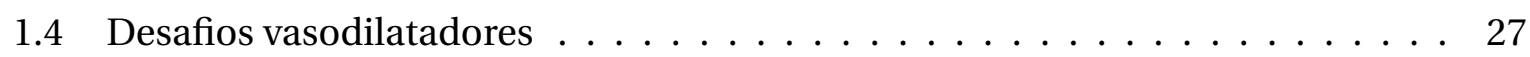

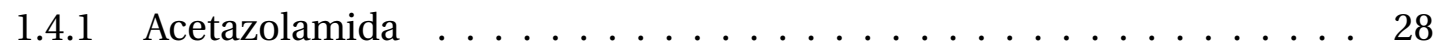

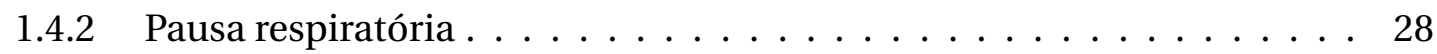

1.4.3 Hipoventilação ou hiperventilação . . . . . . . . . . . . . . . 29

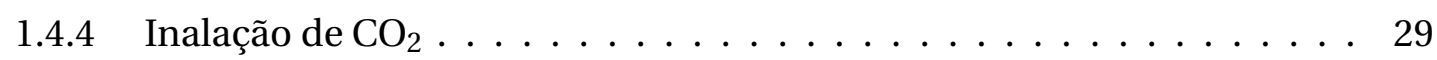

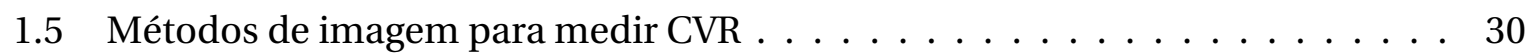

1.5.1 Ultrassom Doppler transcraniano . . . . . . . . . . . . 30

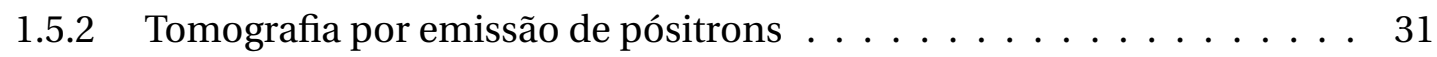

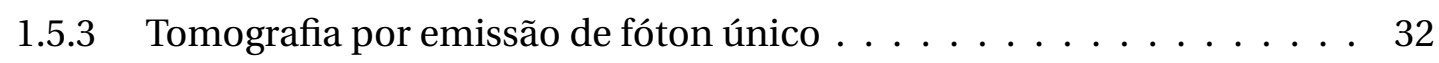

1.5.4 Espectroscopia de infravermelho próximo . . . . . . . . . . . 32

1.5.5 Angiografia por ressonância magnética com contraste de fase . . . . 33

1.5.6 Ressonância magnética de marcação do sangue arterial . . . . . . . . 33

1.5.7 Imagem por ressonância magnética funcional baseada no contraste

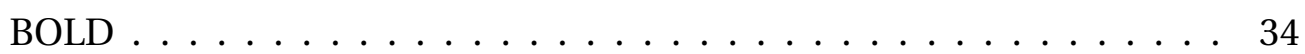

1.6 CVR-BOLD e desafio de hipercapnia $\ldots \ldots \ldots \ldots \ldots \ldots \ldots \ldots$

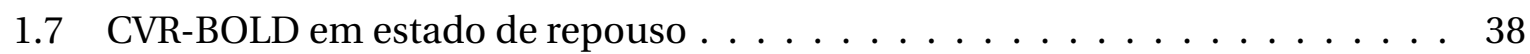

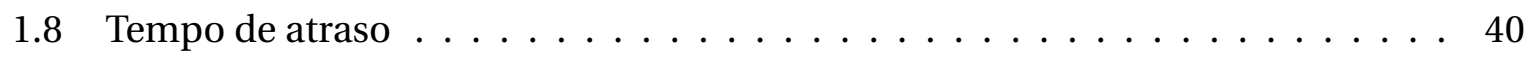

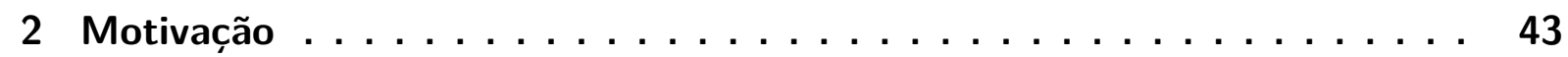

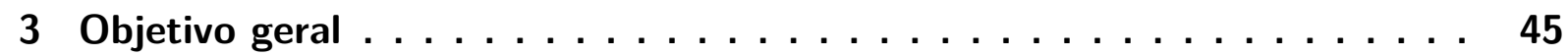

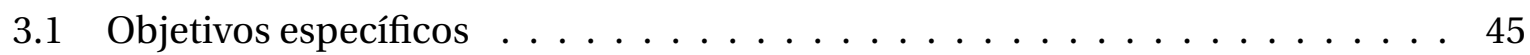

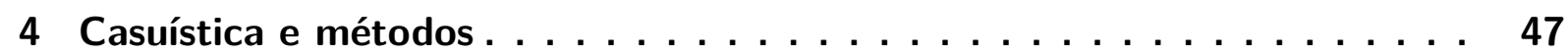

4.1 Verificação da frequência de filtragem temporal $\ldots \ldots \ldots \ldots \ldots \ldots 47$

4.1.1 Parte 1: Correlação entre rs-CVR e CVR em hipercapnia em ECa . . . . 47

4.1.2 Parte 2: Correlação entre rs-CVR e CVR em pausa respiratória . . . . . . 49

4.2 rs-CVR em pacientes com ECa unilateral severa $\ldots \ldots \ldots \ldots \ldots \ldots$

4.3 Tempo de atraso em pacientes com ECa unilateral severa . . . . . . . . 51

5 Resultados . . . . . . . . . . . . . . . . . 53

5.1 Verificação da frequência de filtragem temporal $\ldots \ldots \ldots \ldots \ldots \ldots 5$

5.1.1 Parte 1: Correlação entre rs-CVR e CVR em hipercapnia em ECa . . . . 53 
5.1.2 Parte 2: Correlação entre rs-CVR e CVR em pausa respiratória . . . . . . 54

5.2 rs-CVR em pacientes com ECa unilateral severa . . . . . . . . . . . . 55

5.3 Tempo de atraso em pacientes com ECa unilateral severa . . . . . . . . . . . 56

6 Discussão . . . . . . . . . . . . . . . . . . . . . . . 63

7 Conclusões . . . . . . . . . . . . . . . . . . . . 69

8 Futuros estudos ........................ 71

Referências . . . . . . . . . . . . . . . . . . . 73

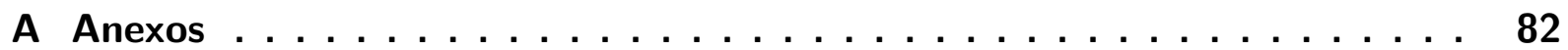

A.1 Termo de consentimento livre e esclarecimento ao grupo clínico . . . . . . . 82

A.2 Termo de consentimento livre e esclarecimento ao grupo controle . . . . . . 85 


\section{Fundamentação Teórica}

\subsection{Neuroanatomia e territórios arteriais}

A anatomia do encéfalo se divide em três principais partes: o cérebro, o tronco encefálico e o cerebelo. O cérebro em si é dividido em duas partes, o telencéfalo que é a maior parte do cérebro, composta pelos giros e sulcos cerebrais; e o diencéfalo que é uma parte mais central composta pelo tálamo e pelo hipotálamo. A parte mais superficial do telencéfalo é composta por uma camada fina conhecida como substância cinzenta. Na substância cinzenta, por sua vez, há uma concentração de corpos de neurônios, e essa região é chamada de córtex cerebral. Abaixo do cortex cerebral, há outra área preenchida pela substância branca, que é composta em sua maior parte por axônios de neurônios (FIELDS, 2008). O cérebro trata-se de uma estrutura extremamente especializada que necessita de um suprimento de oxigênio e nutrientes de forma contínua, e é por intermédio do fluxo sanguíneo cerebral (FSC) que ele recebe o que precisa. O FSC corresponde à quantidade de sangue que atinge o tecido cerebral em certa fração de tempo (LASSEN, 1959).

O FSC da substância cinzenta é maior que o da substância branca, devido à alta atividade e alto consumo energético dos corpos celulares de neurônios (LASSEN, 1959). Além disso, em situações normais o FSC é elevado em resposta ao aumento da atividade neural, chamado como acoplamento neurovascular, e pelas concentraçõoes de $\mathrm{CO}_{2}$ e $\mathrm{O}_{2}$, sendo diretamente proporcial à concentração de $\mathrm{CO}_{2}$ e inversamente proporcional à concentração $\mathrm{O}_{2}$. A ativação neural leva a aumentos locais no FSC via hiperemia funcional, enquanto a mudanças das concentrações de $\mathrm{CO}_{2}$ e $\mathrm{O}_{2}$ produzem um aumento global no FSC, embora haja heterogeneidade entre as regiões cerebrais (NÖTH et al., 2008; LEONI et al., 2017).

O suprimento sanguíneo cerebral vem de dois sistemas arteriais. Os sistemas são carotídeo (ou anterior) e vértebro-basilar (ou posterior) (YANG et al., 2005). O sistema vertebrobasilar é quem supre todo o tronco cerebral, cerebelo, e a porção posterior do encéfalo humano. As artérias vertebrais se juntam, originando a artéria basilar. Esta, por sua vez, se bifurca nas duas artérias cerebrais posteriores de cada um dos hemisférios, as chamadas artéria cerebral posterior (ACP) esquerda e ACP direita. Já o sistema carotídeo se dá pela artéria carótida interna (ACI), que é fruto da bifurcação da carótida comum em ACI e artéria carótida externa (ACE). A ACE irriga estruturas extracranianas, enquanto a ACI é responsável pela irrigação intracraniana. A Figura 1, ilustra o mecanismo de suprimento sanguíneo cerebral, bem como as artérias mais importantes no processo.

Segundo o que foi reportado por Fischer e colaboradores (BOUTHILLIER; LOVEREN; KELLER, 1996), a ACI pode ser dividida em quatro segmentos: cervical, petrosa, cavernosa e cerebral que segue até se bifurcar em artéria cerebral anterior (ACA) e artéria cerebral 
média (ACM). As duas últimas, ainda podem ser divididas em segmentos com fluxo proximal, intermediário e distal com base em tempos de trânsito arterial (MUTSAERTS et al., 2015). Os territórios de fluxo estão ilustrados na Figura 2

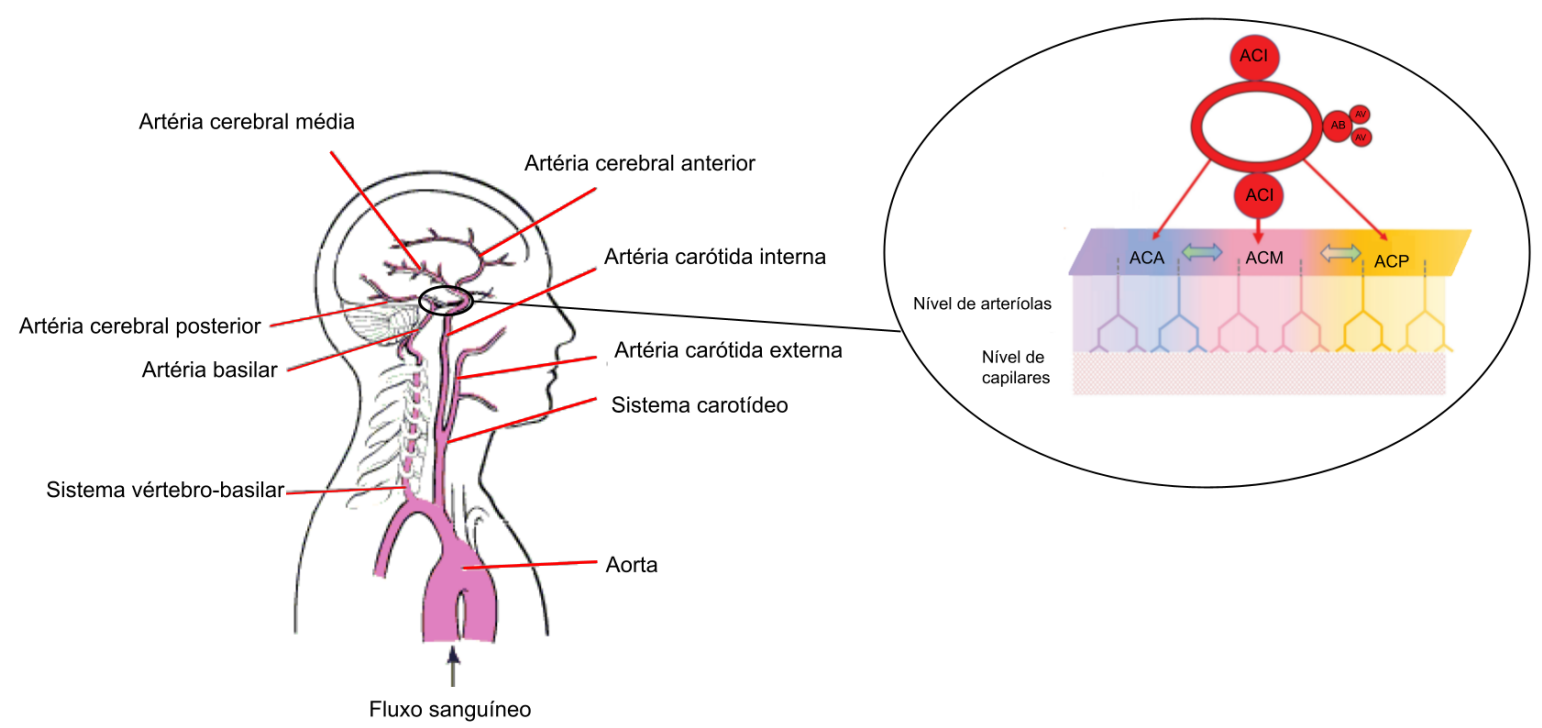

Figura 1 - Suprimento sanguíneo arterial cerebral. Figura adaptada de Manual MSD - Versão para profissionais de saúde (MANUAL-MSD, 2021) e Fisher e colaboradores (FISHER; MIKULIS, 2021). São representados: $\mathrm{ACI}=$ artéria carótida interna, $\mathrm{AB}=$ artéria basilar, $\mathrm{AV}=$ artéria vertebral, $\mathrm{ACA}=$ artéria cerebral anterior, $\mathrm{ACM}=$ artéria cerebral média e ACP = artéria cerebral posterior.

Além disso, a irrigação de um mesmo território, não depende exclusivamente de um único sistema. Então, no mal funcionamento de um território, outro pode compensar, até certo ponto, com o aumento do fluxo. Com isso, é possível reduzir o risco de dano que uma redução de FSC pudesse provocar em alguma região. Isso se deve por conta das circulações colaterais que existem.

\subsection{Doenças cerebrovasculares}

As doenças cerebrovasculares são responsáveis por um sério problema de saúde pública, com alta prevalência, mortalidade e morbidade. Quantitativamente, as mortes provocadas por esse tipo de doença corresponderam a 11\% dos óbitos anuais de 2019 (ORGANIZATION, 2020), além do grande impacto na família do paciente.

O termo doenças cerebrovasculares refere-se a um grupo de condições que afetam o FSC e os vasos sanguíneos do sistema nervoso. Eles podem aparecer em decorrência do estreitamento dos vasos, formação de coágulos, obstrução de artéria ou ruptura de vasos sanguíneos do cérebro. A falta, ou o excesso de FSC causado por estes processos, afeta o tecido cerebral e pode causar um acidente vascular cerebral (AVC). 


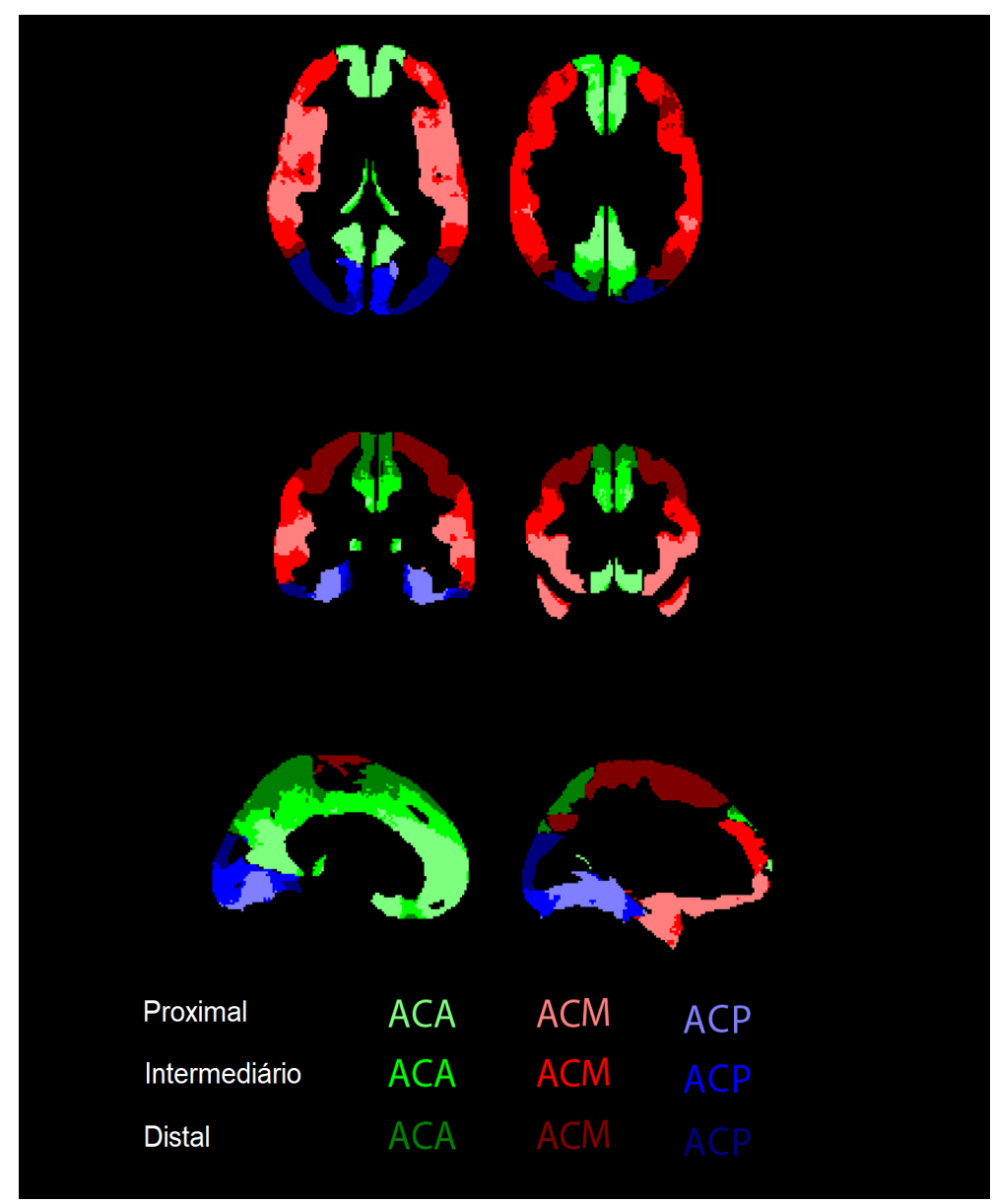

Figura 2 - Artéria cerebral Anterior (ACA) em verde, artéria cerebral média (ACM) em vermelho e artéria cerebral psoterior (ACP) em azul referem-se aos territórios de fluxo padrão perfundidos pelas artérias cerebrais bilaterais anterior, média e posterior, respectivamente, enquanto os sombreamentos representam sua subdivisão em territórios de fluxo proximal, intermediário e distal, com base em tempos de trânsito arterial. Figura adaptada de Mutsaerts e colaboradores (MUTSAERTS et al., 2015).

Segundo a Organização Mundial da Saúde, o AVC é definido como um "déficit neurológico focal (ou global), de início súbito, que persiste por mais de 24 horas (ou conduz à morte antes desse tempo), de provável origem vascular"(SACCO et al., 2013), e se difere de acordo com o mecanismo que o originou entre isquêmico ou hemorrágico.

O AVC hemorrágico é o mais agressivo e se dá quando um vaso sanguíneo ou artéria se rompe, provocando o extravasamento de sangue. Já o AVC isquêmico é quando existe o déficit de FSC, provocado por um entupimento do vaso sanguíneo por acúmulo de placas de gorduras em suas paredes ou por coágulos que dificultam o fluxo, ocasionando a morte do tecido cerebral pela falta de suprimento sanguíneo. Entretanto, cabe dizer que o AVC isquêmico é, sem dúvidas, o mais comum e a maioria dos casos costuma ter uma mesma origem: a aterosclerose (GORY et al., 2017). 


\subsubsection{Doença aterosclerótica de carótidas}

A doença carotídea aterosclerótica (ou estenose de carótida) acontece quando há acúmulo de placas irregulares, que contém lipídeos, células inflamatórias, células musculares e depósitos de cálcio, nas paredes das artérias, podendo acontecer cedo na vida devido a pequenas lesões nas paredes e que podem se desenvolver em grandes placas. Essa obstrução pode afetar o FSC, que por sua vez pode ocasionar um AVC isquêmico, dependendo da sua magnitude.

O processo de oclusão arterial pode induzir a diminuição da perfusão sanguínea em regiões cerebrais ipsilaterais, que em condições agudas podem ser supridas por um mecanismo autorregulatório de vasodilatação a fim de tentar manter o FSC nas suas condições normais (SILVESTRINI et al., 1996). Entretanto, em situações em que a diminuição persiste ocasiona o esgotamento da reserva hemodinâmica, fazendo com que o indivíduo fique mais susceptível ao AVC isquêmico ou ataque isquêmico transitório (AIT) (MARKUS; CULLINANE, 2001; SILVESTRINI et al., 2000).

Clinicamente, a estenose carotídea pode ser classificada em sintomática e assintomática dependendo da presença, ou não, de eventos relacionados a ela, tais como AVC isquêmico ou AIT. Entretanto, apesar dos pacientes ditos como sendo assimtomáticos, é muito reportado na literatura que as funções cognitivas e funcionais desses pacientes são afetadas e tem ligação direta com a doença (SILVESTRINI et al., 2009; LANDGRAFF et al., 2010; BALUCANI et al., 2012).

\subsection{Reatividade Cerebrovascular}

O cérebro representa cerca de $2 \%$ do peso corporal total, mas consome cerca de $20 \%$ da energia total (ATTWELL; LAUGHLIN, 2001). Em um estado fisiológico normal, o fluxo sanguíneo total para o cérebro é notavelmente constante devido em parte à importante contribuição das grandes artérias para a resistência vascular (FARACI; HEISTAD, 1990). Adicionalmente, o cérebro é um órgão temporalmente dinâmico, com diferentes regiões que requerem diferentes quantidades de suprimento de sangue em diferentes momentos. Sabe-se que os vasos sanguíneos não são apenas tubos rígidos e que apresentam uma importante função auto-regulatória de dilatar e contrair com base na demanda do cérebro e nas condições fisiológicas, denominada reatividade cerebrovascular ou, em inglês, cerebrovascular reactivity (CVR). Podemos, então, definir a CVR como sendo a característica da musculatura lisa dos vasos sanguíneos cerebrais de dilatar ou contrair em resposta a alterações metabólicas ou a estímulos vasoreativos (LIU; JILL; LU, 2019).

Portanto, a vasculatura cerebral responde a pequenas reduções na pressão de perfusão cerebral dilatando pequenas artérias, reduzindo assim a resistência cerebrovascular e mantendo o FSC regulado nessas regiões. Essa resposta vasodilatadora resulta em um aumento 
no volume sanguíneo cerebral (VSC), que é o sangue do espaço intravascular dentro de um determinado volume de tecido cerebral. $\mathrm{O}$ aumento do VSC pode ser sutil e difícil de detectar em imagens por ressonância magnética ponderadas em perfusão (COPEN; SCHAEFER; WU, 2011).

A autorregulação do FSC é a capacidade do cérebro de manter o fluxo sanguíneo relativamente constante, apesar das mudanças na pressão de perfusão (PAULSON; STRANDGAARD; EDVINSSON, 1990). Em adultos com pressão arterial normal, o fluxo sanguíneo cerebral é mantido aproximadamente em $50 \mathrm{~mL}$ por $100 \mathrm{~g}$ de tecido cerebral por minuto, desde que o pressão de perfusão cerebral esteja na faixa de 60 a 160 mmHg (PHILLIPS; WHISNANT, 1992). Acima e abaixo deste limite, a autorregulação é perdida e o fluxo sanguíneo cerebral torna-se dependente da pressão arterial média de forma linear (OSOL et al., 2002; CIPOLLA, 2009). Quando a pressão de perfusão cerebral cai abaixo do limite inferior de autorregulação, ocorre isquemia cerebral.

Powers e colaboradores categorizaram esses ajustes cerebrovasculares em três estágios: estágio 0, quando a pressão de perfusão cerebral é normal; estágio 1, quando a pressão de perfusão cerebral é reduzida e a autorregulação dilata os vasos cerebrais para manter a necessidade de FSC; e estágio 2, quando a capacidade compensatória de vasodilatação cerebral é sobrecarregada, o FSC começa a diminuir, tendo a autorregulação cerebrovascular interrompida, e nesse ponto, ocorrem sinais clínicos de hipoperfusão, incluindo tontura, estado mental alterado e, eventualmente, dano irreversível ao tecido (POWERS, 1991).

O FSC pode ser modelado de um ponto de vista físico como o fluxo em um tubo rígido com as suposições de que o fluxo é estável, laminar e uniforme, segundo a lei de Poiseuille (COULSON et al., 2004). Podemos fazer uma analogia com um circuito elétrico, afirmando que o fluxo é proporcional à diferença na pressão de entrada e saída, $\Delta \mathrm{P}$, dividida pela resistência ao fluxo, R. No cérebro, $\Delta \mathrm{P}$ é a pressão de perfusão cerebral, que é a diferença entre a pressão arterial média e a pressão intracraniana. Então, a resistência do vaso pode ser modelado por:

$$
R=\frac{8 \eta \Delta P}{\pi r^{4}}
$$

Assim, o raio é o determinante mais poderoso do FSC e mesmo pequenas alterações no diâmetro do vaso têm efeitos significativos nessa grandeza, e é por esse mecanismo que a resistência vascular pode mudar rapidamente para alterar o FSC regional e global (PAULSON; STRANDGAARD; EDVINSSON, 1990).

A vasodilatação também resulta em um aumento do tempo de trânsito médio ou, em inglês, mean transit time (MTT), que é a quantidade média de tempo que os glóbulos vermelhos passam em um determinado volume de tecido. Quando a pressão de perfusão cai abaixo do limiar no qual o cérebro mantém a autorregulação, a resposta vasodilatadora compensatória é superada e então o FSC começa a cair e se torna dependente da pressão, ou 
seja, reduções adicionais na pressão de perfusão levam a diminuições ainda maiores de FSC (KETY et al., 1950). Embora isso reflita uma diminuição na taxa de entrega de oxigênio ao leito capilar, o comprometimento metabólico pode ser evitado se o FSC for apenas ligeiramente reduzido, devido ao efeito do prolongamento do MTT sobre a extração de oxigênio. Quando o MTT é aumentado, os glóbulos vermelhos passam mais tempo dentro dos capilares permeáveis ao oxigênio, e isso permite um aumento na proporção do oxigênio disponível que pode ser extraído do sangue pelo cérebro. Se a redução do FSC for leve, a reserva de oxigênio provocado pelo efeito do prolongamento do MTT é suficiente para manter o metabolismo do oxigênio, e a função elétrica do cérebro e sua viabilidade não são ameaçadas (COPEN; SCHAEFER; WU, 2011).

Essa característica funcional do vaso é considerada um indicador útil da saúde vascular e pode encontrar aplicações. Como, por exemplo, o que foi apresentado por Vernieri e colaboradores que, na presença de doença severa da artéria carótida, uma CVR prejudicada foi associada a um aumento da probabilidade de acidente vascular cerebral de 32,7\% por ano em comparação com 8\% por ano se a CVR fosse normal (VERNIERI et al., 2001). Ou ainda o que foi apresentado por Sur e colaboradores mostrando que o CVR pode ser um biomarcador útil para avaliar o comprometimento cognitivo relacionado à doença vascular em indivíduos idosos (SUR et al., 2020).

Em pacientes com doença oclusiva crônica, a capacidade de manter o fluxo sanguíneo cerebral normal, reduzindo a resistência vascular secundária à vasodilatação autoregulatória, é comprometida (DERDEYN; GRUBB; POWERS, 1999). A identificação da presença e do grau de vasodilatação autoregulatória (refletindo a reserva cerebrovascular) é um prognóstico significativo em pacientes com doença cerebrovascular crônica (VAGAL et al., 2009a).

Essas observações, portanto, ressaltam a importância de estudar e quantificar a capacidade vasodilatadora por meio de medidas de CVR como um meio de avaliar o estado da vasculatura cerebral, bem como a progressão da doença vascular.

Embora vários métodos tenham sido desenvolvidos para avaliar o CVR, todos estes métodos se baseiam no mesmo princípio do aumento da concentração de $\mathrm{CO}_{2}$ no sangue e um método de imagem para medir as alterações de FSC. Aqui nesse texto iremos focar nos métodos de imagens de ressonância magnética (IRM) com contraste dependente do nível de oxigenação sanguíneo ou, em inglês, blood oxygen level-dependent (BOLD), e metodologia de desafio de inalação de $\mathrm{CO}_{2}$ ou pausa respiratória. Porém, também serão apresentadas, de forma resumida, as técnicas mais utilizadas na literatura.

\subsubsection{Efeito vasoativo da $\mathrm{PaCO}_{2}$}

A vasculatura cerebral é sensível a mudanças de concentração de $\mathrm{CO}_{2}$ em seu meio. Na verdade, pelas leis físicas fica mais correto dizer que é sensível à mudanças na pressão 
parcial de $\mathrm{CO}_{2}$ no sangue arterial $\left(\mathrm{PaCO}_{2}\right)$, pois os gases dissolvem, reagem e se difundem de acordo com suas pressões parciais em uma mistura. Aumentos na $\mathrm{PaCO}_{2}$ provocam uma resposta vasodilatadora e diminuições na $\mathrm{PaCO}_{2}$ provocam uma resposta vasoconstritora (YOON; ZUCCARELLO; RAPOPORT, 2012).

Entretanto, os equipamentos de capnografia indicam a quantidade de $\mathrm{CO}_{2}$ que é eliminada dos pulmões, grandeza denominada pressão parcial de $\mathrm{CO}_{2}$ ao final da expiração $\left(\mathrm{PETCO}_{2}\right)$. Então, aqui nessa dissertação usarei $\mathrm{PaCO}_{2}$ quando me referir ao estímulo direto de mudança vascular e $\mathrm{PETCO}_{2}$ quando me referir ao parâmetro medido que reflete $\mathrm{PaCO}_{2}$. Embora $\mathrm{PETCO}_{2}$ possa ser menor do que $\mathrm{PaCO}_{2}$, uma forte correlação entre eles já foi foi relatada (MCSWAIN et al., 2010; PEEBLES et al., 2007). A Figura 3 mostra a relação do FSC com a $\mathrm{PaCO}_{2}$.

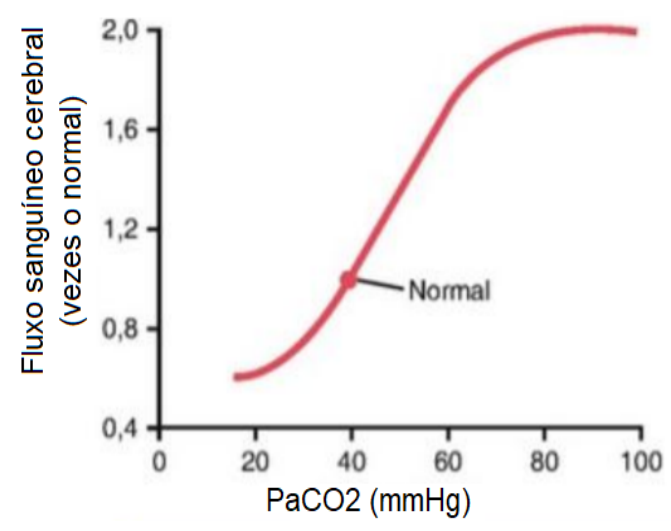

Figura 3 - Relação entre a pressão parcial de CO2 arterial e fluxo sanguíneo cerebral. Figura adaptada de Guyton e coladoradores (GUYTON, 2006)

Fisiologicamente, o $\mathrm{CO}_{2}$ se dissolve no sangue estabelecendo um equilíbrio iônico:

$$
\mathrm{CO}_{2(a q)}+\mathrm{H}_{2} \mathrm{O}_{(l)} \rightleftharpoons \mathrm{H}_{2} \mathrm{CO}_{3(a q)} \rightleftharpoons H_{(a q)}^{+}+\mathrm{HCO}_{(a q)}^{-}
$$

$\mathrm{O}$ aumento do conteúdo de $\mathrm{CO}_{2}$ resulta em uma diminuição do $\mathrm{pH}$ por meio do aumento da formação de ácido carbônico, seguido por sua dissociação em próton e íons bicarbonato. Uma vez alterado o pH, uma série de quimioreceptores são recrutados para exercer seus efeitos mensageiros no centro inspiratório no músculo liso dos vasos cerebrais resultando na sua dilatação (YOON; ZUCCARELLO; RAPOPORT, 2000; GUYTON, 2006).

\subsection{Desafios vasodilatadores}

Alterações na $\mathrm{PaCO}_{2}$ são estímulos vasoativos potentes e, devido à facilidade e segurança de uso, são comumente empregadas em estudos de CVR. Porém, como a medida 
de $\mathrm{PaCO}_{2}$ é invasiva, como colocação de cateter intra-arterial ou punção arterial para obter uma amostra de sangue arterial, a $\mathrm{PETCO}_{2}$ é usada com mais frequência como substituto adequado.

A hipercapnia caracteriza-se por um aumento de $\mathrm{CO}_{2}$ no sangue é o método mais utilizado para a aplicação de CVR. Apesar de que geralmente ocorre como resultado de hipoventilação ou incapacidade de respirar corretamente de forma a captar oxigênio suficiente para os pulmões, ele também pode ser feito de forma induzida.

Nesta seção, os vários métodos de manipulação da $\mathrm{PaCO}_{2}$ são descritos junto com as vantagens e desvantagens de cada método.

\subsubsection{Acetazolamida}

A acetazolamida é um inibidor da anidrase carbônica, enzima que tem um papel importante no transporte do $\mathrm{CO}_{2}$ e no controle do pH do sangue (MA et al., 2007). A inibição da anidrase carbônica causa acidose carbônica, que induz um aumento considerável no FSC.

As vantagens de se usar acetazolamida são:

- É seguro para administrar e geralmente é bem tolerado.

- Com a administração, a pressão arterial sistêmica, as frequências cardíaca e respiratória, e a taxa metabólica cerebral de oxigênio ou, em inglês, cerebral metabolic rate of oxygen $\left(\mathrm{CMRO}_{2}\right)$ geralmente não são afetadas (VAGAL et al., 2009b).

Suas desvantagens são:

- A administração deve ser feita por via intravenosa, pois a resposta à administração oral é altamente variável, tornando seu uso invasivo.

- As mudanças de $\mathrm{PaCO}_{2}$ em resposta às mudanças na ventilação são sobrepostas às de acetazolamida (LEAF; GOLDFARB, 2007).

- O uso descontrolado pode provocar insuficiência renal e/ou hepática.

\subsubsection{Pausa respiratória}

O desafio de pausa respiratória é outro método de induzir alterações na $\mathrm{PaCO}_{2}$. Esse método tem como característica que é esperado que o volume pulmonar permaneça constante durante a retenção da respiração, permitindo que as pressão parcial de $\mathrm{O}_{2}$ no sangue arterial $\left(\mathrm{PaO}_{2}\right)$ e $\mathrm{PaCO}_{2}$ se equilibrem com o sangue venoso. Assim, aumenta-se o FSC, até certo ponto, para garantir que o cérebro tenha oxigênio suficiente (PARKES, 2006).

As vantagens de se usar a metodologia de pausa respiratória são: 
- Não precisa de um sistema de entrega de mistura de gases, só depende do sujeito.

- É tolerável.

As principais desvantagens são:

- Não é possível medir $\mathrm{PETCO}_{2}$ ao longo do tempo e usar a informação como preditor nas análises.

- Desconforto do sujeito.

- Ainda não se sabe como quantificar a retenção da respiração para padronizar uma análise, visto que a tolerância não é a mesma entre os sujeitos.

- As mudanças na $\mathrm{PaCO}_{2}$ e $\mathrm{PaO}_{2}$ não são lineares, portanto, são muito sensíveis ao tempo da retenção da respiração.

\subsubsection{Hipoventilação ou hiperventilação}

O corpo precisa manter a ventilação pulmonar em níveis adequados para garantir todas as funcionalidades. Quando a ventilação escapa dos níveis normais, temos quadros de hiperventilação, resultando em aumento da $\mathrm{PaO}_{2}$ e diminuição da $\mathrm{PaCO}_{2}$, ou também quadros de hipoventilação que tem efeito oposto (ROSTRUP et al., 2000).

As suas vantagens são:

- Nenhuma fonte externa de gás é necessária.

- É seguro e simples de realizar.

Enquanto suas desvantagens são:

- Mudanças na $\mathrm{PaO}_{2}$ e $\mathrm{PaCO}_{2}$ são inversamente proporcionais, e não obedecem uma relação linear.

- A magnitude da mudança na $\mathrm{PaO}_{2}$ e $\mathrm{PaCO}_{2}$ é limitada pela performace do sujeito na ventilação.

- Desconforto.

\subsubsection{Inalação de $\mathrm{CO}_{2}$}

Nesse método, o sujeito repira uma mistura especial de gases através de uma válvula que não permite a reinalação, ou seja, só permite que a mistura seja inspirada. Geralmente essa mistura de gases tem composição de $5 \%$ de $\mathrm{CO}_{2}, 21 \%$ de $\mathrm{O}_{2}$, e $74 \%$ de $\mathrm{N}_{2}$ (LU et al., 2014), 
mas pode ser ajustada conforme a necessidade, levando-se em consideração características individuais do sujeito e a meta de $\mathrm{PaCO}_{2}$ e $\mathrm{PaO}_{2}$ que deve ser atingida. (SLESSAREV et al., 2007).

As suas vantagens são:

- A concentração do gás inspirado é conhecida.

- Único método em que $\mathrm{PETCO}_{2}$ demonstrou ser igual à variável independente, $\mathrm{PaCO}_{2}$.

- Entrega de um estímulo padronizado e repetível.

Enquanto suas desvantagens são:

- O uso de aparato extra (por exemplo, máscara facial) que deve se ajustar dentro da bobina de cabeça e pode aumentar a sensação de claustrofobia.

- Requer uma cooperação suficiente do sujeito.

- Requer equipamentos apropriados para a entrega e leitura dos dados de respiração.

\subsection{Métodos de imagem para medir CVR}

Até aqui foi discutido sobre os métodos de manipulação de $\mathrm{PaCO}_{2}$, mas ainda não vimos como visualizar a resposta. Estudos anteriores de CVR incorporaram vários métodos de imagens para detectar a alteração de FSC (MAEDA et al., 1993; BOORDER et al., 2006; ISHII et al., 2020; LIU et al., 2017). No entanto, cada método difere de várias maneiras, como a precisão da quantificação, aquisição de dados, cobertura do cérebro e resolução espacial ou temporal; todos os quais podem conferir vantagens e desvantagens na medição da CVR.

Esta seção fornecerá uma breve visão geral de cada método de imagem comumente usado junto com suas vantagens e desvantagens.

\subsubsection{Ultrassom Doppler transcraniano}

O ultrassom com doppler transcraniano (UDTC) permite a medida da CVR por meio da medida das velocidades do fluxo sanguíneo nas principais artérias cerebrais e é baseado no efeito Doppler, que detecta a mudança na frequência das ondas sonoras refletidas de objetos em movimento (NAQVI et al., 2013). O UDTC permite o monitoramento dinâmico da velocidade do fluxo sanguíneo e da pulsatilidade do vaso, com alta resolução temporal.

Vantagens:

- É considerado o padrão ouro para avaliação de CVR. 
- É uma técnica não invasiva, tornando-a bastante reprodutível.

- Alta resolução temporal.

- É relativamente barato e portátil.

Desvantagens:

- Limitada a grandes vasos.

- A resolução espacial é limitada para cada hemisfério.

- Altamente dependente do operador.

- Pode dar respostas equivocadas, pois as mudanças de velocidade nas grandes artérias podem mascarar as mudanças no fluxo sanguíneos nos pequenos vasos.

\subsubsection{Tomografia por emissão de pósitrons}

A tomografia por emissão de pósitrons ou, em inglês, positron emission tomography (PET) é um método de imagem que se beneficia do decaimento radioativo de determinados radioisótipos que emitem pósitron, que por sua vez se aniquilam transformando-se em dois fótons de mesma energia que são detectados simultaneamente e diametralmente opostos para a formação da imagem. É uma modalidade de imagem que tem informação acerca do estado funcional dos órgãos (PHELPS; MAZZIOTTA, 1985). É feito usando a marcação da molécula da água com a substituição do oxigênio por ${ }^{15} \mathrm{O}$, um emissor de pósitron que tem tempo de meia vida de 2 minutos. Com isso pode-se medir e quantificar o fluxo sanguíneo usando PET no coração, cérebro e tumores (KAHANE et al., 1999).

Vantagens:

- Cobertura de todo o cérebro.

- Fornece avaliação quantitativa de parâmetros do metabolismo e da fisiologia do cérebro.

Desvantagens:

- Administração de traçadores radioativos; técnica invasiva.

- Necessita de um cíclotron para produzir os traçados, que têm vida útil.

- A resolução espacial de imagem é limitada e varia de 4 a 6 mm. 


\subsubsection{Tomografia por emissão de fóton único}

A tomografia por emissão de fóton único ou, em inglês, single photon emission computed tomography (SPECT) é uma técnica baseada no uso de um composto radiomarcado com meia-vida curta, como o ${ }^{133} \mathrm{Xe}$, que é inalado ou injetado no sistema circulatório. Uma vez no sistema circulatório, o composto radiomarcado se liga aos glóbulos vermelhos que são transportados por todo o corpo enquanto sofrem decaimento radioativo, emitindo radiação gama. Os fótons emitidos são coletados por uma câmera gama que é girada em torno da cabeça, gerando uma imagem tridimensional localizada de FSC (OGASAWARA; OGAWA; YOSHIMOTO, 2002).

Vantagens:

- Custo mais baixo em comparação com PET e IRM.

- Os marcadores usados são obtidos a partir de geradores que permitem que sejam produzidos no local em que vai ser utilizado, não precisando de cícloton como a técnica de PET.

Desvantagens:

- Uso de radiação ionizante.

- Baixa resolução espacial (em torno de $6 \mathrm{~mm})$.

\subsubsection{Espectroscopia de infravermelho próximo}

A espectroscopia de infravermelho próximo ou, em inglês, near-infrared spectroscopy (NIRS) é um método que depende das propriedades de absorção de luz no comprimento de onda do infravermelho-próximo da oxihemoglobina (oxi-Hb) e da desoxihemoglobina (deoxi-Hb) para estudar alterações no FSC (VILLRINGER; CHANCE, 1997). Ao transmitir luz para o cérebro e analisar o que é refletido pelos sensores, é possível analisar as alterações do FSC.

Vantagens:

- Alta resolução temporal.

Desvantagens:

- Baixa resolução espacial (aproximadamente $5 \mathrm{~mm}$ ).

- A medição em estruturas profundas do cérebro não pode ser obtida devido a limitações de profundidade óptica. 


\subsubsection{Angiografia por ressonância magnética com contraste de fase}

A imagem ressonância magnética com contraste de fase (RM-PC) é uma técnica não invasiva que utiliza gradientes bipolares para manipular a fase dos spins do sangue que fluem de maneira dependente da velocidade. É útil para medir as velocidades de fluxo em grandes vasos (JUTTUKONDA; DONAHUE, 2019).

Vantagens:

- É possível medir o fluxo em uma ou em várias direções dependendo do vaso de interesse.

- Permite a quantificação da velocidade do fluxo e da taxa de fluxo volumétrico.

Desvantagens:

- Limitado a grandes vasos.

\subsubsection{Ressonância magnética de marcação do sangue arterial}

A técnica de imagem por ressonância magnética baseada na marcação do sangue arterial, denominada arterial spin labeling (ASL), permite a avaliação do FSC usando os prótons da água presente no sangue arterial como um marcador. Esse método se baseia na diferenciação de imagens não marcadas e marcadas usando pulsos de radiofrequência, empregando um atraso pós-marcação para permitir que os prótons marcados atinjam o tecido cerebral, momento em que uma imagem é adquirida. Portanto, podemos obter imagens de perfusão mostrando valores quantitativos de FSC. No contexto de CVR a quantificação da perfusão requer a medição em duas condições fisiológicas diferentes, uma delas basal e outra com algum desafio vasodilatador (LEONI et al., 2012).

Vantagens:

- A medida feita é reflexo somente das alterações de FSC.

Desvantagens:

- Baixa relação sinal-ruído porque os spins do sangue marcado são de 0,5 à 1,5\% de todos os spins do tecido (PETCHARUNPAISAN; RAMALHO; CASTILLO, 2010).

- A resposta pode ser confundida por alterações no tempo de chegada do sangue marcado.

- Dependente da eficiência da marcação, devido à alterações na velocidade do fluxo sanguíneo durante a hipercapnia. 


\subsubsection{Imagem por ressonância magnética funcional baseada no contraste BOLD}

No final da década de 1980, sabia-se que o fluxo sanguíneo cerebral regional (FSCr) aumentava próximo a áreas de atividade neuronal (ROY; SHERRINGTON, 1890), e estudos de PET de baixa resolução já haviam documentado esse fenômeno em humanos (FOX; RAICHLE, 1986).

A explicação fisiológica para o aumento de FSCr parte do princípio que o cérebro necessita de energia para realizar suas funções. Essa energia é obtida através da glicose, da qual se obtém o trifosfato de adenosina (ATP) em uma reação com o oxigênio. Por sua vez, esse oxigênio é fornecido por uma proteína, a hemoglobina $(\mathrm{Hb})$ contida no sangue, e na qual o oxigênio se liga. Essa é conhecida como oxi-Hb. Logo, uma região cerebral ativa possui nível de oxigênação regional maior que uma área em condição basal.

O contraste BOLD resulta da alteração das concentrações sanguíneas regionais dessas proteínas quando ligadas, chamadas de oxi-Hb ou não ligadas, chamadas de deoxi-Hb. A oxi-Hb não tem elétrons desemparelhados e é fracamente diamagnética. Quando o oxigênio é liberado para formar a deoxi-Hb, quatro elétrons desemparelhados são expostos em cada centro de ferro, fazendo com que a molécula se torne fortemente paramagnética (PAULING; CORYELL, 1936). A presença de deoxi-Hb cria distorções do campo magnético local, dentro e ao redor dos vasos sanguíneos. Essas distorções locais de campo fazem com que spins tenham a frequência de precessão alterada, causando uma defasagem mais rápida que por sua vez acaba diminuindo o sinal de ressonância magnética (RM).

Os resultados observados até então podem até parecer contraditórios. Esse fenômeno também foi intrigante para os primeiros investigadores de imagens por ressonância magnética funcional (IRMf). Na verdade o que foi observado nas primeiras imagens feitas do tecido cerebral durante a realização de tarefas com inalação de um gás com concentração de $100 \%$ de oxigênio foi um aumento na intensidade de sinal nas regiões neuronais ativas e não uma redução (OGAWA et al., 1990).

Porém, o que acontece é que em resposta à ativação de certas regiões cerebrais, ocorre dilação anteriolar regional com o aumento do enchimento capilar de uma demanda muito maior de sangue com oxi-Hb do que o necessário. Essa ideia foi apresentada por Fox e colaboradores (FOX; RAICHLE, 1986) que demonstraram, usando PET que existe um desacoplamento fisiológico entre o aumento do FSCr e a demanda por oxigênio para produção de energia. Em outras palavras, durante a ativação neuronal, o FSCr aumenta, mas a $\mathrm{CMRO}_{2}$ não segue esse aumento.

Esse excesso de sangue oxigenado significa que a concentração de deoxi-Hb nas áreas ativas diminuirá em relação a concentração de oxi-Hb, fazendo com que haja uma diminuição na susceptibilidade magnética da região ativa. Então, em regiões que existe um excesso de 
deoxi-Hb em relação a oxi-Hb existirá uma diminuição no sinal de RM, mas o contrário não é verdade. Um esquema ilustrativo do efeito BOLD é apresentado na Figura 4A.

No contexto de CVR não existirá uma ativação regional, mas sim um aumento de $\mathrm{PaCO}_{2}$ de maneira global, fazendo que haja um aumento de FSC provocado pela acidez do sangue, e como o sangue que chega ao cérebro é rico em oxi-Hb, esta por sua vez, aumentará sua concentração em relação a deoxi-Hb, provocando o contraste BOLD (LIU; JILL; LU, 2019) (Figura4B).

As vantagens de se escolher a técnica BOLD em comparação às outras são:

- Pode-se obter outros fatores de importância vascular, como por exemplo o tempo do início de resposta, duração e amplitude (MAZZETTO-BETTI et al., 2013).

- Maior sensibilidade.

Desvantagens:

- O sinal reflete uma interação complexa entre vários parâmetros hemodinâmicos e metabólicos.

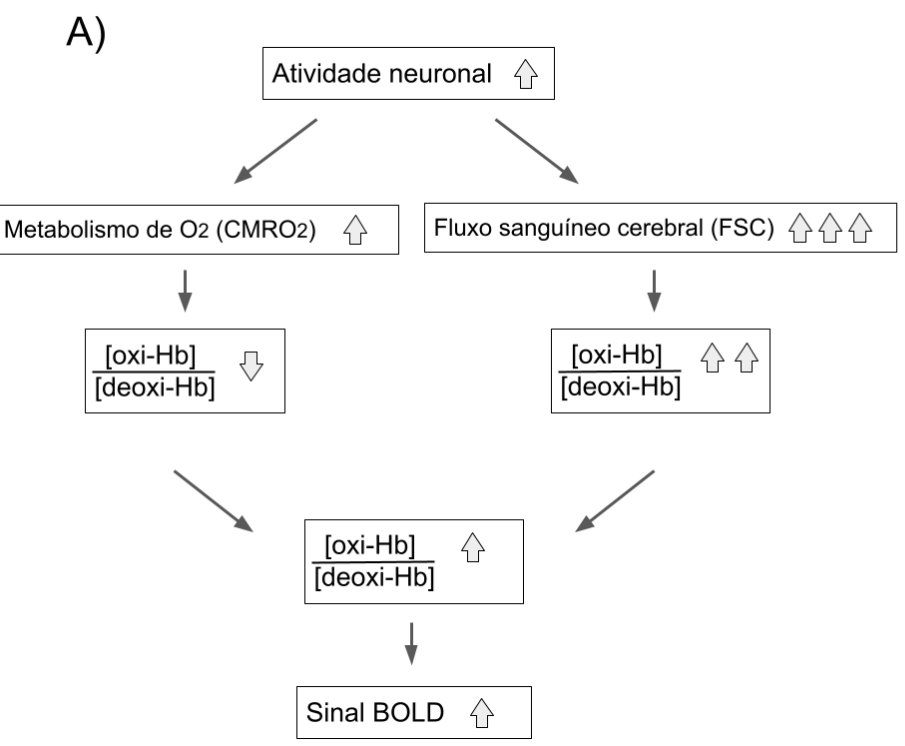

B)

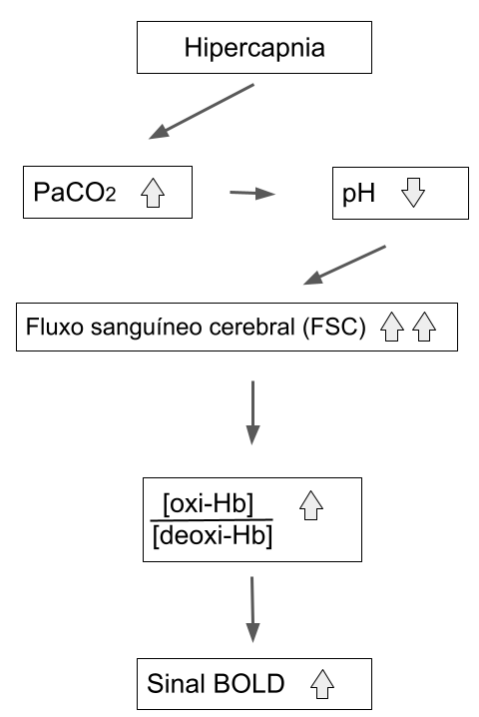

Figura 4 - Esquema do efeito BOLD em atividade neuronal (A) e em desafios de hipercapnia (B).

\subsection{CVR-BOLD e desafio de hipercapnia}

Uma das metodologias mais reportadas na literatura para o cálculo de CVR é a de inalação de $\mathrm{CO}_{2}$ com IRMf de contraste BOLD. A avaliação de CVR consiste em métodos que 
usam a inalação de $\mathrm{CO}_{2}$ como um desafio fisiológico enquanto monitoram as mudanças nos sinais hemodinâmicos durante aquisição de IRMf. Essa avaliação pode ter diferentes aspectos metodológicos, incluindo o aparelho de distribuição de gás, o paradigma do tempo do desafio respiratório, a sequência de imagens de ressonância magnética e a análise de dados. Mas a medição de $\mathrm{PETCO}_{2}$ é um componente importante em um experimento de CVR, a fim de avaliar com precisão a CVR, pois este parâmetro fisiológico significa a extensão ao qual o sistema vascular é desafiado, isto é, a força do estímulo.

A entrega da mistura de gases dentro do ambiente do scanner de IRM não é uma tarefa trivial visto que: (1) todos os equipamentos devem ser nao-metálicos, (2) o sistema deve funcionar dentro de um pequeno espaço entre a bobina e a cabeça do sujeito, (3) os parâmetros fisiológicos relevantes, tais como $\mathrm{PETCO}_{2}$ e a saturação de oxigênio arterial, devem ser registrados com precisão de segundos e armanezados. Um esquema mostrando os equipamentos necessários é apresentado na Figura 5.

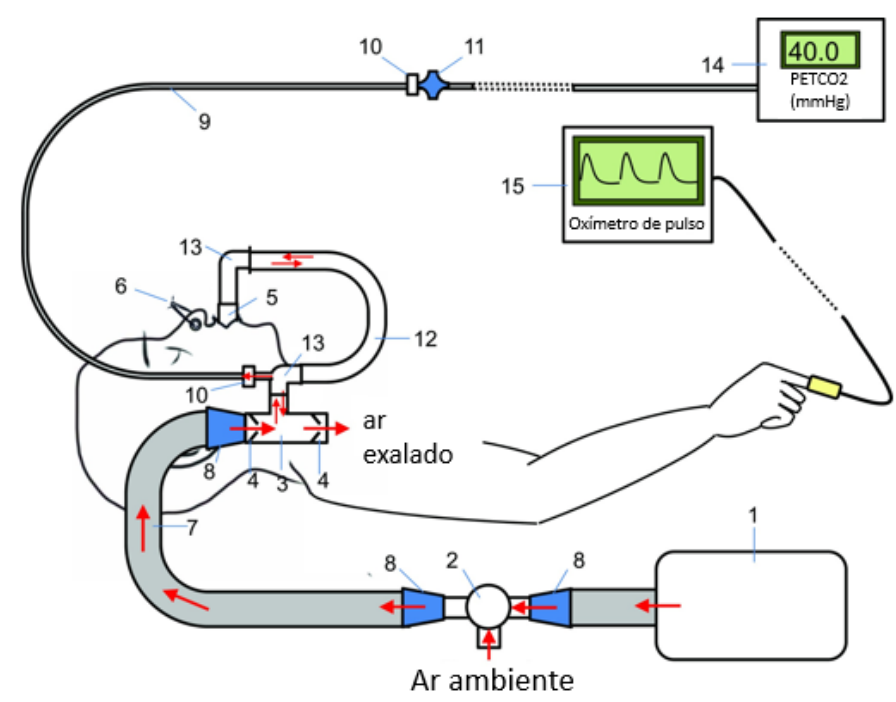

\#1 Bolsa de mistura de gases \#2 Válvula de três vias \#3 Válvula de duas vias de não reinalação \#4 Diafragma \#5 Tubo de respiração bucal \#6 Presilha Nasal \#7 Tubo de entrega de gás \#8 Adaptador de cânulas \#9 Tubo de amostragem de gás \#10 Luer lock macho \#11 Filtro hidrofóbico \#12 Tudo em forma de $U$ \#13 Conector de cotovelo \#14 Monitor de PETCO2 \#15 Monitor de oxímetro de pulso

Figura 5 - Esquema dos equipamentos necessários para desafio de hipercapnia. Adaptada de Lu e colaboradores (LU et al., 2014).

Para experimentos de inalação de $\mathrm{CO}_{2}$, a entrega do estímulo pode acontecer de várias formas diferentes, mas o mais utilizado é o paradigma em bloco. Nessa metodologia os blocos de ar ambiente e gás hipercápnico são fornecidos ao sujeito de maneira intercalada, onde a duração do bloco hipercápnico pode variar de 14 segundos (SECCHINATO et al., 2019) até 2-3 minutos (TANCREDI; HOGE, 2013), e a duração dos blocos de ar ambiente pode seguir o mesmo raciocínio ou ter uma duração maior. Ainda não existe nenhum protocolo estabelecido. Existem algumas variações do paradigma em bloco, como a não periodização dos blocos e a variação da concentração do $\mathrm{CO}_{2}$ nos diferentes blocos.

Além do paradigma em blocos, existem variações como a entrega de $\mathrm{CO}_{2}$ na forma senoidal, em que o $\mathrm{PETCO}_{2}$ é modulado na forma senoidal (HALANI et al., 2015) e também 
um paradigma em rampa em que $\mathrm{PETCO}_{2}$ aumenta progressivamente até um nível máximo estabelecido (FISHER et al., 2017).

O cálculo de CVR geralmente é feita pela razão entre a variação do sinal BOLD pelo aumento de $\mathrm{PETCO}_{2}$. Entretanto, para dados com um grande número de pontos no tempo, é necessária uma análise mais avançada, como uma regressão linear. Sabemos que em imagens de RM os valores dos voxels são variações de tons de cinza ao longo do tempo de aquisição da imagem. A regresão linear busca explicar essas variações, chamadas variáveis dependentes, por um conjunto de variáveis independentes. Na forma matricial temos:

$$
\left[\begin{array}{c}
Y_{1} \\
Y_{2} \\
\ldots \\
Y_{t}
\end{array}\right]=\left[\begin{array}{cccc}
1 & X_{11} & \ldots & X_{k 1} \\
1 & X_{12} & \ldots & X_{k 2} \\
\ldots & \ldots & \ldots & \ldots \\
1 & X_{1 t} & \ldots & X_{k t}
\end{array}\right] *\left[\begin{array}{c}
\beta_{0} \\
\beta_{1} \\
\ldots \\
\beta_{k}
\end{array}\right]+\left[\begin{array}{c}
\epsilon_{0} \\
\epsilon_{1} \\
\ldots \\
\epsilon_{k}
\end{array}\right]
$$

Onde X é a matriz de variáveis que podem explicar a matriz Y, que por sua vez é o sinal BOLD de cada voxel. Observe que a primeira coluna de $\mathrm{X}$ é um vetor de valores 1 referente ao termo constante (intercepto) de cada equação e os valores de $\beta$ são parâmetros obtidos. De forma mais resumida temos:

$$
Y=X * \beta+\epsilon
$$

Para o cálculo de CVR a variável X é considerada a curva de $\mathrm{PETCO}_{2}$ corrigida pelo tempo em que o $\mathrm{CO}_{2}$ demora para viajar do pulmão para o coração, depois para o cérebro, e só depois iniciar a mudança de sinal BOLD. Esse tempo de atraso entre $\mathrm{PETCO}_{2}$ e o sinal BOLD pode ser determinado adiantando a série temporal de $\mathrm{PETCO}_{2}$ em espaçamentos de tempo entre duas aquisições de IRM, conhecido do inglês, de time repetition (TR), e calcular para cada adiantamento o coeficiente de correlação cruzada entre as duas séries temporais, de $\mathrm{PETCO}_{2}$ e BOLD. O sinal BOLD usado aqui é geralmente com base em uma grande region of interest (ROI) ou em todo o cérebro onde o sinal é confiável. O valor de deslocamento que produz o maior coeficiente de correlação cruzada é considerado o atraso "pulmão-cérebro". Em sujeitos saudáveis, esse tempo de atraso é aproxidamente 8 segundos (DONAHUE et al., 2016a), mas varia para diferentes áreas do cérebro (LEONI et al., 2008).

Uma vez que a curva de $\mathrm{PETCO}_{2}$ é corrigida pelo atraso para interferir no sinal BOLD, a relação matemática 1.4 fica:

$$
\triangle B O L D=P E T C O_{2} * \beta_{1}+\beta_{0}+\epsilon
$$

Onde os parâmetros $\beta_{1}$ e $\beta_{0}$ são obtidos na regressão linear em todos os voxels. Outros fatores também podem ser adicionados na regressão, como por exemplo os vetores de movimento nos 6 graus de liberdade e a pulsação cardíaca. Mas um cuidado especial precisa 
ser tomado para não incluir fatores que se correlacionam com o $\mathrm{PETCO}_{2}$ interferindo nos valores calculados de CVR. Feito isso, os valores de CVR para todos os voxels são obtidos partir da referência a um estado correspondente ao $\mathrm{PETCO}_{2}$ de linha base, valor médio mínimo, pela seguinte relação:

$$
C V R(i, j, k)=\frac{\beta_{1}(i, j, k)}{\beta_{0}+\min \left(P E T C O_{2}\right) * \beta_{1}(i, j, k)}
$$

\subsection{CVR-BOLD em estado de repouso}

Como foi visto até aqui, não há uma padronização entre as características do estímulo vasodilatador, além do fato de necessitar que todos os equipamentos utilizados precisam ser adaptados para o ambiente da sala de RM, o experimento é bastante desconfortável para os sujeitos, em especial para idosos. Com base na literatura, mesmo entre aqueles submetidos a mapeamento CVR, até $24,3 \%$ são incapazes de completar o desafios respiratórios (SPANO et al., 2013). Essas considerações limitam significativamente a aplicabilidade clínica de técnicas convencionais de CVR, e são particularmente difíceis para aqueles indivíduos idosos com algum tipo de doença crônica. Com isso, uma abordagem mais simples, padronizada, repetitível e reprodutível poderia ser apresentada.

A motivação de estudos que buscam uma nova abordagem para quantificar CVR com base apenas em resting-state functional magnetic resonance imaging (rs-fMRI), sem a necessidade de agentes invasivos, manipulação da respiração ou inalação de $\mathrm{CO}_{2}$, vem de que esse sinal obtido engloba contribuições não neurais que podem ter origens de processos fisiológicos intrínsecos (LIU, 2013), que geralmente não são tão compreendidos em análises de estudos com conectividade funcional.

A rs-fMRI se beneficia do contraste BOLD e tem sido amplamente utilizada para medir a conectidade funcional do cérebro, baseada em sinais sincronizados de redes cerebrais (DIJK et al., 2010). Entretanto, o sinal BOLD é apenas uma medida indireta da atividade neuronal e é inerentemente modulado tanto pela atividade neuronal quanto pela fisiologia vascular de maneira não trivial (CHEN; GAUTHIER, 2021). A literatura sugere que o sinal de IRMf baseado em contraste BOLD é fundamentalmente modulado pela fisiologia vascular local (CHAMPAGNE et al., 2020; LIU et al., 2014; KANNURPATTI et al., 2011)

Wise e colaboradores, mostraram pela primeira vez a forte influência entre o sinal de rs-fMRI e flutuações espontâneas no $\mathrm{PETCO}_{2}$ (WISE et al., 2004). Nesse mesmo raciocínio, Liu e colaboraradores demonstraram que essa componentes do sinal BOLD em estado de respouso pode ser um substituto da monitoração do $\mathrm{PETCO}_{2}$ para a quantificação de CVR (LIU et al., 2017), mas em uma banda de frequência ligeiramente diferente do que foi proposto por Wise e colaboradores. Nesse mesmo estudo, os autores validaram a hipótese, onde os mapas de CVR apresentavam grande semelhança espacial com o método de hipercapnia, tanto em 
sujeitos saudáveis quanto pacientes com doença de moyamoya. Outros estudos seguiram a mesma metodologia, em pacientes com estenose careotídea assintomática (SECCHINATO et al., 2019), e AVC isquêmico (TANEJA et al., 2019).

As flutuações do sinal BOLD atribuídas às variações de $\mathrm{CO}_{2}$ podem ser extraídas aplicando uma filtragem temporal na primeira variável de por exemplo, 0,02-0,04 Hz (LIU et al., 2017; SECCHINATO et al., 2019), 0-0,025 Hz (JAHANIAN et al., 2014) ou 0-0,05 Hz (WISE et al., 2004), e até mesmo por fatoração de outros sinais fisiológicos dos dados do estado de repouso (GOLESTANI; WEI; CHEN, 2016). Feito isto, é possível seguir com a regressão da Equação 1.5 substituindo a curva de $\mathrm{PETCO}_{2}$ pelo sinal BOLD filtrado em determinada banda de frequência que melhor se correlacionada com a primeira em questão, produzindo um índice CVR para cada voxel. Normalizando todos os índices pela média global calculada é obtido o mapa de CVR em estado de repouso em escala relativa.

O diagrama da Figura 6 ilustra as etapas do procedimento da metodologia de mapeamento de reatividade cerebrovascular em estado de repouso.

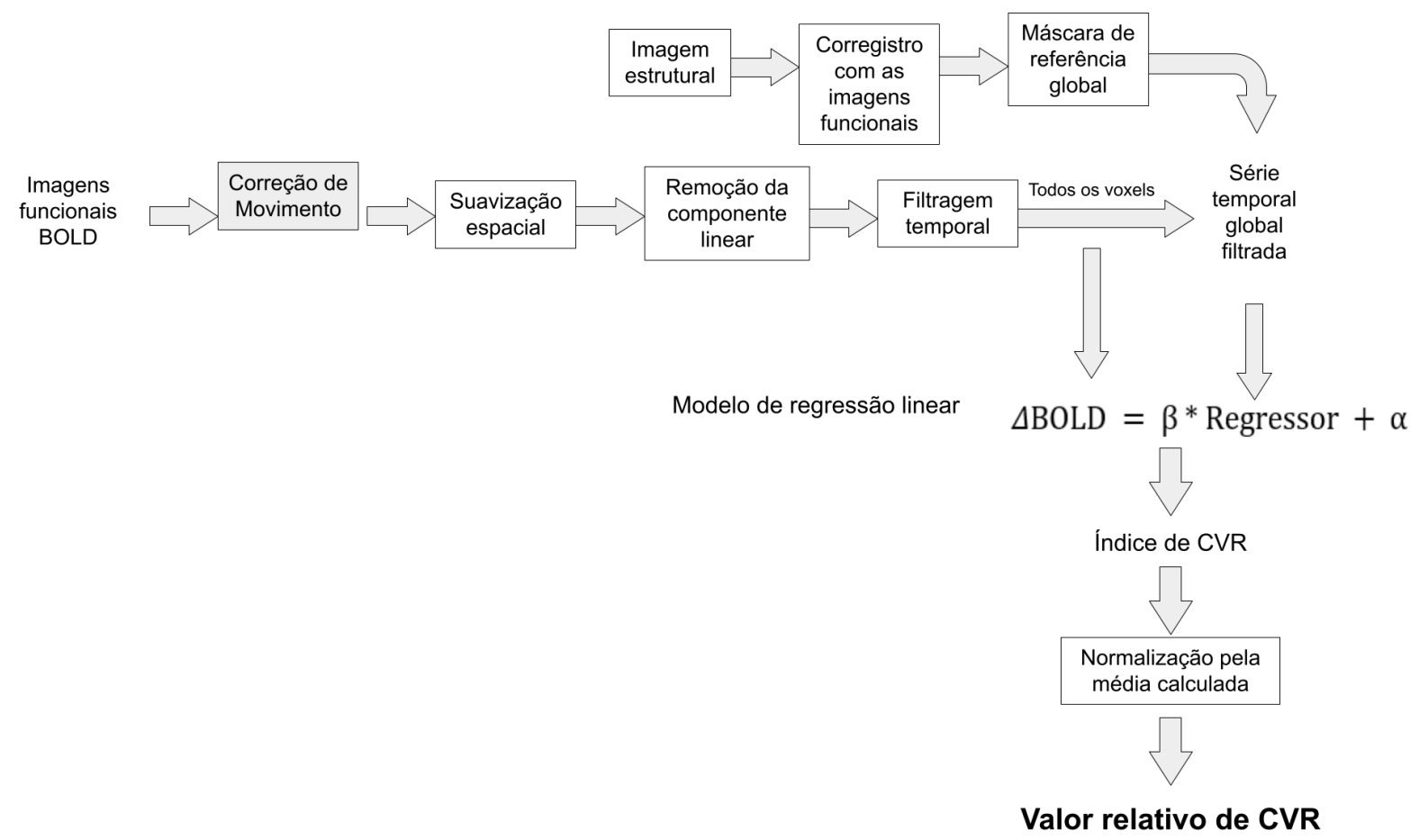

Figura 6 - O diagrama mostra as etapas do procedimento da metodologia de mapeamento de reatividade cerebrovascular em estado de repouso.

Devido à sua simplicidade e implementação barata, essas estratégias podem oferecer uma nova oportunidade para a aplicação do mapeamento CVR como uma ferramenta clínica e de pesquisa poderosa. 


\subsection{Tempo de atraso}

Outra grandeza que desperta o interesse de vários estudos é o tempo de atraso de resposta hemodinâmica, ou deslocamento temporal, conhecido como time shift (TS). O sinal BOLD pode ser atrasado em regiões do cérebro onde a circulação sanguínea é afetada (LV et al., 2018). Portanto, esses fatores devem ser levados em consideração ao projetar experimentos de conectividade funcional, especialmente em pacientes com doenças vasculares.

Recentemente estudos estão mostrando que a dinâmica das componentes de baixa frequência do sinal BOLD podem ser usadas para avaliar o comprometimento do estado hemodinâmico de pacientes com AVC (LV et al., 2013; NI et al., 2017; AMEMIYA et al., 2014). Essa dinâmica geralmente é identificada por atrasos, da ordem de segundos, nas flutuações de rs-fMRI que são obtidos através de correlações cruzadas do sinal BOLD de cada voxel com algum sinal de referência. Esta técnica foi aplicada com diferentes escolhas de sinais de referência, incluindo sinal da substância cinzenta (SIEGEL et al., 2016), sinal homotópico do hemisfério não lesado (BAUER et al., 2014), e sinal de máscaras que são iteradas (NISHIDA et al., 2019). A Figura 7 ilustra a metodologia de correlação entre todos os voxels com alguma curva de referência (em vermelho), fazendo adiantamento (em em cinza) e atrasando (em vermelho).

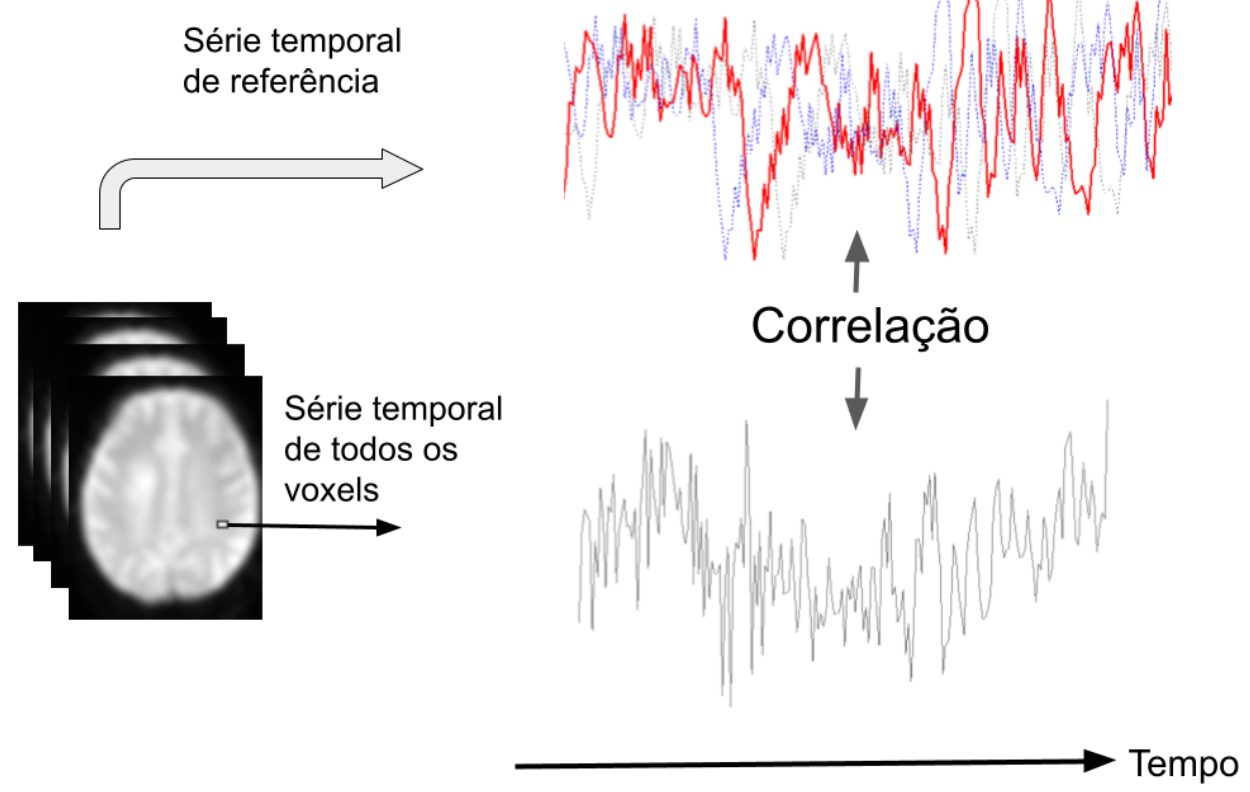

Figura 7 - Metodologia de correlação entre todos os voxels com alguma curva de referência (em vermelho), fazendo adiantamento (em em cinza) e atrasando (em vermelho), para obtenção do mapa de deslocamento temporal. 
É importante notar que o atraso pode ser visto em áreas de déficit de perfusão, conforme medido por imagem ponderada por perfusão com contraste, como a MTT e o tempo ao pico (TTP) (LV et al., 2013; AMEMIYA et al., 2014) e também com a ASL (SIEGEL et al., 2016). Além disso, também é uma metodologia não invasiva que se correlaciona com alterações de CVR para identificar tecidos em risco de AVC isquêmico (NISHIDA et al., 2019). Tal grandeza se torna interessante para o estudo a partir de que o AVC isquêmico interrompe o suprimento vascular do cérebro, não apenas dentro, mas também fora das áreas de infarto e essas áreas adjacentes podem ser suceptíveis a novos eventos de falta de suprimentos hemodinâmicos, chamada de região de penumbra, que pode ser salva, justificando o interesse em delinear essas regiões precocemente (EBINGER et al., 2009). 



\section{Motivação}

Do ponto de vista metodológico, seria importante apresentar um modelo de avaliação da reatividade cerebrovascular mais simples, padronizado, repetitível e reprodutível para conseguir atenter indivíduos que não conseguem realizar o experimento de hipercapnia. Além do fato do desconforto do sujeito, como por exemplo não se sentir seguro a inspirar uma mistura de gases, prendendo a respiraçao e tornando os resultados muitos imprecisos, todo o aparato experimental não seria necessário.

Esse aparato experimental precisa ter algumas observações especiais: 1) todos os componentes devem ser não metálicos, compatíveis com o ambiente de RM; 2) o dispositivo de entrega do gás (máscara, por exemplo) deve caber entre a bobina de cabeça (de recepção do sinal) e o indivíduo; 3 ) o sistema deve funcionar na posição deitada (conforme o aparelho de ressonância magnética) em vez de sentado, sem desconforto; 4) parâmetros fisiológicos relevantes, como por exemplo o $\mathrm{CO}_{2}$ expirado $\left(\mathrm{PETCO}_{2}\right.$, uma aproximação do conteúdo de $\mathrm{CO}_{2}$ no sangue arterial) deve ser registrado com precisão de segundos e armazenado em um computador para uso de análise. Esses problemas podem limitar o escopo das aplicações de mapeamento de CVR.

Do ponto de vista clínico, ainda há dúvidas de como deve ser o manejo de pacientes com estenose de carótida assintomática (ECa). Por um lado, existe a possibilidade do procedimento cirúrgico como a endarterectomia ou angioplastia com stent de carótida, que são dois procedimentos que consistem na desobstrução do vaso sanguíneo e, por outro lado, apenas o acompanhamento médico regularmente sem a intervenção cirúrgica. Assim, a avaliação da hemodinâmica cerebral, não invasiva, em respouso, nesses pacientes pode ajudar a estratificá-loa quanto à necessidade de procedimento cirúrgico.

Nossa hipótese é que pacientes com ECa unilateral severa irão apresentar alterações regionais de CVR e TS, comparados a indivíduos sem doença carotídea e mesma faixa etária. Porém, esperamos observar variabilidade entre os pacientes, que poderá ajudar na sua estratificação. 



\section{Objetivo geral}

Nosso principal objetivo foi aplicar o novo método de mapeamento de CVR usando dados de IRMf com contraste BOLD adquiridos em estado de repouso sem a necessidade de desafios de hipercapnia, além da obtenção de mapas de TS com esses mesmos dados, para a avaliação da hemodinânica cerebral em pacientes com ECa.

\subsection{Objetivos específicos}

- Verificar a frequência de filtragem temporal do sinal BOLD em estado de repouso para obtenção do mapa de rs-CVR, através da correlação com mapas de CVR para pausa respiratória e inalação de $\mathrm{CO}_{2}$.

- Testar a utilidade dessa nova abordagem de rs-CVR em estado de repouso para detectar déficits de CVR em um grupo de pacientes com ECa unilateral severa.

- Obter os mapas rs-CVR para diferentes atrasos de sinal global usados como a variável independente na análise de regressão dos dados dos pacientes com ECa unilateral severa.

- Testar a utilidade da abordagem de TS em um grupo de pacientes com doença de ECa unilateral severa. 



\section{Casuística e métodos}

Trata-se de um estudo de coorte transversal de sujeitos com estenose carotídea assintomática unilateral grave $(70 \%)$.

\subsection{Verificação da frequência de filtragem temporal}

A verificação da faixa de frequência para a filtragem temporal foi realizada em duas partes.

Na primeira parte, compararam-se os resultados obtidos para CVR em repouso e CVR em hipercapnia (inalação de $\mathrm{CO}_{2}$ ) em pacientes com ECa unilateral severa. Foram utilizados dados adquiridos no Hospital das Clínicas da Faculdade de Medicina de Ribeirão Preto. Cinco pacientes (70 \pm 3 anos; 3 mulheres, 2 homens) com ECa unilateral severa e cinco sujeitos controles ( $65 \pm 3$ anos; 2 mulheres, 3 homens) participaram do estudo aprovado pelo Comitê de Ética em Pesquisa da instituição, após lerem e assinarem o termpo de consentimento livre esclarecido (Anexo A.1 para pacientes e Anexo A.2 para controles). Os dados demográficos dos pacientes são apresentados na Tabela 4.1.1. Todos os sujeitos foram submetidos a aquisições de IRMf com inalação de $\mathrm{CO}_{2}$ em uma mistura de $5 \%$ intercalados por blocos de respiração natural.

Já na segunda parte, também foram comparados os resultados de CVR para respouso e hipercapnia (pausa respiratória) em um grupo de idosos saudáveis. Foi usado uma amostra de 23 sujeitos saudáveis ( $67 \pm 6$ anos) do banco de dados mantido pelo Instituto Nathan Kline situado em Orangeburg em Nova York, que compõe o Rockland Sample (NKI-RS) (NOONER et al., 2012). As aquisições de IRMf foram feitas em repouso e com desafio de pausa respiratória. Para o último caso, o protocolo consistiu em 7 blocos de respiração normal com duração de 12 segundos intercalados por 7 blocos de pausa respiratória com duração de 18 segundos.

\subsubsection{Parte 1: Correlação entre rs-CVR e CVR em hipercapnia em ECa}

As imagens foram adquiridas em um scanner 3T MR (Philips Medical Systems, Holanda) usando uma bobina de recepção de 32 canais. Para referência anatômica, as imagens estruturais foram adquiridas usando uma sequência gradiente eco (GRE) ponderada em T1 com os seguintes parâmetros: $\mathrm{TR}=6,7 \mathrm{~ms}, \mathrm{TE}=3,1 \mathrm{~ms}$, ângulo de rotação $=8^{\circ}$, matriz $=256 \mathrm{x}$ 256 , número de cortes $=180$, espessura de corte $=1 \mathrm{~mm}$, tamanho do voxel $=1 \times 1 \times 1 \mathrm{~mm}^{3}$.

Imagens de rs-fMRI foram adquiridas usando uma sequência GRE com leitura ecoplanar (em inglês, Echo planar imaging (EPI)) e os seguintes parâmetros: TR = $2000 \mathrm{~ms}$, TE = $30 \mathrm{~ms}$, matriz $=128 \times 128, \mathrm{FOV}=230 \times 230 \mathrm{~mm}^{2}$, número de fatias $=31$, espessura de corte 
Tabela 1 - Dados demográficos dos pacientes para o estudo da correlação entre rs-CVR e CVR em hipercapnia em ECa.

\begin{tabular}{ccccc}
\hline Paciente & Idade & Sexo & $\begin{array}{c}\text { Grau da estenose } \\
\text { à esquerda (\%) }\end{array}$ & $\begin{array}{c}\text { Grau da estenose } \\
\text { à direita (\%) }\end{array}$ \\
\hline p1 & 81 & $\mathrm{~F}$ & $>70$ & $<30$ \\
p2 & 65 & $\mathrm{~F}$ & $>70$ & 50 \\
p3 & 65 & $\mathrm{M}$ & 50 & $>70$ \\
p4 & 71 & $\mathrm{~F}$ & - & $>70$ \\
p5 & 68 & $\mathrm{M}$ & - & $>70$ \\
\hline \hline
\end{tabular}

${ }^{1} \mathrm{O}$ grau da estenose é medido como a porcentagem do diâmetro do vaso ocupado pela oclusão.

$=4 \mathrm{~mm}, 200$ volumes. Imagens BOLD durante a inalação de $\mathrm{CO}_{2}$ foram adquiridas usando uma sequência GRE com leitura EPI e os seguintes parâmetros: $\mathrm{TR}=1000 \mathrm{~ms}$, $\mathrm{TE}=30 \mathrm{~ms}$, matriz $=128 \times 128, \mathrm{FOV}=230 \times 230 \mathrm{~mm}^{2}$, número de cortes $=20$, espessura de corte $=4 \mathrm{~mm}$, 250 volumes. O paradigma de bloco consistia em cinco blocos de inalação de $\mathrm{CO}_{2}$ (duração: 14 segundos cada), intercalados por seis blocos de respiração normal (duração: 30 segundos cada). O aparato experimental foi descrito anteriormente por Leoni e colaboradores (LEONI et al., 2017).

As imagens funionais em repouso e de inalaçao de $\mathrm{CO}_{2}$ foram pré-processadas usando o software Statistical Parametric Mapping (SPM) e rotinas próprias escritas em MATLAB (MathWorks Natick, Massachusetts). As etapas do pré-processamento foram:

1. Reorientação das imagens tendo a comissura anterior de cada indivíduo como referência;

2. Correção do tempo entre as fatias, pois essas foram adquiridas sequencialmente com diferença temporal entre elas;

3. Correção do movimento da cabeça entre os volumes;

4. Coregistro com imagens estruturais;

5. Normalização para o espaço padrão do Montreal Neurological Institute (MNI);

6. Suavização espacial com filtro gaussiano de $6 \mathrm{~mm}$ de largura a meia altura nas três direções.

Para o mapeamento de de CVR com inalação de $\mathrm{CO}_{2}$ foi realizada uma regressão linear onde a variável dependente foi o sinal de todos os voxels da imagem e a variável independente 
foi a curva preditora (equação 1.4). Essa consistia nos blocos dos períodos de inalação de $\mathrm{CO}_{2}$ corrigidos pelo atraso vascular e, posteriormente, convoluídos com a função de resposta hemodinâmica. Essa correção se deu de forma a maximizar a correlação entre os blocos com o sinal global médio de cada indivíduo. O mapa de CVR foi obtido pelos coeficientes de $\beta$ de todos os voxels divido pelo valor médio calculado dentro do cérebro todo, pois não foi monitorada a curva de $\mathrm{PETCO}_{2}$ durante o experimento.

Para o mapeamento de CVR com imagens rs-fMRI, foi feita a remoção da componente linear do sinal de todos os voxels além da filtragem temporal em bandas de frequência específicas. As bandas utilizadas foram de 0-0,01Hz; 0,01-0,02Hz; 0,02-0,04Hz; 0,04-0,08 e 0,08-0,2Hz. A partir disso, foi obtida a média temporal do sinal global, em cada caso, que posteriormente foi usada como regressor, como mostrado em detalhes em (LIU et al., 2017). Um esquema ilustrando a metodologia é apresentado na Figura 8.

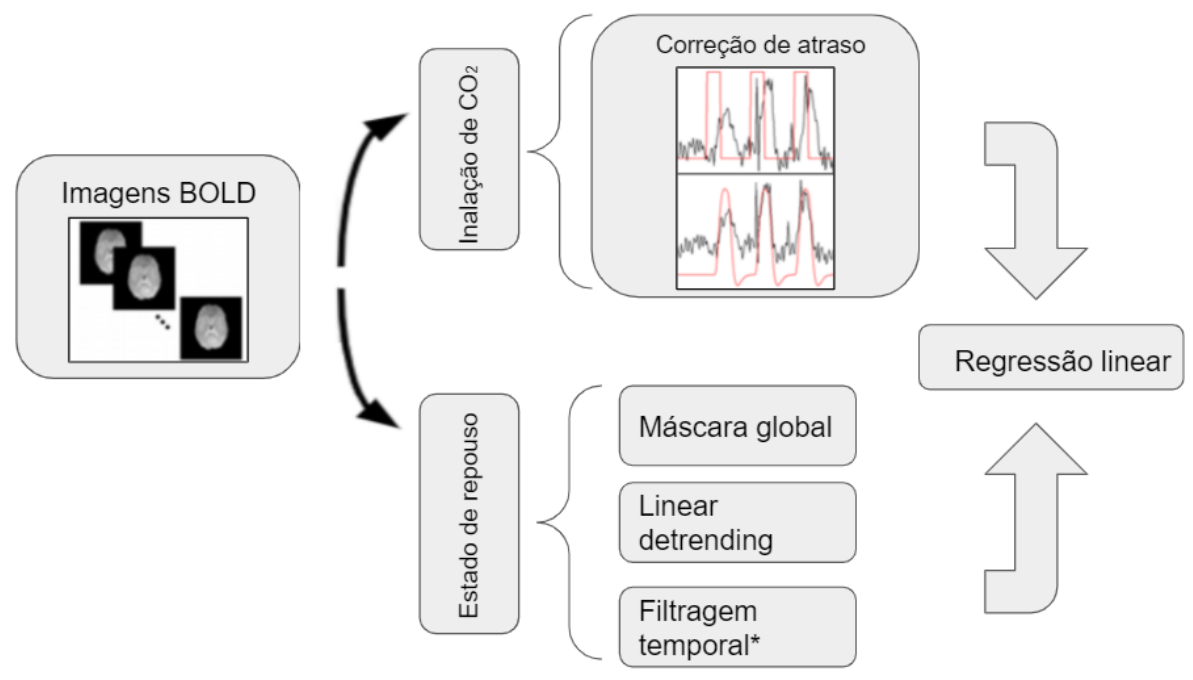

Figura 8 - Metodologia para mapeamento de CVR com inalação de CO2 e em estado de repouso. $\left(^{*}\right)$ Indica todas as 5 bandas de frequências utilizadas.

Feito isso, foi feita uma correlação linear entre todos os pontos dentro da máscara global do cérebro obtidos entre as duas análises descritas.

\subsubsection{Parte 2: Correlação entre rs-CVR e CVR em pausa respiratória}

Essa parte do trabalho teve como objetivo aumentar o número de sujeitos idosos analisados para confirmar a banda de frequência mais adequada para o mapeamento de CVR em estado de repouso. Para isso, novamente os resultados obtidos diferentes filtragens foram correlacionados com CVR em pausa respiratória.

As imagens utilizadas foram adquiridas por um scanner Siemens Magnetom TrioTim 
multibanda. Para a sequência estrututal foram utilizados os seguintes parâmetros: TR/TE = 1900/2,52 ms, FOV=250 x 250 x $250 \mathrm{~mm}$ e com tamanho de voxel isotropico de $1 \mathrm{~mm}$. Já para as imagens BOLD: TR/TE $=1400 / 30 \mathrm{~ms}, \mathrm{FOV}=224 \times 224 \times 224 \mathrm{~mm}$, com tamanho de voxel isotropico de $2 \mathrm{~mm}$, totalizando 4,5 minutos de aquisição. O desafio de pausa respiratória consistiu em 7 blocos de respiração normal com duração de 12 segundos intercaldados por 7 blocos de pausa respiratória com duração de 18 segundos.

Para o mapeamento de CVR, tanto com a metodologia de pausa respiratória, quanto com a metodologia em estado de repouso, foi feito o mesmo processamento descrito na Seção 4.1.1, com a diferença de que o regressor foi o envelope da curva individual que mensurava o controle da respiração por uma cinta que permitia captar a deflexão torácica.

\section{2 rs-CVR em pacientes com ECa unilateral severa}

Nessa parte do estudo, aplicamos a metodologia com rs-fMRI em vinte pacientes com ECa unilateral severa (12 mulheres; 8 homens; idade média $=67 \pm 10$ anos) e vinte controles saudáveis ( 8 mulheres; 12 homens; idade média $=68 \pm 7$ anos) após a assinatura do consentimento de participação. O estudo foi aprovado pelo Comitê de Ética da Instituição.

Os critérios de inclusão dos pacientes foram estenose da artéria carótida, unilateral, severa (maior que 70\%) ou oclusão e, para os controles, ausência de estenose ou oclusão, identificada por um neurorradiologista experiente por meio de angiografia por ressonância magnética. Os critérios de exclusão para pacientes e controles foram história de qualquer evento cerebrovascular (AIT, AVC isquêmico, etc); presença de estenose bilateral severa (maior que 70\%); presença de doenças neurológicas, como epilepsia, esclerose múltipla, esclerose lateral amiotrófica, tumor cerebral, doença de Binswanger e demência; distúrbios psiquiátricos; dependência de álcool e/ou outras substâncias neurotóxicas nos últimos 12 meses; distúrbios da comunicação verbal; gravidez; claustrofobia; e contra-indicações de RM.

As informações demográficas de todos os pacientes estão listadas na Tabela 2, sendo os cinco primeiros pacientes os mesmos do estudo anterior.

As imagens BOLD-MRI em estado de repouso e estruturais foram adquiridas com o mesmo protocolo e analisadas com o mesmo procedimento descritos na seção 4.1.1. A partir dos mapas de rs-CVR, os valores foram quantificados para as regiões do template de territórios arteriais de Mutsaerts e colaboradores, totalizando dezoito regiões de interesse (MUTSAERTS et al., 2015) (Figura 2).

Feito isso, a normalidade dos valores de CVR foi testada pelo método de KolmogorovSmirnov, e esses valores foram submetidos à análise estatística intra-sujeito no software $\mathrm{R}(\mathrm{R}$ Core Team, 2020), usando ANOVA de dois fatores com medidas repetidas e teste post-hoc de Tukey, para testar a hipótese de diferenças significativas entre hemisférios e territórios dentro 
Tabela 2 - Dados demográficos dos pacientes com ECa unitaleral severa para avaliação da rs-CVR.

\begin{tabular}{ccccc}
\hline Paciente & Idade & Sexo & $\begin{array}{c}\text { Grau da estenose } \\
\text { à esquerda }(\%)\end{array}$ & $\begin{array}{c}\text { Grau da estenose } \\
\text { à direita }(\%)^{1}\end{array}$ \\
\hline p1 & 81 & F & $>70$ & $<30$ \\
p2 & 65 & F & $>70$ & 50 \\
p3 & 65 & M & 50 & $>70$ \\
p4 & 71 & F & - & $>70$ \\
p5 & 68 & M & - & $>70$ \\
p6 & 82 & F & 30 & $>70$ \\
p7 & 68 & F & $>70$ & - \\
p8 & 62 & F & $>70$ & $<50$ \\
p9 & 77 & M & $>70$ & $<30$ \\
p10 & 83 & M & $>70$ & $<30$ \\
p11 & 77 & M & - & $>70$ \\
p12 & 67 & F & $>50$ & - \\
p13 & 67 & F & $>70$ & - \\
p14 & 59 & F & $>70$ & $>70$ \\
p15 & 56 & F & - & $>70$ \\
p16 & 61 & M & - & - \\
p17 & 52 & F & $>70$ & $>75$ \\
p18 & 70 & M & - & - \\
p19 & 53 & F & $>70$ & $>70$ \\
p20 & 53 & F & - & \\
\hline \hline
\end{tabular}

${ }^{1} \mathrm{O}$ grau da estenose é medido como a porcentagem do diâmetro do vaso ocupado pela oclusão.

dos grupos. Essa análise foi realizada para cada grupo separadamente. Em seguida, os valores de CVR foram comparados entre os grupos usando os mesmos testes estatísticos. Nesse caso, para o grupo controle, foram utilizados o valor médio de CVR entre os hemisférios direito e esquerdo para uma mesma região. Significância estatística foi considerada para $\mathrm{p}<0,05$.

\subsection{Tempo de atraso em pacientes com ECa unilateral severa}

Os mesmos sujeitos citados na seção 4.2 participaram desse estudo. Os dados foram adquiridos e pré-processados conforme descrito anteriormente na seção 4.1.1, seguido por uma remoção adicional de tendência linear e filtragem temporal com banda de frequência de 0,02 a $0,12 \mathrm{~Hz}$.

O método para se obter um mapa de TS é descrito em detalhes em (NISHIDA et al., 2019). Resumidamente, usamos o sinal médio do cérebro inteiro para criar uma série temporal de referência inicial, que foi correlacionada com todas as séries temporais de todos os voxels 
no cérebro. Os voxels com coeficiente de correlação superior a 0,2 foram agrupados em uma nova máscara e a série temporal média dessa nova máscara foi usada como a nova referência para o procedimento recursivo. A série temporal de referência foi atualizada recursivamente usando o sinal combinado de voxels com o critério de correlação atendido $(r>0,2)$. O passo para a atualização foi $0,5 \mathrm{~s}$ ou $-0,5 \mathrm{~s}$. Esse procedimento foi repetido oito vezes para atingir o rastreamento de $\pm 4 \mathrm{~s}$. É apresentado um diagrama esquemático ilustrando o procedimento na Figura 9.
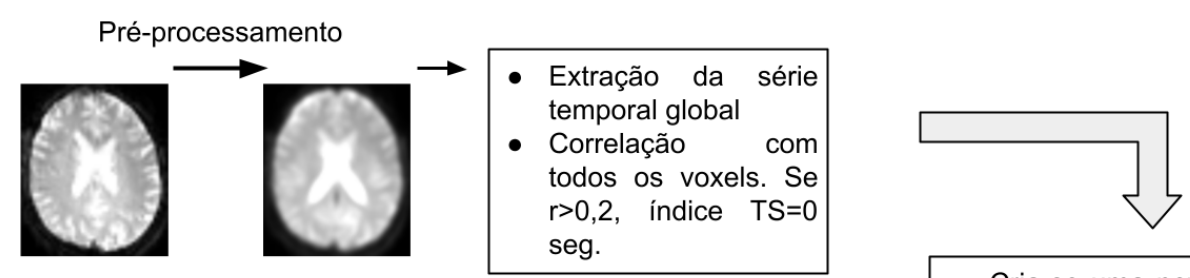

- Cria-se uma nova máscara com esses voxels

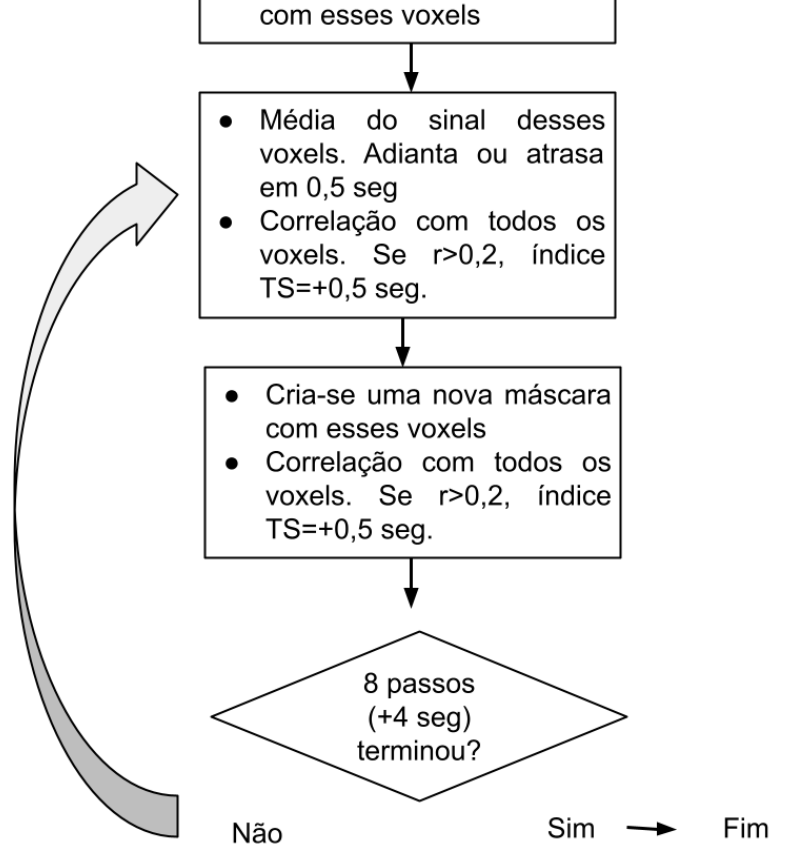

Figura 9 - Esquema ilustrativo do método iterativo para o mapeamento do deslocamento temporal (TS). 


\section{Resultados}

\subsection{Verificação da frequência de filtragem temporal}

\subsubsection{Parte 1: Correlação entre rs-CVR e CVR em hipercapnia em ECa}

A Figura 10 mostra os coeficientes de correlação de Pearson entre os valores de rs-CVR obtidos da filtragem do sinal com diferentes bandas de frequência, com os obtidos para inalação de $\mathrm{CO}_{2}$. A correlação foi significativamente mais forte quando as séries temporais foram filtradas em 0,02-0,04 Hz, em comparação com as outras bandas de frequência ( $\mathrm{p}<$ 0,05).Isso sugere que o componente do sinal BOLD em estado de repouso em uma banda de frequência de 0,02-0,04 Hz fornece uma melhor correção com o $\mathrm{PETCO}_{2}$. Além disso, os mapas rs-CVR para frequência de banda de 0,02-0,04 Hz, mostraram bom contraste entre as substâncias cinzenta e branca, e concordância espacial com os mapas de CVR com $\mathrm{CO}_{2}$.

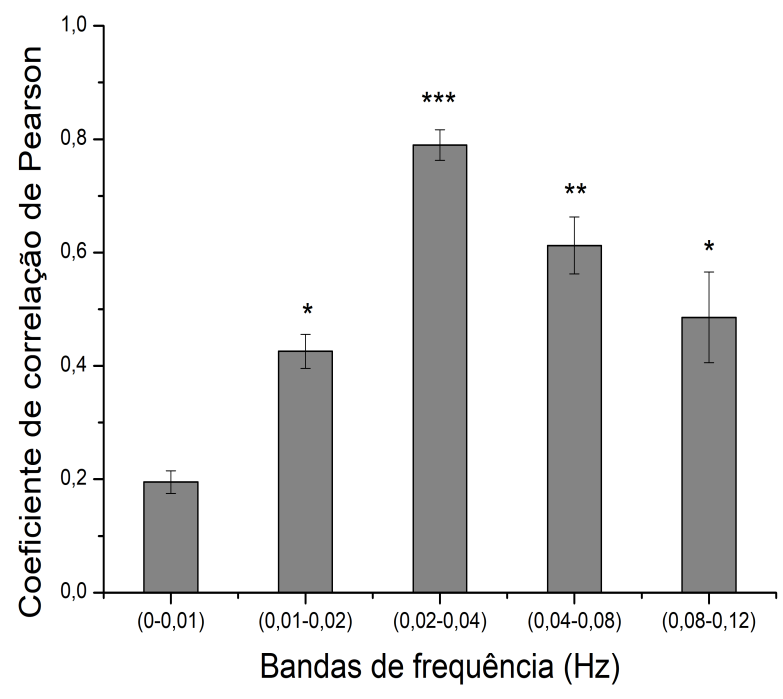

Figura 10 - Coeficientes de correlação de Pearson entre os valores de reatividade cerebrovascular obtidos para o estado de repouso (rs-CVR), filtrados para diferentes bandas de frequências, comparados com aqueles obtidos durante a inalação de $\mathrm{CO}_{2}$. ( ${ }^{*} \mathrm{p}$ $\left.<0.05 ;^{* *} \mathrm{p}<0.01 ;{ }^{* * *} \mathrm{p}<0.001\right)$. Figura adaptada de Secchinato e colaboradores (SECCHINATO et al., 2019)

A Figura 11 mostra os resultados para quatro pacientes representativos. Os coeficientes de correlação de Pearson entre os valores de rs-CVR e CVR com $\mathrm{CO}_{2}$ foram superiores a 0,60 para todos os participantes. Por fim, os mapas de rs-CVR de pacientes mostraram déficits principalmente nas regiões do cérebro irrigadas pelas ACM, ramos da ACI, no hemisfério 
ipsilateral à estenose de grau severo. Tais alterações foram observadas em regiões similares nos mapas de rs-CVR e HC-CVR.

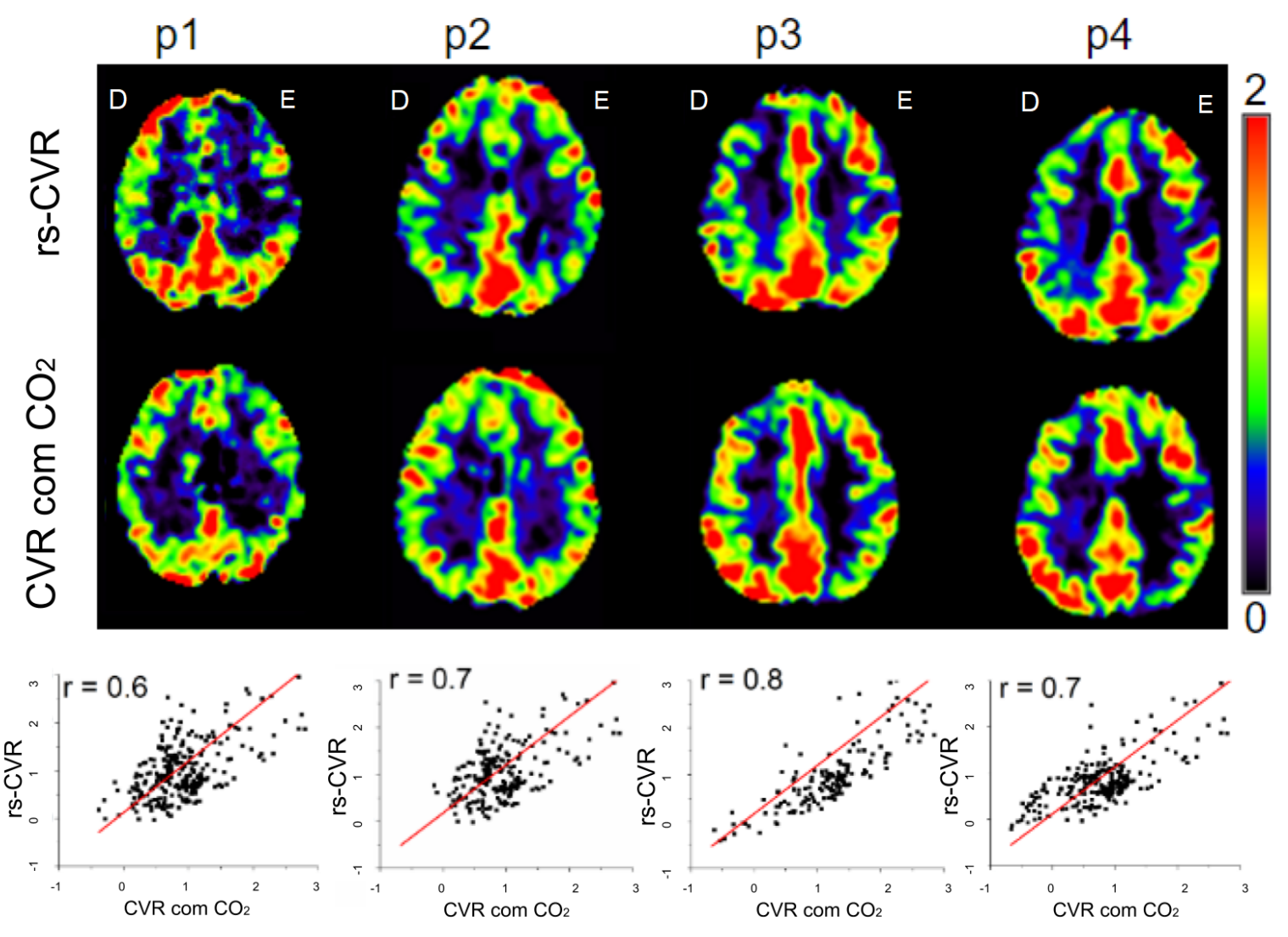

Figura 11 - Mapas de CVR obtidos com BOLD-MRI adquiridos durante o estado de repouso (rs-CVR, primeira linha) e durante a hipercapnia (CVR com $\mathrm{CO}_{2}$, segunda linha). Foi observada boa correlação entre os valores de CVR obtidos pelos dois métodos (terceira linha; r: coeficiente de correlação de Pearson; com todos os valores sendo $\mathrm{p}<0,05)$. Uma fatia de cada paciente é mostrada em orientação radiológica. D: direita; E: esquerda.

\subsubsection{Parte 2: Correlação entre rs-CVR e CVR em pausa respiratória}

A Figura 12 mostra os mapas médios de CVR obtidos com pausa respiratória e também com cada banda de frequência analisada. Não foi apresentada nenhuma diferença significativa entre a metodologia de pausa respiratória com valores obtidos em cada banda de frequência para as regiões do template analisado.

Para comparar as bandas de frequências analisadas, também é apresentado um histograma dos valores de CVR de ambas as metodologias. Podemos ver que para a banda de frequência de $0,02-0,04 \mathrm{~Hz}$, o histograma mais se sobrepõem aos valores de CVR calculados em pausa respiratória. 


\section{2 rs-CVR em pacientes com ECa unilateral severa}

A Figura 13 mostra os mapas de rs-CVR de todos os indivíduos de ambos os grupos. A análise ANOVA do grupo controle não mostrou efeito do hemisfério ( $p=0,32)$, mas um efeito significante do território vascular $\left(\mathrm{p}=10^{-16}\right)$ nos valores de rs-CVR. Para ambos os hemisférios, a parte proximal do território da ACA apresentou rs-CVR reduzida em relação às porções intermediária e distal $\left(\mathrm{p}=10^{-9}\right)$, e a parte proximal do território ACM apresentou rs-CVR reduzida quando comparada à porção distal $\left(\mathrm{p}=10^{-3}\right)$.

Para os pacientes, não foi observada diferença estatística entre os hemisférios ( $\mathrm{p}=$ $0,18)$. No entanto, diferenças significativas foram observadas entre as regiões $\left(\mathrm{p}=10^{-16}\right)$. Para ambos os hemisférios, valores reduzidos foram observados para a parte distal do território ACA em relação à porção proximal (ipsilateral, $\mathrm{p}=10^{-5}$; contralateral, $\mathrm{p}=10^{-5}$ ) e também em relação à porção intermediária (ipsilateral, $\mathrm{p}=10^{-4}$; contralateral, $\mathrm{p}=10^{-4}$ )

Uma vez que não foi encontrada diferença significante nos valores médios de CVR em relação aos hemisférios esquerdo e direito para o grupo controle, os valores médios das nove regiões foi calculado entre os dois hemisférios para comparação com os pacientes. A nova análise apresentou os mesmos resultados da anterior, com achados adicionais, como apresentado na Figura 14.

Para o grupo controle, a parte intermediária do território da ACP apresentou valores médios de CVR maiores do que para a região proximal $(p=0,03)$. Para os pacientes, foram observados valores reduzidos para a parte intermediária do ACA quando comparada à proximal (ipsilateral, $\mathrm{p}=0,003$; contralateral $\mathrm{p}=10-4$ ), e para a ACM proximal quando comparada à distal (ipsilateral, $p=0,008$; $p$ contralateral $=0,007$ ). A média da CVR foi significativamente maior no território do ACP intermediário do que no território distal do PCA para o hemisfério ipsilateral à estenose $(p=0,01)$.

Além disso, os valores médios de CVR para o território distal do ACA em pacientes foram significativamente menores em ambos os hemisférios (ipsilateral, $p=0,008$; contralateral $\mathrm{p}=0,009$ ) quando comparados aos controles. No entanto, para o território ACA proximal, esses valores foram significativamente maiores para os pacientes (ipsilateral, $\mathrm{p}=10-5$; contralateral $\mathrm{p}=10-5)$ do que para o grupo controle.

Também obtivemos os mapas rs-CVR para diferentes atrasos de sinais globais usados como variável independente na análise de regressão dos dados dos pacientes, apresentados na Figura 15.

A maior parte dos pacientes apresentaram mapas rs-CVR semelhantes para todos os atrasos, mas alguns demonstraram depedência com essa série temporal atrasada. Por exemplo, o paciente 10 mostrou rs-CVR reduzida no território ACM do hemisfério ipsilateral à estenose severa (esquerda) independente do atraso do sinal global para regressão. Porém, o paciente 15 apresentou valor de CVR reduzido no hemisfério direito, ipsilateral à 
estenose severa, sem deslocamento temporal ( $\mathrm{TS}=0 \mathrm{~s}$ ), mas aumentou gradativamente até o deslocamento de 4 segundos.

\subsection{Tempo de atraso em pacientes com ECa unilateral severa}

A Figura 16 mostra o mapa de TS de cada indivíduo. Deslocamentos temporais mais longos são exibidos em cores quentes. Para o grupo controle, a análise ANOVA não mostrou efeito de hemisfério $(\mathrm{p}>0,5)$, mas um efeito significativo do território vascular $\left(\mathrm{p}=10^{-7}\right)$. $\mathrm{O}$ valor de TS foi maior para o território esquerdo do ACA do que para o território esquerdo do ACP $(p=0,01)$. Ao agrupar os valores para ambos os hemisférios, o TS para o território ACA proximal apresentou valores maiores do que para os territórios ACA intermediário ( $p=0,007$ ) e distal $\left(\mathrm{p}=10^{-4}\right)$ (Figura 17).

Os valores de TS foram maiores nos pacientes nas três partes do território da ACM e na parte distal do território ACP, no hemisfério ipsilateral, quando comparados aos territórios correspondentes no grupo controle (proximal $\mathrm{p}=0,004$; intermediária e distal $\mathrm{p}=0,002$ ), como apresentados na Figura 17. Além disso, nos pacientes, a TS foi maior na ACM ipsilateral distal em comparação com a mesma região do hemisfério contralateral ( $p=0,002)$.

É possível observar a variabilidade entre os indivíduos, principalmente entre os pacientes. Os mapas de TS de alguns pacientes (por exemplo, p3, p4 e p11) foram muito semelhantes aos mapas dos controles. Entretanto, os mapas de outros pacientes (por exemplo, p6, p12 e p17) mostraram deslocamentos temporais mais longos em determinadas regiões cerebrais.

A Figura 18 mostra a correlação negativa entre os valores de CVR e TS para os pacientes (Figura 18A) e controles (Figura 18B). A normalidade das variáveis foi avaliada usando o Teste de Kolmogorov-Smirnov ( $p=0,39$ ). A correlação de Pearson mostrou um TS mais alto para um índice CVR mais baixo, sugerindo que as metodologias são complementares. 
Pausa respiratória
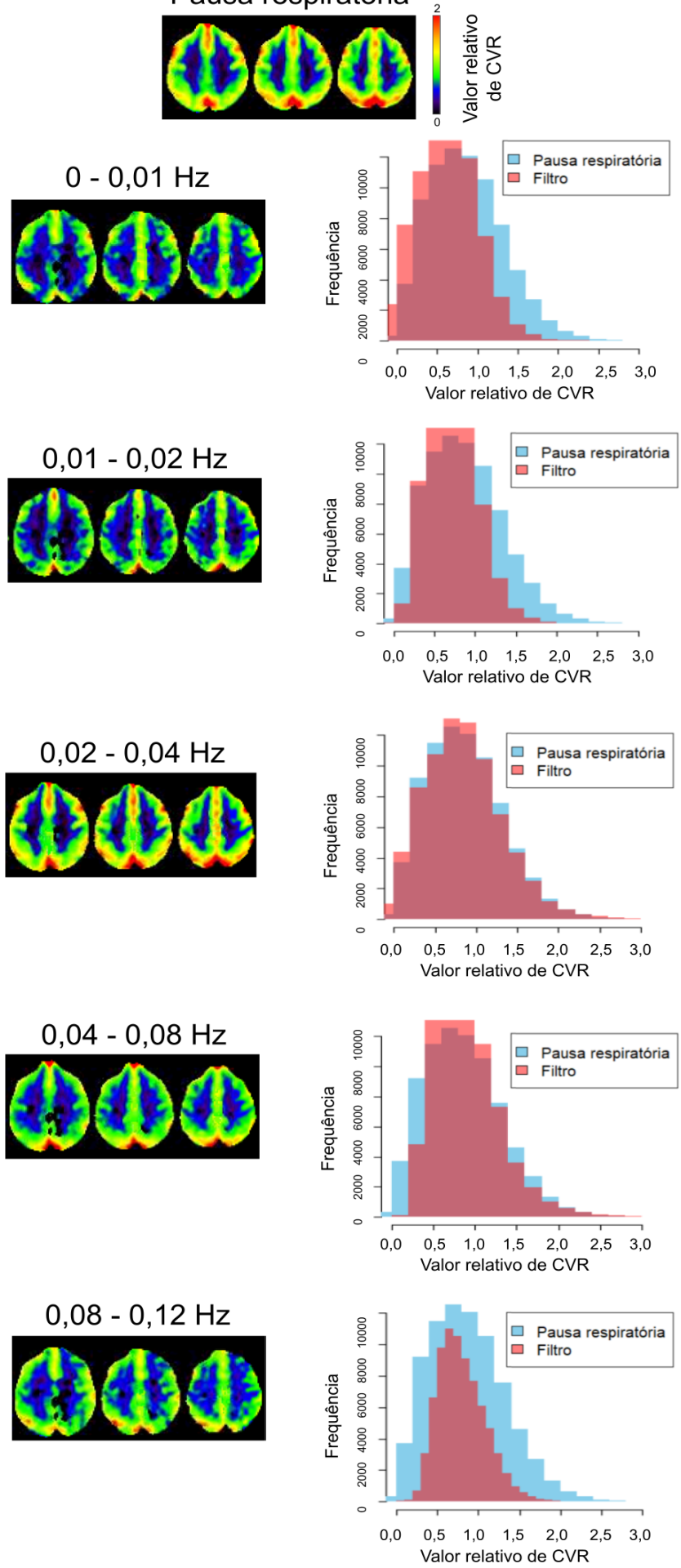

Figura 12 - Comparação entre o mapa médio de CVR do grupo obtido a partir desafio de pausa respiratória e em estado de repouso. Na minha linha é apresentado o mapa de CVR em pausa respiratória; na segunda linha o mapa de CVR em estado de repouso obtidos com determinadas frequência; e na terceira linha os histogramas dos valores de CVR de ambas metodologias comparado com CVR em pausa respiratória. 


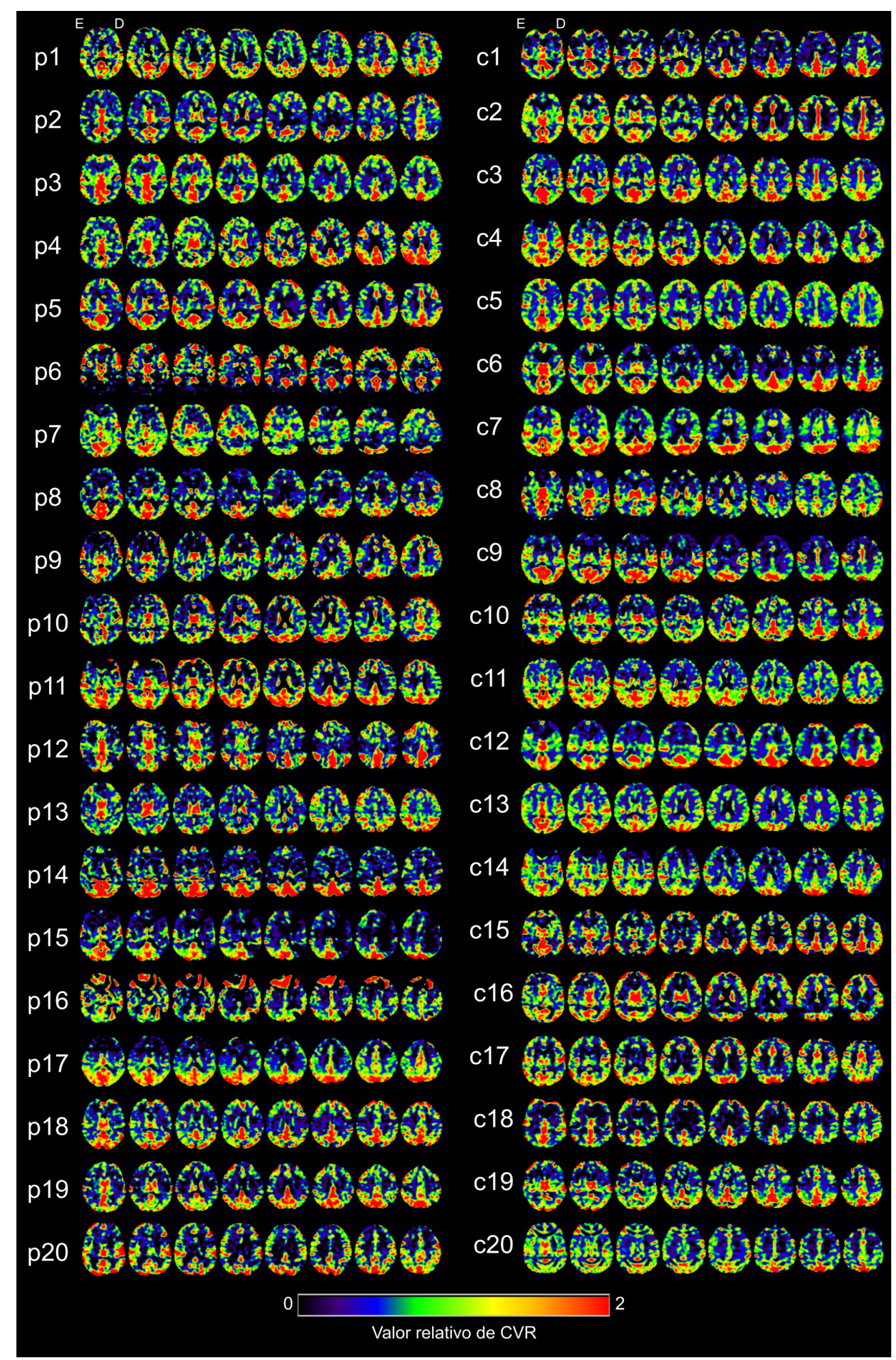

Figura 13 - Mapas de reatividade cerebrovascular em estado de repouso (rs-CVR) para pacientes (à esquerda) e para controle saudáveis (à direita). Os mapas estão em unidades relativas. $\mathrm{D}=$ direita; $\mathrm{E}=$ esquerda. 

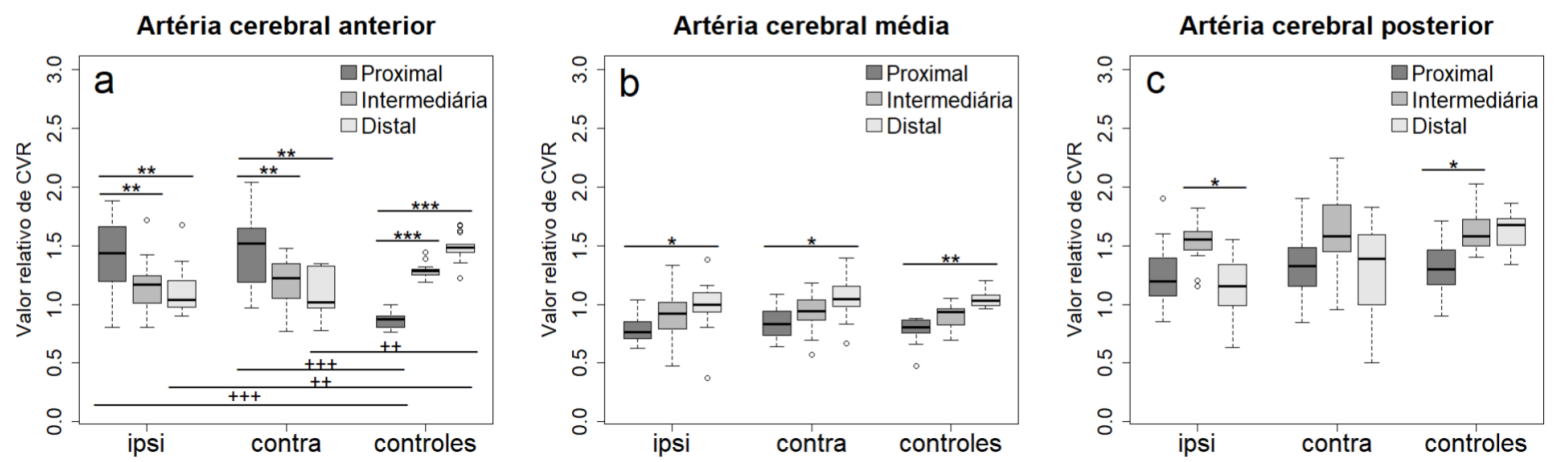

Figura 14 - Reatividade cerebrovascular em repouso (rs-CVR) para os territórios das artérias cerebrais dos pacientes, ambos os hemisférios (ipsi e contralateral ao lado da estenose severa) e controles. São apresentadas diferenças estatísticas significantes dentro dos grupos $\left({ }^{*} \mathrm{p}<0,05 ;{ }^{* *} \mathrm{p}<0,01 ;{ }^{* * *} \mathrm{p}<0,001\right)$ e entre os grupos $(++\mathrm{p}<0,01$; $+++\mathrm{p}<0,001)$. 


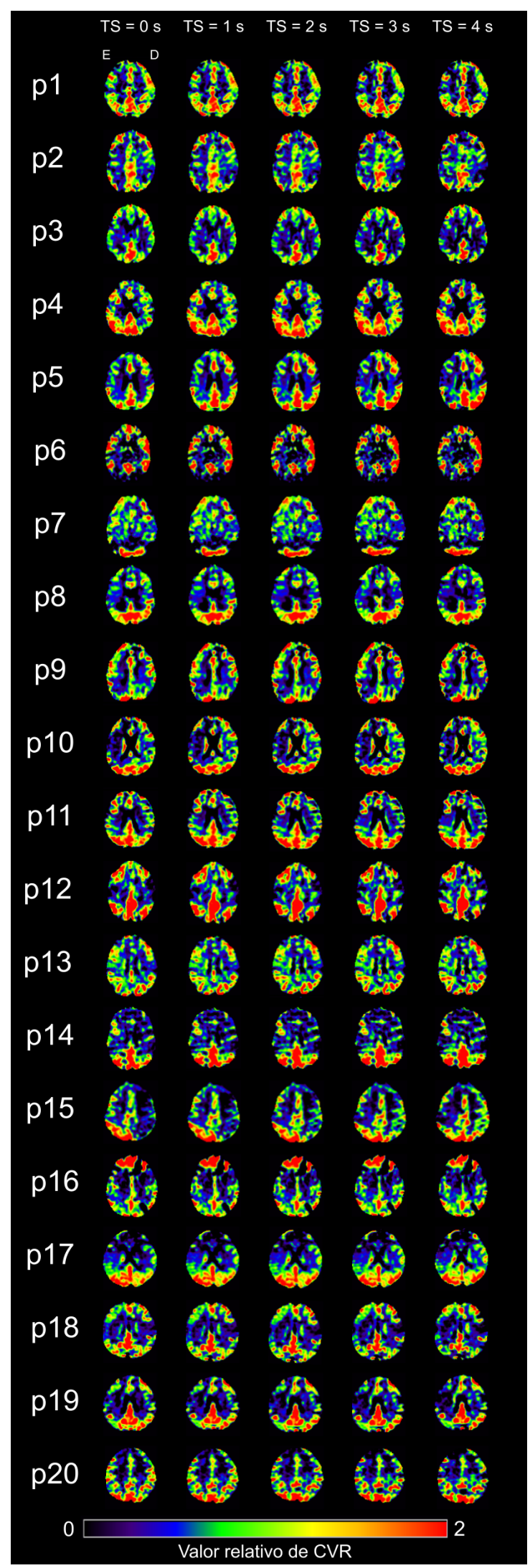

Figura 15 - Mapas de reatividade cerebrovascular em estado de repouso (rs-CVR) usando o sinal global atrasado para regressão linear. A série temporal do sinal global foi atrasada em deslocamentos de 1 segundo até 4 segundos (deslocamentos temporais (TS) de 0, 1, 2, 3 e 4 segundos). Uma fatia é mostrada para cada atraso e cada paciente. 


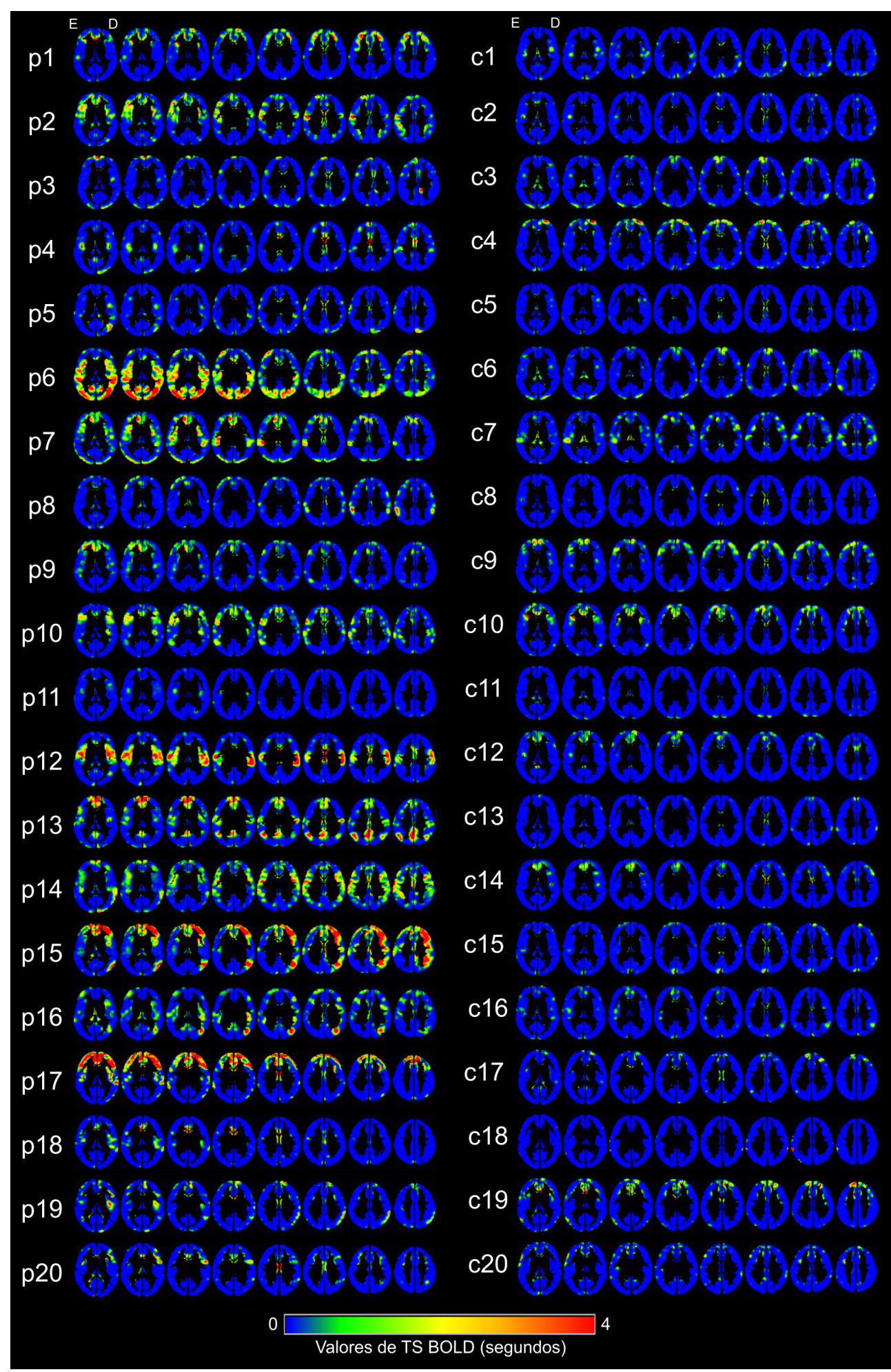

Figura 16 - Mapas de deslocamento temporal (BOLD-TS) para pacientes (esquerda) e controles (direita). Os mapas estão em segundos. $\mathrm{E}=$ esquerda; $\mathrm{D}=$ Direita. 

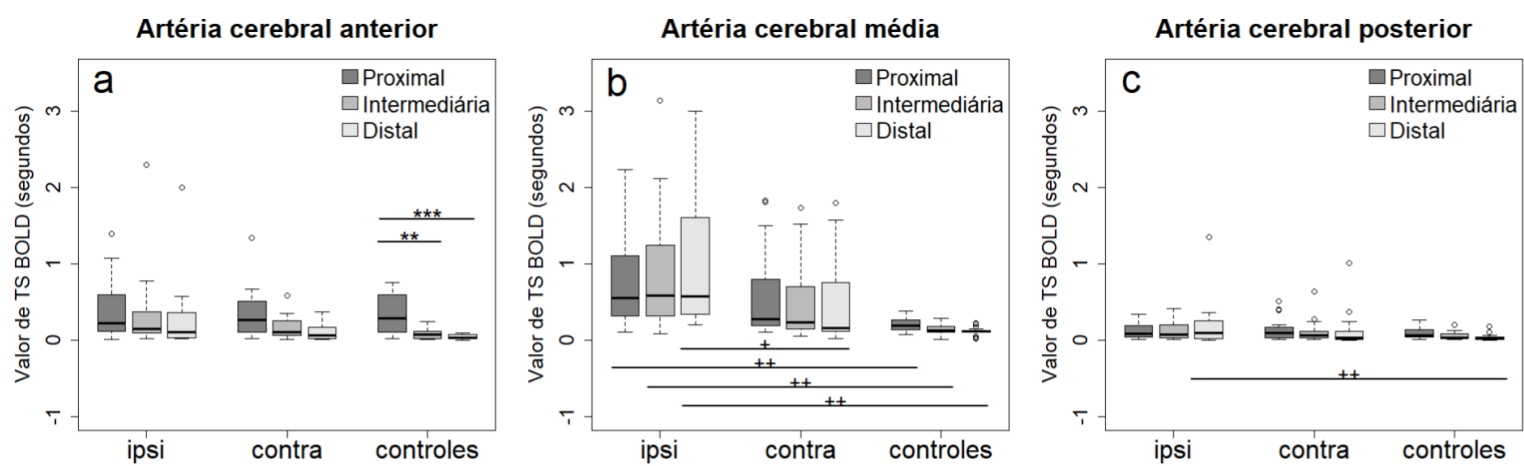

Figura 17 - Índice de deslocamento de tempo (TS BOLD) para os territórios da artéria cerebral dos pacientes, ambos os hemisférios (ipsi e contralateral ao lado da estenose) e controles. São apresentadas diferenças estatísticas significativas dentro dos grupos $\left({ }^{*} \mathrm{p}<0,05 ;{ }^{* *} \mathrm{p}<0,01 ;{ }^{* * *} \mathrm{p}<0,001\right)$ e entre os grupos $(+\mathrm{p}<0,05 ;++\mathrm{p}<0,01$; $+++\mathrm{p}<0,001)$.

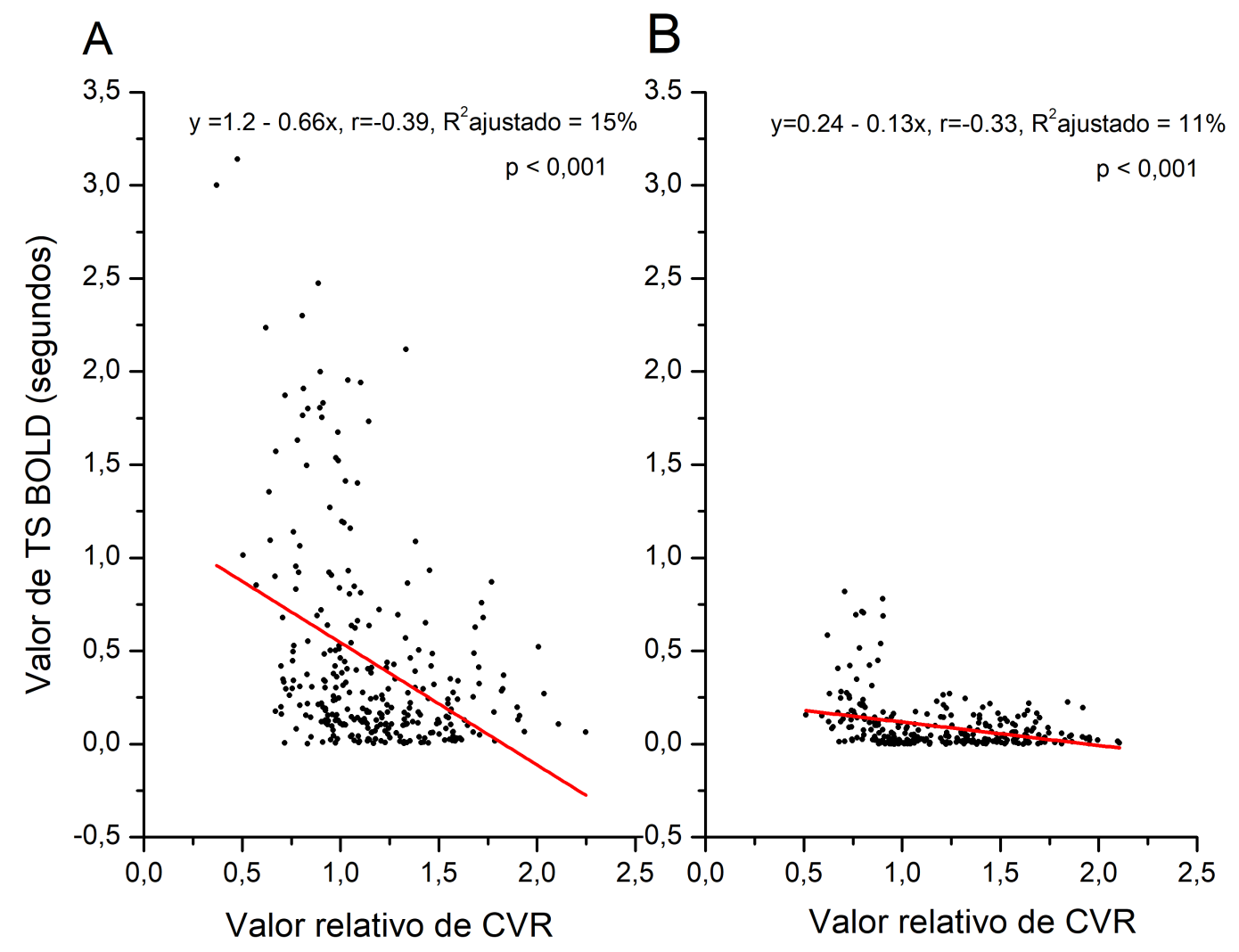

Figura 18 - Regressão linear entre destolamento temporal (valores de TS BOLD) e o reatividade cerebrovascular (CVR), mostrando uma correlação negativa significativa entre (A) pacientes e (B) controles. O teste de normalidade Kolmogorov-Smirnov foi realizada e os coeficientes de correlação de Pearson ( $r)$ e de determinação $\left(R^{2}\right.$ ajustado) foram apresentados. 


\section{Discussão}

Na primeira parte do estudo, buscamos verificar a banda de frequência mais adequada para filtrar o sinal BOLD em estado de repouso a fim de obter mapas de rs-CVR similares aqueles obtidos sob hipercapnia (pausa respiratória e inalação de $\mathrm{CO}_{2}$ ). Nos últimos anos, estudos têm mostrado que o sinal BOLD em estado de repouso em baixas frequências possui informações relacionadas às mudanças de $\mathrm{PETCO}_{2}$ (LIU et al., 2017; TANEJA et al., 2019; JAHANIAN et al., 2014; WISE et al., 2004; SECCHINATO et al., 2019), sugerindo uma alternativa para a avaliação de CVR. Entretanto, esses estudos não fizeram essa avaliação em idosos, como realizado no presente estudo.

Na segunda parte foi apresentada a aplicação da metodologia na avaliação de pacientes com ECa unilateral severa, mostrando o mapeamento de CVR e TS. Em geral, os pacientes não apresentaram diferenças de rs-CVR entre os hemisférios. Porém, apresentaram TS alterado em regiões irrigadas pela $\mathrm{ACM}$, enquanto o grupo controle não apresentou diferenças hemisféricas para ambas as medidas. Alterações regionais semelhantes foram observadas ao analisar visualmente mapas individuais de CVR e TS. Tais parâmetros apresentaram correlação negativa quando analisamos os valores de CVR e TS de todas as regiões de todos os sujeitos juntos. Porém, mesmo separando em pacientes e controles, podemos ter um erro associado ao paradoxo de Simpson onde pode acontecer que essa relação linear esteja presente em uma ou mais regiões, mas não em todas, e na média final, não existir relação entre as variáveis mostradas (TU; GUNNELL; GILTHORPE, 2008).

Para usar os dados rs-BOLD para o mapeamento de CVR, é crucial identificar a faixa de frequêncial ideal na qual a componente de sinal é relacionada às mudanças de $\mathrm{PETCO}_{2}$ e, portanto, à vasorreatividade. Mostramos na primeira parte desse tópico, que a frequência ótima seria de 0,02-0,04Hz. Entretanto, para a atividade de pausa respiratória, não observamos diferenças significantes entre os valores de CVR calculados em desafio vasodilatador com as cinco bandas de frequência analisadas no template utilizado. Porém, visualmente, a filtragem na frequência de 0,02-0,04 Hz forneceu os mapas de CVR mais similares com o mapa de pausa repsiratória, do que as outras bandas analisadas. Essa mesma faixa de frequências foi utilizada em estudos anteriores (LIU et al., 2017; TANEJA et al., 2019; SECCHINATO et al., 2019).

É relevante ressaltar que aquisições com desafio de pausa respiratória são muito desconfortáveis e introduzem uma componente de erro relacionado ao movimento da cabeça do indivíduo. Esse movimento da cabeça acaba por ser síncrono aos períodos em que o indivíduo precisa prender a respiração, interferindo na análise dos resultados para obtenção dos mapas de CVR (MOIA et al., 2021). Além disso, o desempenho dos indivíduos pode variar bastante, fazendo com que os valores de CVR se tornem muito variáveis entre os indivíduos 
para uma mesma região (MOIA et al., 2020).

Além disso, recentemente Liu e colaboradores exploraram os dados de 170 sujeitos com inalação de $\mathrm{CO}_{2}$ e encontraram que a frequência ótima seria de 0-0,1164 Hz (LIU et al., 2021). Esses resultados mostram que a frequência de 0,02-0,04 Hz que foi analisada nesse trabalho, pode ser um pouco restritiva, apesar de ser a banda de frequência que mais se correlaciona com $\mathrm{PETCO}_{2}$ em estado de respouso (LIU et al., 2017). Entretanto, nesse mesmo estudo, Liu e colaboradores aplicaram a banda de frequência de 0,02-0,04 Hz e reportaram que o resultado ainda teve uma alta correlação espacial com o mapa de referência de inalação de $\mathrm{CO}_{2}$.

As medições de CVR sob hipercapnia têm sido amplamente realizadas no envelhecimento normal e doenças cerebrovasculares (LEONI et al., 2017; TANEJA et al., 2019; BLAIR et al., 2020). Apesar de seu alto potencial clínico, o mapeamento CVR durante a ressonância magnética não é amplamente utilizado na rotina médica. A limitação mais relevante do uso da hipercapnia é a necessidade da contribuição do paciente. A retenção da respiração normalmente aumenta o desconforto e o movimento durante um exame de ressonância magnética, e a inalação de dióxido de carbono pode causar complicações transitórias, como dor de cabeça e tontura, especialmente para pacientes com doenças agudas (LIU; JILL; LU, 2019). Além disso, a necessidade de aparelhos adicionais exige profissionais treinados e custos extras. Por outro lado, outros parâmetros relacionados a características temporais da hemodinâmia cerebral, como TTP e MTT, que são amplamente usados para avaliação da perfusão sanguínea cerebral, são obtidos a partir de imagens por ressonância magnética ponderadas em perfusão com o uso de agente de contraste exógeno (LV et al., 2013; AMEMIYA et al., 2014; NI et al., 2017).

Nosso estudo é o primeiro que utilizou ambas as abordagens (rs-CVR e TS) para avaliar um grupo de pacientes ECa unilateral severa. Em controles normais, mostramos que o CVR é menor em territórios proximais do que distais e intermediários, principalmente em regiões irrigadas pelas ACA. No entanto, os pacientes com ECa unilateral severa perderam esse gradiente, fazendo com que os valores de CVR ficassem maiores em regiões proximais do que em regiões intermediárias e distais irrigadas pelas ACA. Isso pode sugerir que a ECa leva a um defeito microcirculatório, corroborando com achados prévios do grupo de pacientes, como a maior quantidade de lesão de substância branca ipsilateral à estenose (Afonso et al, em elaboração).

Como o TS reflete a dinâmica de perfusão de origem vascular (AMEMIYA et al., 2014), nossos dados sugerem que esse método é mais sensível para detectar atrasos temporais em vasos de maior calibre, pois foi visto que o TS é maior nos três territórios (proximal, intermediário e distal) irrigados pela ACM. Além disso, o território da ACM é o território mais comumente afetado em um infarto cerebral, devido a seu tamanho e também pelo fato do fluxo ser direto da ACI proporcionando o caminho mais fácil para o tromboembolismo 
(SHETTY et al., 2020).

Além disso, foi apresentado que em alguns dos pacientes com ECa unilateral severa era visto que estes apresentavam um atraso de tempo para regiões que possivelmente são afetadas pela oclusão da artéria. O estudo em questão pode estar mostrando a utilidade de utilizar dados de rs-CVR para mensurar a circulação colateral dos vasos distais que se comunicam para tentar suprir a necessidade de FSC provocadas pela oclusão da principal artéria de irrigação sanguínea cerebral.

A presença de disfunção rs-CVR proporcional ao TS confirma que a isquemia crônica leva à disfunção hemodinâmica microvascular. Esses dados são relevantes porque vários estudos associaram distúrbios CVR a um maior risco de acidente vascular cerebral (MOLINA et al., 1999) ou perda cognitiva (CANTIN et al., 2011; GAO et al., 2013). Assim, o estudo da hemodinâmica cerebral por meio de RS-BOLD-MRI pode se tornar uma ferramenta não invasiva para estratificar pacientes com ECa unilateral severa.

O declínio da CVR também foi relacionado ao envelhecimento (LEONI et al., 2017), hipertensão (HAJJAR et al., 2010) e diabetes tipo 2 (CHUNG et al., 2015), que são todos fatores de risco para doença da artéria carótida. No entanto, os mecanismos de baixo CVR não são totalmente compreendidos nessas condições. O envelhecimento tem sido relacionado a modificações na estrutura dos vasos sanguíneos, como a espessura e o raio do vaso e, consequentemente, causando rigidez vascular, disfunção endotelial e aumento da permeabilidade da barreira hematoencefálica (XU et al., 2017). Além disso, o diabetes tipo 2 foi considerado como causador de estresse oxidativo que causa inflamação e consequente disfunção endotelial, resultando em CVR prejudicado (CHUNG et al., 2015). Finalmente, um estudo sobre a relação entre CVR e hipertensão utilizando a técnica de imagens de RM com ASL sugeriu que a produção de óxido nítrico endotelial e as mudanças estruturais nos vasos sanguíneos podem afetar negativamente o CVR (HAJJAR et al., 2010).

Além disso, o raio do vaso é uma das variáveis que afetam o fluxo sanguíneo, bem como, a pressão arterial que em conjunto, afetam o CVR. Quanto menor o raio dos vasos sanguíneos, mais sangue entra em contato com a parede do vaso, aumentando a resistência e diminuindo o fluxo sanguíneo. Um estudo anterior de angiografia por ressonância magnética (angio-MR) analisou o número de vasos, o raio e a tortuosidade das circulações cerebrais anterior, média e posterior durante a vida (BULLITT et al., 2010). O envelhecimento saudável foi associado à perda de vasos e ao aumento do raio dos vasos para a circulação cerebral média e posterior direita (BULLITT et al., 2010), e também à maior rigidez vascular da ACM (FLÜCK et al., 2014). No entanto, o comprometimento da dilatação microvascular e rarefação capilar em adultos jovens com predisposição à hipertensão foi relatado na literatura (NOON et al., 1997). No presente estudo, observamos regiões com valores aumentados de CVR e outras com valores diminuídos de CVR em pacientes com ECa unilateral severa em comparação com controles saudáveis, sugerindo que investigações adicionais, considerando as características 
dos vasos sanguíneos cerebrais e fatores de risco, como hipertensão e diabetes, devem ser realizadas para elucidar os achados contrastantes.

Além disso, as oscilações sistêmicas de baixa frequência (systemic low-frequency oscillations (sLFOs)) presentes no sinal BOLD IRMf foram encontradas nas ACI, e os atrasos de tempo entre o sinal desta área, o sinal global e as veias previram os diferentes tempos de trânsito do sangue pelo cérebro (TONG et al., 2019). O sinal sLFOs BOLD aparece nas artérias antes de qualquer local do cérebro. De lá, ele passa pelas arteríolas, capilares, vênulas e finalmente drena pelas veias. Essas oscilações fisiológicas tornam-se confusas e se sobrepõem às sLFOs em um estado de repouso $(<0,1 \mathrm{~Hz})$ e apenas contribuem para o sinal BOLD. Uma vez que é difícil isolar a parte do estado de repouso do sinal BOLD em humanos, é quase impossível comparar esses dois sinais diretamente em um conjunto de dados IRMf. No entanto, foi demonstrado que os sLFOs podem explicar até $50 \%$ da variância do sinal BOLD na banda de LFO (TONG et al., 2013). Então, em nosso estudo, o sinal BOLD pode indicar alterações vasculares de artérias, arteríolas, capilares, vênulas ou veias, embora a localização exata de tal comprometimento deva ser difícil e exige análises adicionais com métodos mais espacialmente específicos.

Os dados apresentados de CVR e TS podem se complementar. Quando avaliamos o CVR, podemos medir a mudança na dinâmica do oxigênio através das medidas BOLD. No entanto, já se sabe que existe um atraso entre a $\mathrm{PETCO}_{2}$ e a resposta BOLD local, devido aos atrasos de medição, e principalmente fisiológicos, como o tempo para o sangue chegar às regiões cerebrais ou até mesmo o atraso das arteríolas locais em responder ao estímulo vasolilatador (DONAHUE et al., 2016b). Moia e colaboradores propuseram uma estrutura para o mapeamento de atraso hemodinâmico (MOIA et al., 2020) que pode ser usado para corrigir os valores de CVR em cada voxel. Entretanto, os dois estudos apresentados anteriormente usam algum tipo de estímulo sendo pausa respiratória (MOIA et al., 2020), e hipercapnia (DONAHUE et al., 2016b). Por tanto, nosso estudo pode ajudar a melhorar o mapeamento de CVR sem qualquer tipo de estímulo que provoque desconforto ao sujeito, considerando até mesmo os atrasos considerados normais que por ventura possam a atrapalhar a interpretabilidade dos resultados.

O presente estudo tem algumas limitações. Em primeiro lugar, a amostra é pequena e heterogênea, que incluiu estenose bilateral, embora não severa. Porém, apesar dessa heterogeneidade, esse seria um ponto positivo do trabalho. Pacientes que apresentam déficit tanto de CVR quanto de TS poderiam sugerir a intervenção cirúrgica, e os pacientes que não apresentam esses déficits, ou seja, que seus mapas são muito semelhantes aos de controle de mesma idade, não precisariam passar pela cirurgia e suas possíveis complicações. Em segundo lugar, como os indivíduos não estavam sob estresse, esta metodologia pode não avaliar toda a extensão de sua reserva cerebrovascular. No entanto, os mapas rs-CVR apresentaram alta similaridade quando comparados às situações de estresse. Terceiro, os mapas 
rs-CVR são obtidos em escalas relativas, ao invés unidades absolutas de \%BOLD/mmHg de $\mathrm{CO}_{2}$, uma vez que o $\mathrm{CO}_{2}$ expirado não foi registrado. No entanto, é importante destacar que uma análise intra-sujeito para avaliar os déficits de CVR é de interesse clínico; então, um valor quantitativo não é obrigatório. Por fim, foi demonstrado que o sinal BOLD global dentro da faixa de frequência de 0,02-0,04 Hz tem uma correlação mais forte com a concentração de $\mathrm{CO}_{2}$ no sangue no estado de repouso (LIU et al., 2017), mas foi comprovado por Liu e colabioradores que a faixa ótima para a otimização da frequência que mais se correlacionava com o mapa de CVR em hipercapnia é de 0 - 0,1164 Hz (LIU et al., 2021) . Portanto, análises adicionais devem ser analisadas futuramente. 



\section{Conclusões}

Neste trabalho, avaliamos um novo método para mapear CVR e o TS usando imagens de RM com contraste BOLD em estado de repouso sem a necessidade de desafios de hipercapnia, com o sinal filtrado em baixas frequências.

Nossos resultados mostraram que os mapas de CVR em estado de repouso obtidos por este método são altamente consistentes com os mapas convencionais de CVR baseados na inalação de $\mathrm{CO}_{2}$ e pausa respiratória e que apresentam muita similaridade com alterações regionais de TS ao analisar visualmente mapas individuais sugerindo que as metodologias são complementares, tendo informações acerca da amplitude e do atraso temporal. Essas métodologias podem ser alternativas úteis na detecção de déficits vasculares em aplicações clínicas quando desafios de hipercapnia não são viáveis.

Nesse contexto, apresentamos uma ferramenta alternativa para avaliar riscos de alterações da hemodinâmica cerebral. Nossos resultados sugerem que os parâmetros estudados podem refletir alterações hemodinâmicas subclínicas e são úteis para investigar áreas com maior risco de dano neuronal ou AVC isquêmico em um nível individual, auxilindo no complemento da decisão de manejo clínico de pacientes com ECa, estratificando-os a partir da necessidade, ou não, de algum tipo de intervensão clínica, a partir da probabilidade de evolução para AVC isquêmico. 



\section{Futuros estudos}

São necessários estudos utilizando uma amostra de pacientes mais homogênea, isto é, pacientes que não apresentam estenose em ambos os hemisférios, até mesmo que a oclusão do hemisfério contralateral não seja severa (com mais de 70\% do vaso ocupado pela oclusão).

Além disso, é necessário o controle de informações mais robustas acerca do diagnóstico clínico dos pacientes, pois são fatores que podem estar influenciando as medidas. Como por exemplo o uso de algum tipo de medicamento, se são tabagistas, se apresentam algum tipo de doença de diabetes ou algum tipo de doença vascular.

Por fim, estudar a influência da banda de baixa frequência relacionado ao $\mathrm{PETCO}_{2}$ não sendo tão restritivo como o utilizado nesse estudo e apresentado recentemente por outros estudos aqui citados. 



\section{Referências}

AMEMIYA, S. et al. Cerebral hemodynamic impairment: assessment with resting-state functional mr imaging. Radiology, Radiological Society of North America, v. 270, n. 2, p. 548-555, 2014. Citado 3 vezes nas páginas 40, 41 e 64.

ATTWELL, D.; LAUGHLIN, S. B. An energy budget for signaling in the grey matter of the brain. Journal of Cerebral Blood Flow \& Metabolism, SAGE Publications Sage UK: London, England, v. 21, n. 10, p. 1133-1145, 2001. Citado na página 24.

BALUCANI, C. et al. Cerebral hemodynamics and cognitive performance in bilateral asymptomatic carotid stenosis. Neurology, AAN Enterprises, v. 79, n. 17, p. 1788-1795, 2012. Citado na página 24.

BAUER, A. Q. et al. Optical imaging of disrupted functional connectivity following ischemic stroke in mice. Neuroimage, Elsevier, v. 99, p. 388-401, 2014. Citado na página 40.

BLAIR, G. W. et al. Intracranial hemodynamic relationships in patients with cerebral small vessel disease. Neurology, AAN Enterprises, v. 94, n. 21, p. e2258-e2269, 2020. Citado na página 64.

BOORDER, M. J. de et al. Spect measurements of regional cerebral perfusion and carbondioxide reactivity: correlation with cerebral collaterals in internal carotid artery occlusive disease. Journal of neurology, Springer, v. 253, n. 10, p. 1285-1291, 2006. Citado na página 30.

BOUTHILLIER, A.; LOVEREN, H. R. V.; KELLER, J. T. Segments of the internal carotid artery: a new classification. Neurosurgery, Oxford University Press, v. 38, n. 3, p. 425-433, 1996. Citado na página 21.

BULLITT, E. et al. The effects of healthy aging on intracerebral blood vessels visualized by magnetic resonance angiography. Neurobiology of aging, Elsevier, v. 31, n. 2, p. 290-300, 2010. Citado na página 65.

CANTIN, S. et al. Impaired cerebral vasoreactivity to co2 in alzheimer's disease using bold fmri. Neuroimage, Elsevier, v. 58, n. 2, p. 579-587, 2011. Citado na página 65.

CHAMPAGNE, A. A. et al. Multi-modal normalization of resting-state using local physiology reduces changes in functional connectivity patterns observed in mtbi patients. NeuroImage: Clinical, Elsevier, v. 26, p. 102204, 2020. Citado na página 38.

CHEN, J. J.; GAUTHIER, C. J. The role of cerebrovascular-reactivity mapping in functional mri: Calibrated fmri and resting-state fmri. Frontiers in physiology, Frontiers, v. 12, p. 361, 2021. Citado na página 38.

CHUNG, C.-C. et al. Inflammation-associated declines in cerebral vasoreactivity and cognition in type 2 diabetes. Neurology, AAN Enterprises, v. 85, n. 5, p. 450-458, 2015. Citado na página 65.

CIPOLLA, M. J. The cerebral circulation. Integrated systems physiology: From molecule to function, Morgan \& Claypool Publishers, v. 1, n. 1, p. 1-59, 2009. Citado na página 25. 
COPEN, W. A.; SCHAEFER, P. W.; WU, O. Mr perfusion imaging in acute ischemic stroke. Neuroimaging Clinics, Elsevier, v. 21, n. 2, p. 259-283, 2011. Citado 2 vezes nas páginas 25 e 26 .

COULSON, R. J. et al. Mechanical properties of rat middle cerebral arteries with and without myogenic tone. J. Biomech. Eng., v. 126, n. 1, p. 76-81, 2004. Citado na página 25.

DERDEYN, C.; GRUBB, R.; POWERS, W. Cerebral hemodynamic impairment: methods of measurement and association with stroke risk. Neurology, AAN Enterprises, v. 53, n. 2, p. 251-251, 1999. Citado na página 26.

DIJK, K. R. V. et al. Intrinsic functional connectivity as a tool for human connectomics: theory, properties, and optimization. Journal of neurophysiology, American Physiological Society Bethesda, MD, v. 103, n. 1, p. 297-321, 2010. Citado na página 38.

DONAHUE, M. J. et al. Time delay processing of hypercapnic fmri allows quantitative parameterization of cerebrovascular reactivity and blood flow delays. Journal of Cerebral Blood Flow \& Metabolism, SAGE Publications Sage UK: London, England, v. 36, n. 10, p. 1767-1779, 2016. Citado na página 37.

DONAHUE, M. J. et al. Time delay processing of hypercapnic fmri allows quantitative parameterization of cerebrovascular reactivity and blood flow delays. Journal of Cerebral Blood Flow \& Metabolism, SAGE Publications Sage UK: London, England, v. 36, n. 10, p. 1767-1779, 2016. Citado na página 66.

EBINGER, M. et al. Imaging the penumbra-strategies to detect tissue at risk after ischemic stroke. Journal of Clinical Neuroscience, Elsevier, v. 16, n. 2, p. 178-187, 2009. Citado na página 41.

FARACI, F. M.; HEISTAD, D. D. Regulation of large cerebral arteries and cerebral microvascular pressure. Circulation research, Am Heart Assoc, v. 66, n. 1, p. 8-17, 1990. Citado na página 24.

FIELDS, R. D. White matter matters. Scientific American, JSTOR, v. 298, n. 3, p. 54-61, 2008. Citado na página 21.

FISHER, J. A.; MIKULIS, D. J. Cerebrovascular reactivity: Purpose, optimizing methods, and limitations to interpretation-a personal 20-year odyssey of (re) searching. Frontiers in Physiology, Frontiers, v. 12, p. 420, 2021. Citado 2 vezes nas páginas 13 e 22.

FISHER, J. A. et al. Assessing cerebrovascular reactivity by the pattern of response to progressive hypercapnia. Human brain mapping, Wiley Online Library, v. 38, n. 7, p. 3415-3427, 2017. Citado na página 37.

FLÜCK, D. et al. Effects of aging on the association between cerebrovascular responses to visual stimulation, hypercapnia and arterial stiffness. Frontiers in physiology, Frontiers, v. 5, p. 49, 2014. Citado na página 65.

FOX, P. T.; RAICHLE, M. E. Focal physiological uncoupling of cerebral blood flow and oxidative metabolism during somatosensory stimulation in human subjects. Proceedings of the National Academy of Sciences, National Acad Sciences, v. 83, n. 4, p. 1140-1144, 1986.

Citado na página 34 . 
GAO, Y.-Z. et al. Regional cerebral blood flow and cerebrovascular reactivity in alzheimer's disease and vascular dementia assessed by arterial spinlabeling magnetic resonance imaging. Current neurovascular research, Bentham Science Publishers, v. 10, n. 1, p. 49-53, 2013. Citado na página 65.

GOLESTANI, A. M.; WEI, L. L.; CHEN, J. J. Quantitative mapping of cerebrovascular reactivity using resting-state bold fmri: validation in healthy adults. Neuroimage, Elsevier, v. 138, p. 147-163, 2016. Citado na página 39.

GORY, B. et al. Thrombectomy in acute stroke with tandem occlusions from dissection versus atherosclerotic cause. Stroke, Am Heart Assoc, v. 48, n. 11, p. 3145-3148, 2017. Citado na página 23.

GUYTON, A. C. Tratado de fisiologia médica. [S.1.]: Elsevier Brasil, 2006. Citado 2 vezes nas páginas 13 e 27.

HAJJAR, I. et al. Hypertension and cerebral vasoreactivity: a continuous arterial spin labeling magnetic resonance imaging study. Hypertension, Am Heart Assoc, v. 56, n. 5, p. 859-864, 2010. Citado na página 65.

HALANI, S. et al. Comparing cerebrovascular reactivity measured using bold and cerebral blood flow mri: The effect of basal vascular tension on vasodilatory and vasoconstrictive reactivity. Neuroimage, Elsevier, v. 110, p. 110-123, 2015. Citado na página 36.

ISHII, Y. et al. Simultaneous phase-contrast mri and pet for noninvasive quantification of cerebral blood flow and reactivity in healthy subjects and patients with cerebrovascular disease. Journal of Magnetic Resonance Imaging, Wiley Online Library, v. 51, n. 1, p. 183-194, 2020. Citado na página 30.

JAHANIAN, H. et al. Spontaneous bold signal fluctuations in young healthy subjects and elderly patients with chronic kidney disease. PLoS One, Public Library of Science, v. 9, n. 3, p. e92539, 2014. Citado 2 vezes nas páginas 39 e 63.

JUTTUKONDA, M. R.; DONAHUE, M. J. Neuroimaging of vascular reserve in patients with cerebrovascular diseases. Neuroimage, Elsevier, v. 187, p. 192-208, 2019. Citado na página 33.

KAHANE, P. et al. An h215o-pet study of cerebral blood flow changes during focal epileptic discharges induced by intracerebral electrical stimulation. Brain, Oxford University Press, v. 122, n. 10, p. 1851-1865, 1999. Citado na página 31.

KANNURPATTI, S. S. et al. Increasing measurement accuracy of age-related bold signal change: Minimizing vascular contributions by resting-state-fluctuation-of-amplitude scaling. Human brain mapping, Wiley Online Library, v. 32, n. 7, p. 1125-1140, 2011. Citado na página 38.

KETY, S. S. et al. The effects of an acute reduction in blood pressure by means of differential spinal sympathetic block on the cerebral circulation of hypertensive patients. The Journal of clinical investigation, Am Soc Clin Investig, v. 29, n. 4, p. 402-407, 1950. Citado na página 26.

LANDGRAFF, N. C. et al. Cognitive and physical performance in patients with asymptomatic carotid artery disease. Journal of neurology, Springer, v. 257, n. 6, p. 982-991, 2010. Citado na página 24. 
LASSEN, N. A. Cerebral blood flow and oxygen consumption in man. Physiological reviews, v. 39, n. 2, p. 183-238, 1959. Citado na página 21.

LEAF, D. E.; GOLDFARB, D. S. Mechanisms of action of acetazolamide in the prophylaxis and treatment of acute mountain sickness. Journal of Applied Physiology, American Physiological Society, v. 102, n. 4, p. 1313-1322, 2007. Citado na página 28.

LEONI, R. et al. Cerebral blood flow and vasoreactivity in aging: an arterial spin labeling study. Brazilian Journal of Medical and Biological Research, SciELO Brasil, v. 50, n. 4, 2017. Citado 4 vezes nas páginas 21, 48, 64 e 65.

LEONI, R. F. et al. Quantitative evaluation of hemodynamic response after hypercapnia among different brain territories by fmri. Neuroimage, Elsevier, v. 41, n. 4, p. 1192-1198, 2008. Citado na página 37.

LEONI, R. F. et al. Assessing cerebrovascular reactivity in carotid steno-occlusive disease using mri bold and asl techniques. Radiology research and practice, Hindawi, v. 2012, 2012. Citado na página 33.

LIU, P.; JILL, B.; LU, H. Cerebrovascular reactivity (cvr) mri with co2 challenge: A technical review. Neuroimage, Elsevier, v. 187, p. 104-115, 2019. Citado 3 vezes nas páginas 24, 35 e 64.

LIU, P. et al. Cerebrovascular reactivity mapping without gas challenges. Neuroimage, Elsevier, v. 146, p. 320-326, 2017. Citado 7 vezes nas páginas 30, 38, 39, 49, 63, 64 e 67.

LIU, P. et al. Cerebrovascular reactivity mapping using resting-state bold functional mri in healthy adults and patients with moyamoya disease. Radiology, Radiological Society of North America, p. 203568, 2021. Citado 2 vezes nas páginas 64 e 67.

LIU, T. T. Neurovascular factors in resting-state functional mri. Neuroimage, Elsevier, v. 80, p. 339-348, 2013. Citado na página 38.

LIU, Z. et al. Neuroelectrical decomposition of spontaneous brain activity measured with functional magnetic resonance imaging. Cerebral Cortex, Oxford University Press, v. 24, n. 11, p. 3080-3089, 2014. Citado na página 38.

LU, H. et al. Mri mapping of cerebrovascular reactivity via gas inhalation challenges. JoVE (Journal of Visualized Experiments), n. 94, p. e52306, 2014. Citado 3 vezes nas páginas 13, 29 e 36 .

LV, H. et al. Resting-state functional mri: everything that nonexperts have always wanted to know. American Journal of Neuroradiology, Am Soc Neuroradiology, v. 39, n. 8, p. 1390-1399, 2018. Citado na página 40.

LV, Y. et al. Identifying the perfusion deficit in acute stroke with resting-state functional magnetic resonance imaging. Annals of neurology, Wiley Online Library, v. 73, n. 1, p. 136-140, 2013. Citado 3 vezes nas páginas 40, 41 e 64 .

MA, J. et al. Perfusion mri before and after acetazolamide administration for assessment of cerebrovascular reserve capacity in patients with symptomatic internal carotid artery (ica) occlusion: comparison with 99m tc-ecd spect. Neuroradiology, Springer, v. 49, n. 4, p. 317-326, 2007. Citado na página 28. 
MAEDA, H. et al. Reactivity of cerebral blood flow to carbon dioxide in various types of ischemic cerebrovascular disease: evaluation by the transcranial doppler method. Stroke, Am Heart Assoc, v. 24, n. 5, p. 670-675, 1993. Citado na página 30.

MANUAL-MSD. 2021. Disponível em: <https://www.msdmanuals.com/pt-pt/profissional/ multimedia/figure/neu_arteries_brain_pt>. Acessado em: 13 Abril 2021. Citado 2 vezes nas páginas 13 e 22 .

MARKUS, H.; CULLINANE, M. Severely impaired cerebrovascular reactivity predicts stroke and tia risk in patients with carotid artery stenosis and occlusion. Brain, Oxford University Press, v. 124, n. 3, p. 457-467, 2001. Citado na página 24.

MAZZETTO-BETTI, K. C. et al. Quantification of bold fmri parameters to infer cerebrovascular reactivity of the middle cerebral artery. Journal of Magnetic Resonance Imaging, Wiley Online Library, v. 38, n. 5, p. 1203-1209, 2013. Citado na página 35.

MCSWAIN, S. D. et al. End-tidal and arterial carbon dioxide measurements correlate across all levels of physiologic dead space. Respiratory care, Respiratory Care, v. 55, n. 3, p. 288-293, 2010. Citado na página 27.

MOIA, S. et al. Voxelwise optimization of hemodynamic lags to improve regional cvr estimates in breath-hold fmri. In: IEEE. 2020 42nd Annual International Conference of the IEEE Engineering in Medicine \& Biology Society (EMBC). [S.1.], 2020. p. 1489-1492. Citado 2 vezes nas páginas 64 e 66.

MOIA, S. et al. Ica-based denoising strategies in breath-hold induced cerebrovascular reactivity mapping with multi echo bold fmri. NeuroImage, Elsevier, v. 233, p. 117914, 2021. Citado na página 63.

MOLINA, C. et al. Impaired cerebrovascular reactivity as a risk marker for first-ever lacunar infarction: a case-control study. Stroke, Am Heart Assoc, v. 30, n. 11, p. 2296-2301, 1999. Citado na página 65.

MUTSAERTS, H. et al. Cerebral perfusion measurements in elderly with hypertension using arterial spin labeling. PloS one, Public Library of Science, v. 10, n. 8, p. e0133717, 2015. Citado 4 vezes nas páginas 13, 22, 23 e 50.

NAQVI, J. et al. Transcranial doppler ultrasound: a review of the physical principles and major applications in critical care. International journal of vascular medicine, Hindawi, v. 2013, 2013. Citado na página 30.

NI, L. et al. The value of resting-state functional mri in subacute ischemic stroke: comparison with dynamic susceptibility contrast-enhanced perfusion mri. Scientific reports, Nature Publishing Group, v. 7, n. 1, p. 1-8, 2017. Citado 2 vezes nas páginas 40 e 64.

NISHIDA, S. et al. Resting-state functional magnetic resonance imaging identifies cerebrovascular reactivity impairment in patients with arterial occlusive diseases: a pilot study. Neurosurgery, Oxford University Press, v. 85, n. 5, p. 680-688, 2019. Citado 3 vezes nas páginas 40, 41 e 51.

NOON, J. P. et al. Impaired microvascular dilatation and capillary rarefaction in young adults with a predisposition to high blood pressure. The Journal of clinical investigation, Am Soc Clin Investig, v. 99, n. 8, p. 1873-1879, 1997. Citado na página 65. 
NOONER, K. B. et al. The nki-rockland sample: a model for accelerating the pace of discovery science in psychiatry. Frontiers in neuroscience, Frontiers, v. 6, p. 152, 2012. Citado na página 47.

NÖTH, U. et al. Mapping of the cerebral vascular response to hypoxia and hypercapnia using quantitative perfusion mri at 3 t. NMR in biomedicine, Wiley Online Library, v. 21, n. 5, p. 464-472, 2008. Citado na página 21.

OGASAWARA, K.; OGAWA, A.; YOSHIMOTO, T. Cerebrovascular reactivity to acetazolamide and outcome in patients with symptomatic internal carotid or middle cerebral artery occlusion: a xenon-133 single-photon emission computed tomography study. Stroke, Am Heart Assoc, v. 33, n. 7, p. 1857-1862, 2002. Citado na página 32.

OGAWA, S. et al. Brain magnetic resonance imaging with contrast dependent on blood oxygenation. proceedings of the National Academy of Sciences, National Acad Sciences, v. 87, n. 24, p. 9868-9872, 1990. Citado na página 34.

ORGANIZATION, W. H. The top 10 causes of death. 2020. Disponível em: <https: //www.who.int/news-room/fact-sheets/detail/the-top-10-causes-of-death>. Acessado em: 04 maio de 2021. Citado na página 22.

OSOL, G. et al. Myogenic tone, reactivity, and forced dilatation: a three-phase model of in vitro arterial myogenic behavior. American Journal of Physiology-Heart and Circulatory Physiology, American Physiological Society Bethesda, MD, v. 283, n. 6, p. H2260-H2267, 2002. Citado na página 25.

PARKES, M. Breath-holding and its breakpoint. Experimental physiology, Wiley Online Library, v. 91, n. 1, p. 1-15, 2006. Citado na página 28.

PAULING, L.; CORYELL, C. D. The magnetic properties and structure of hemoglobin, oxyhemoglobin and carbonmonoxyhemoglobin. Proceedings of the National Academy of Sciences, National Acad Sciences, v. 22, n. 4, p. 210-216, 1936. Citado na página 34.

PAULSON, O.; STRANDGAARD, S.; EDVINSSON, L. Cerebral autoregulation. Cerebrovascular and brain metabolism reviews, v. 2, n. 2, p. 161-192, 1990. Citado na página 25.

PEEBLES, K. et al. Human cerebrovascular and ventilatory co2 reactivity to end-tidal, arterial and internal jugular vein pco2. The Journal of physiology, Wiley Online Library, v. 584, n. 1, p. 347-357, 2007. Citado na página 27.

PETCHARUNPAISAN, S.; RAMALHO, J.; CASTILLO, M. Arterial spin labeling in neuroimaging. World journal of radiology, Baishideng Publishing Group Inc, v. 2, n. 10, p. 384, 2010. Citado na página 33.

PHELPS, M. E.; MAZZIOTTA, J. C. Positron emission tomography: human brain function and biochemistry. Science, American Association for the Advancement of Science, v. 228, n. 4701, p. 799-809, 1985. Citado na página 31.

PHILLIPS, S. J.; WHISNANT, J. P. Hypertension and the brain. Archives of internal medicine, American Medical Association, v. 152, n. 5, p. 938-945, 1992. Citado na página 25.

POWERS, W. J. Cerebral hemodynamics in ischemic cerebrovascular disease. Annals of Neurology: Official Journal of the American Neurological Association and the Child Neurology Society, Wiley Online Library, v. 29, n. 3, p. 231-240, 1991. Citado na página 25. 
R Core Team. R: A Language and Environment for Statistical Computing. Vienna, Austria, 2020. Disponível em: <https://www.R-project.org/>. Citado na página 50.

ROSTRUP, E. et al. Regional differences in the cbf and bold responses to hypercapnia: a combined pet and fmri study. Neuroimage, Elsevier, v. 11, n. 2, p. 87-97, 2000. Citado na página 29.

ROY, C. S.; SHERRINGTON, C. S. On the regulation of the blood-supply of the brain. The Journal of physiology, Wiley Online Library, v. 11, n. 1-2, p. 85-158, 1890. Citado na página 34.

SACCO, R. L. et al. An updated definition of stroke for the 21st century: a statement for healthcare professionals from the american heart association/american stroke association. Stroke, Am Heart Assoc, v. 44, n. 7, p. 2064-2089, 2013. Citado na página 23.

SECCHINATO, K. F. et al. Cerebrovascular reactivity mapping without hypercapnic challenge in patients with carotid artery stenosis. Revista Brasileira De Física Médica, v. 13, n. 2, p. 62-65, 2019. Citado 5 vezes nas páginas 13, 36, 39, 53 e 63.

SHETTY, K. et al. Malignant middle cerebral artery stroke management in developing world-outcome predictors. Neurology Asia, v. 25, n. 2, 2020. Citado na página 65.

SIEGEL, J. S. et al. The effects of hemodynamic lag on functional connectivity and behavior after stroke. Journal of Cerebral Blood Flow \& Metabolism, SAGE Publications Sage UK: London, England, v. 36, n. 12, p. 2162-2176, 2016. Citado 2 vezes nas páginas 40 e 41.

SILVESTRINI, M. et al. Cerebral hemodynamics and cognitive performance in patients with asymptomatic carotid stenosis. Neurology, AAN Enterprises, v. 72, n. 12, p. 1062-1068, 2009. Citado na página 24.

SILVESTRINI, M. et al. Transcranial doppler assessment of cerebrovascular reactivity in symptomatic and asymptomatic severe carotid stenosis. Stroke, Am Heart Assoc, v. 27, n. 11, p. 1970-1973, 1996. Citado na página 24.

SILVESTRINI, M. et al. Impaired cerebral vasoreactivity and risk of stroke in patients with asymptomatic carotid artery stenosis. Jama, American Medical Association, v. 283, n. 16, p. 2122-2127, 2000. Citado na página 24.

SLESSAREV, M. et al. Prospective targeting and control of end-tidal co2 and o2 concentrations. The Journal of physiology, Wiley Online Library, v. 581, n. 3, p. 1207-1219, 2007. Citado na página 30.

SPANO, V. R. et al. Co2 blood oxygen level-dependent mr mapping of cerebrovascular reserve in a clinical population: safety, tolerability, and technical feasibility. Radiology, Radiological Society of North America, Inc., v. 266, n. 2, p. 592-598, 2013. Citado na página 38.

SUR, S. et al. Association of cerebrovascular reactivity and alzheimer pathologic markers with cognitive performance. Neurology, AAN Enterprises, v. 95, n. 8, p. e962-e972, 2020. Citado na página 26.

TANCREDI, F. B.; HOGE, R. D. Comparison of cerebral vascular reactivity measures obtained using breath-holding and co2 inhalation. Journal of Cerebral Blood Flow \& Metabolism, SAGE Publications Sage UK: London, England, v. 33, n. 7, p. 1066-1074, 2013. Citado na página 36. 
TANEJA, K. et al. Evaluation of cerebrovascular reserve in patients with cerebrovascular diseases using resting-state mri: A feasibility study. Magnetic resonance imaging, Elsevier, v. 59, p. 46-52, 2019. Citado 3 vezes nas páginas 39, 63 e 64 .

TONG, Y. et al. Evaluating the effects of systemic low frequency oscillations measured in the periphery on the independent component analysis results of resting state networks. Neuroimage, Elsevier, v. 76, p. 202-215, 2013. Citado na página 66.

TONG, Y. et al. The resting-state fmri arterial signal predicts differential blood transit time through the brain. Journal of Cerebral Blood Flow \& Metabolism, SAGE Publications Sage UK: London, England, v. 39, n. 6, p. 1148-1160, 2019. Citado na página 66.

TU, Y.-K.; GUNNELL, D.; GILTHORPE, M. S. Simpson's paradox, lord's paradox, and suppression effects are the same phenomenon-the reversal paradox. Emerging themes in epidemiology, BioMed Central, v. 5, n. 1, p. 1-9, 2008. Citado na página 63.

VAGAL, A. et al. The acetazolamide challenge: techniques and applications in the evaluation of chronic cerebral ischemia. American journal of neuroradiology, Am Soc Neuroradiology, v. 30, n. 5, p. 876-884, 2009. Citado na página 26.

VAGAL, A. et al. The acetazolamide challenge: techniques and applications in the evaluation of chronic cerebral ischemia. American journal of neuroradiology, Am Soc Neuroradiology, v. 30, n. 5, p. 876-884, 2009. Citado na página 28.

VERNIERI, F. et al. Effect of collateral blood flow and cerebral vasomotor reactivity on the outcome of carotid artery occlusion. Stroke, Am Heart Assoc, v. 32, n. 7, p. 1552-1558, 2001. Citado na página 26.

VILLRINGER, A.; CHANCE, B. Non-invasive optical spectroscopy and imaging of human brain function. Trends in neurosciences, Elsevier, v. 20, n. 10, p. 435-442, 1997. Citado na página 32.

WISE, R. G. et al. Resting fluctuations in arterial carbon dioxide induce significant low frequency variations in bold signal. Neuroimage, Elsevier, v. 21, n. 4, p. 1652-1664, 2004. Citado 3 vezes nas páginas 38, 39 e 63.

$\mathrm{XU}, \mathrm{X}$. et al. Age-related impairment of vascular structure and functions. Aging and disease, JKL International LLC, v. 8, n. 5, p. 590, 2017. Citado na página 65.

YANG, C. W. et al. Contrast-enhanced $\mathrm{mr}$ angiography of the carotid and vertebrobasilar circulations. American journal of neuroradiology, Am Soc Neuroradiology, v. 26, n. 8, p. 2095-2101, 2005. Citado na página 21.

YOON, S.; ZUCCARELLO, M.; RAPOPORT, R. M. pco2 and ph regulation of cerebral blood flow. Frontiers in physiology, Frontiers, v. 3, p. 365, 2012. Citado na página 27.

YOON, S. H.; ZUCCARELLO, M.; RAPOPORT, R. M. Reversal of hypercapnia induces endothelin-dependent constriction of basilar artery in rabbits with acute metabolic alkalosis. General Pharmacology: The Vascular System, Elsevier, v. 35, n. 6, p. 333-340, 2000. Citado na página 27. 


\title{
A Anexos
}

\section{A.1 Termo de consentimento livre e esclarecimento ao grupo clí- nico}

\author{
Termo de Consentimento Livre e Esclarecido ao Grupo Clínico \\ TERMO DE CONSENTIMENTO LIVRE E ESCLARECIDO
}

\begin{abstract}
Título da Pesquisa: BIOMARCADORES DE RESSONÂNCIA MAGNÉTICA E PERFORMANCE COGNITIVA EM ESTENOSE CAROTÍDEA ASSINTOMÁTICA
\end{abstract}

Pesquisadores:

Ms. Ana Paula Afonso Camargo. Depto. de Neurociência e Ciência do Comportamento da Faculdade de Medicina de Ribeirão Preto da Universidade de São Paulo, Ribeirão Preto, Brasil. Telefone: (16) 3602-2839; Celular (16) 981394903;

Dr. Octávio Marques Pontes Neto. Depto. de Neurociência e Ciência do Comportamento da Faculdade de Medicina de Ribeirão Preto da Universidade de São Paulo, Ribeirão Preto, Brasil. Telefone: (16) 3602-1147;

Dra. Renata Ferranti Leoni. Depto. de Neurociência e Ciência do Comportamento da Faculdade de Medicina de Ribeirão Preto da Universidade de São Paulo, Ribeirão Preto, Brasil. Telefone: (16) 3602-2558;

Telefone CEP (Comitê de Ética em Pesquisa): (16) 3602-2228.

De que se trata este documento que estou lendo?

Este documento é um termo de consentimento, no qual serão abordadas todas as informações sobre o estudo. O pesquisador irá revisar as informações para ter certeza que o senhor / a senhora entendeu todas elas. Você pode fazer perguntas quando quiser. Se você concordar em participar do estudo, você terá que assinar este termo de consentimento e você terá uma cópia para guardar. Antes de receber as informações sobre o estudo é importante que o senhor / a senhora saiba dos seguintes detalhes:

a) Sua participação é completamente voluntária;

b) Você poderá decidir não participar do estudo quando quiser, sem perder o direito de receber os cuidados médicos de rotina, ou quaisquer outros benefícios aos quais tenha direito na assistência médica regular na clínica habitual, qualquer que seja sua decisão.

Porque está sendo feito este estudo?

O senhor (a) está sendo convidado (a) a participar de uma pesquisa que tem como objetivo avaliar a circulação do cérebro e o funcionamento cognitivo de pessoas que apresentem alguma artéria do pescoço comprometida.

\section{O que eu preciso fazer se eu decidir participar do estudo?}

Se concordar em participar do estudo, o senhor / a senhora deverá autorizar o pesquisador a analisar os dados sobre sua saúde no seu prontuário médico. Deverá então, comparecer ao Hospital das Clínicas, do Campus, por dois dias, cujos quais serão agendados pelo pesquisador.

No primeiro dia agendado, o pesquisador irá fazer algumas perguntas sobre sua saúde e sobre os remédios que utiliza. Além disso, será realizado um exame de ultrassom parecido com aquele feito na barriga das grávidas para ver o bebê, mas no seu caso será colocado o instrumento no pescoço e na cabeça, para ver alguns vasos sanguíneos. O exame irá durar, em média, 20 minutos. Você não sentirá nenhuma dor durante o exame.

No segundo dia será realizado um exame na máquina de Ressonância Magnética. Esse aparelho tem a forma de um grande tubo de metal, largo, com uma abertura por onde o senhor (a) entrará deitado (a) de barriga para cima. Essa máquina produz um campo magnético, como se fosse um imã, que passa através do seu corpo sem desordenar ou prejudicar nenhuma parte dele. A função dela será de produzir imagens do seu cérebro, além de demonstrar o funcionamento dele. Nada disso será sentido e não estará fazendo nenhum mal à sua saúde. Durante o exame, a máquina fará um barulho alto. Será também colocada uma cânula na parte de fora do seu nariz, pela qual sairá um ar durante algum tempo do exame, sendo que esse ar não causa nenhum mal para sua saúde. Não sentirá nenhuma dor durante o exame. Não é necessário que faça nada, além de permanecer o mais parado possível.

A permanência dentro da máquina será por um período médio de 45 minutos. O senhor / a senhora poderá ser retirado (a) a qualquer momento que sentir algum desconforto. Dependendo da roupa que estiver usando, poderá ser pedido a utilizar um roupão do Hospital, a fim de garantir seu conforto e não gerar nenhum problema nas imagens. 
Neste mesmo dia o pesquisador, também, deverá fazer alguns testes, para avaliar a sua condição cognitiva, como memória, atenção, linguagem e funções executivas. Tal avaliação deverá ser realizada em um período médio de 1 hora e 30 minutos. Portanto, as avaliações equivalentes ao segundo dia totalizarão, em média, 2 horas e 15 minutos.

\section{Quantas pessoas irão participar do estudo?}

Participarão do estudo quarenta pessoas que apresentem comprometimento da artéria do pescoço e que não tiveram acidente vascular cerebral (AVC).

\section{Porque eu fui escolhido para participar do estudo?}

Um dos objetivos deste estudo é saber como está a circulação sanguínea cerebral e o funcionamento cognitivo de pessoas que apresentem comprometimento das artérias do pescoço. Se o senhor ou a senhora foi escolhido (a) é porque preenche este critério.

\section{Quais são os riscos e desconfortos do estudo?}

Algumas pessoas podem sentir-se desconfortáveis devido à máquina de Ressonância Magnética ser um tubo que produz ruídos, bem como devido à permanência, por um período de tempo de 45 minutos, sem se mexer.

\section{Existem benefícios em participar deste estudo?}

Sim. No seu caso os dados colhidos serão anexados ao seu prontuário do Hospital das Clínicas da FMRP e no caso da observação de alguma alteração nos exames, o senhor (a) será prontamente encaminhado para o serviço de saúde mais apropriado.

\section{Existe alguma compensação financeira ou custos para mim?}

O senhor (a) não receberá nenhuma compensação financeira relacionada à sua participação neste estudo. Da mesma forma, o Sr. (a) não terá nenhuma despesa pessoal em qualquer fase do estudo, incluindo exames e consultas. Durante o período de sua participação, a despesa relacionada ao transporte será reembolsada.

Como é protegida minha privacidade?

As informações coletadas neste estudo serão anexadas ao seu prontuário no Hospital das Clínicas, os médicos e outros profissionais autorizados a terem acesso ao prontuário terão acesso às informações. Além disto, estes dados serão vistos e analisados apenas pelos pesquisadores responsáveis por este estudo, os dados poderão ser comunicados para outros pesquisadores e médicos, mas sua identidade será mantida em sigilo. Nenhum dado que possa revelar sua identidade estará disponível para quaisquer pessoas ou em quaisquer textos ou publicações.

Os dados deste estudo são mantidos em um banco de dados do Centro de Ciências das Imagens da Física Médica, caso estes dados sejam consultados para outros estudos, o CEP será consultado, para ver a necessidade de se assinar um novo termo de consentimento, ou não.

\section{Quem você deve procurar caso tenha problemas ou perguntas.}

Caso o senhor / a senhora tenha perguntas, dúvidas ou qualquer outra informação que deseje saber a respeito deste estudo, poderá procurar os pesquisadores aqui citados, Ana Paula Afonso Camargo (telefones 36022839; 981394903) ou Dr. Octávio Marques Pontes Neto (telefone 3602-1147), ou ainda, o Comitê de Ética em Pesquisa (telefone 3602-2228).

Uma via deste documento, assinada pelo pesquisador, deverá ser devolvida ao senhor (a) e uma segunda via ficará arquivada com o pesquisador.

\section{Assinaturas}

Os detalhes deste estudo foram explicados a você, que teve a oportunidade de fazer todas as perguntas ao pesquisador. Se tiver lido o consentimento livre e esclarecido (ou se ele tiver sido explicado para você), tiver entendido a informação e concordar voluntariamente em participar deste estudo, por favor, assine abaixo: 


\begin{tabular}{lc}
\hline Nome do Voluntário & (impresso ou em letra de forma) \\
& \\
\hline Nome da Testemunha & (impresso ou em letra de forma) \\
& Data:
\end{tabular}

\section{Declaração do Pesquisador}

Declaro que revisei este estudo e o formulário de consentimento com o participante. Segundo meu entendimento, ele compreendeu os objetivos, os procedimentos, riscos e benefícios do estudo.

Nome do Pesquisador

Assinatura do Pesquisador

(impresso ou em letra de forma)

Data: 


\title{
A.2 Termo de consentimento livre e esclarecimento ao grupo con- trole
}

\author{
Termo de Consentimento Livre e Esclarecido ao Grupo Controle \\ TERMO DE CONSENTIMENTO LIVRE E ESCLARECIDO
}

Título da Pesquisa: BIOMARCADORES DE RESSONÂNCIA MAGNÉTICA E PERFORMANCE COGNITIVA EM ESTENOSE CAROTÍDEA ASSINTOMÁTICA

Pesquisadores:

\begin{abstract}
Ms. Ana Paula Afonso Camargo. Depto. de Neurociência e Ciência do Comportamento da Faculdade de Medicina de Ribeirão Preto da Universidade de São Paulo, Ribeirão Preto, Brasil. Telefone: (16) 3602-2839; Celular (16) 981394903;

Dr. Octávio Marques Pontes Neto. Depto. de Neurociência e Ciência do Comportamento da Faculdade de Medicina de Ribeirão Preto da Universidade de São Paulo, Ribeirão Preto, Brasil. Telefone: (16) 3602-1147;

$\mathrm{Dr}^{\mathrm{a}}$. Renata Ferranti Leoni. Depto. de Neurociência e Ciência do Comportamento da Faculdade de Medicina de Ribeirão Preto da Universidade de São Paulo, Ribeirão Preto, Brasil. Telefone: (16) 3602-2558;

Telefone CEP (Comitê de Ética em Pesquisa): (16) 3602-2228.
\end{abstract}

\section{De que se trata este documento que estou lendo?}

Este documento é um termo de consentimento, no qual serão abordadas todas as informações sobre o estudo. O pesquisador irá revisar as informações para ter certeza que o senhor / a senhora entendeu todas elas. Você pode fazer perguntas quando quiser. Se você concordar em participar do estudo, você terá que assinar este termo de consentimento e você terá uma cópia para guardar. Antes de receber as informações sobre o estudo é importante que o senhor / a senhora saiba dos seguintes detalhes:

c) Sua participação é completamente voluntária;

d) Você poderá decidir não participar do estudo quando quiser, sem perder o direito de receber os cuidados médicos de rotina, ou quaisquer outros benefícios aos quais tenha direito na assistência médica regular na clínica habitual, qualquer que seja sua decisão.

Porque está sendo feito este estudo?

O senhor (a) está sendo convidado (a) a participar de uma pesquisa que tem como objetivo avaliar a circulação do cérebro e o funcionamento cognitivo de pessoas que apresentem alguma artéria do pescoço comprometida.

\section{O que eu preciso fazer se eu decidir participar do estudo?}

Se concordar em participar do estudo, o senhor / a senhora deverá autorizar o pesquisador a analisar os dados sobre sua saúde no seu prontuário médico. Deverá então, comparecer ao Hospital das Clínicas, do Campus, por dois dias, cujos quais serão agendados pelo pesquisador.

No primeiro dia agendado, o pesquisador irá fazer algumas perguntas sobre sua saúde e sobre os remédios que utiliza. Além disso, será realizado um exame de ultrassom parecido com aquele feito na barriga das grávidas para ver o bebê, mas no seu caso será colocado o instrumento no pescoço e na cabeça, para ver alguns vasos sanguíneos. O exame irá durar, em média, 20 minutos. Você não sentirá nenhuma dor durante o exame.

No segundo dia será realizado um exame na máquina de Ressonância Magnética. Esse aparelho tem a forma de um grande tubo de metal, largo, com uma abertura por onde o senhor (a) entrará deitado (a) de barriga para cima. Essa máquina produz um campo magnético, como se fosse um imã, que passa através do seu corpo sem desordenar ou prejudicar nenhuma parte dele. A função dela será de produzir imagens do seu cérebro, além de demonstrar o funcionamento dele. Nada disso será sentido e não estará fazendo nenhum mal à sua saúde. Durante o exame, a máquina fará um barulho alto. Será também colocada uma cânula na parte de fora do seu nariz, pela qual sairá um ar durante algum tempo do exame, sendo que esse ar não causa nenhum mal para sua saúde. Não sentirá nenhuma dor durante o exame. Não é necessário que faça nada, além de permanecer o mais parado possível.

A permanência dentro da máquina será por um período médio de 45 minutos. O senhor / a senhora poderá ser retirado (a) a qualquer momento que sentir algum desconforto. Dependendo da roupa que estiver usando, 
poderá ser pedido a utilizar um roupão do Hospital, a fim de garantir seu conforto e não gerar nenhum problema nas imagens.

Neste mesmo dia o pesquisador, também, deverá fazer alguns testes, para avaliar a sua condição cognitiva, como memória, atenção, linguagem e funções executivas. Tal avaliação deverá ser realizada em um período médio de 1 hora e 30 minutos. Portanto, as avaliações equivalentes ao segundo dia totalizarão, em média, 2 horas e 15 minutos.

\section{Quantas pessoas irão participar do estudo?}

Participarão do estudo dez pessoas que não apresentem comprometimento da artéria do pescoço e que não tiveram acidente vascular cerebral (AVC).

\section{Porque eu fui escolhido para participar do estudo?}

Um dos objetivos deste estudo é saber como está a circulação sanguínea cerebral e o funcionamento cognitivo de pessoas saudáveis, que não apresentem comprometimento das artérias do pescoço. Se o senhor ou a senhora foi escolhido (a) é porque preenche este critério.

\section{Quais são os riscos e desconfortos do estudo?}

Algumas pessoas podem sentir-se desconfortáveis devido à máquina de Ressonância Magnética ser um tubo que produz ruídos, bem como devido à permanência, por um período de tempo de 45 minutos, sem se mexer.

\section{Existem benefícios em participar deste estudo?}

Sim. No seu caso os dados colhidos serão anexados ao seu prontuário do Hospital das Clínicas da FMRP e no caso da observação de alguma alteração nos exames, o senhor (a) será prontamente encaminhado para o serviço de saúde mais apropriado.

\section{Existe alguma compensação financeira ou custos para mim?}

O senhor (a) não receberá nenhuma compensação financeira relacionada à sua participação neste estudo. Da mesma forma, o Sr. (a) não terá nenhuma despesa pessoal em qualquer fase do estudo, incluindo exames e consultas. Durante o período de sua participação, a despesa relacionada ao transporte será reembolsada.

\section{Como é protegida minha privacidade?}

As informações coletadas neste estudo serão anexadas ao seu prontuário no Hospital das Clínicas, os médicos e outros profissionais autorizados a terem acesso ao prontuário terão acesso às informações. Além disto, estes dados serão vistos e analisados apenas pelos pesquisadores responsáveis por este estudo, os dados poderão ser comunicados para outros pesquisadores e médicos, mas sua identidade será mantida em sigilo. Nenhum dado que possa revelar sua identidade estará disponível para quaisquer pessoas ou em quaisquer textos ou publicações.

Os dados deste estudo são mantidos em um banco de dados do Centro de Ciências das Imagens da Física Médica, caso estes dados sejam consultados para outros estudos, o CEP será consultado, para ver a necessidade de se assinar um novo termo de consentimento, ou não.

\section{Quem você deve procurar caso tenha problemas ou perguntas.}

Caso o senhor / a senhora tenha perguntas, dúvidas ou qualquer outra informação que deseje saber a respeito deste estudo, poderá procurar os pesquisadores aqui citados, Ana Paula Afonso Camargo (telefones $3602-$ 2839; 981394903) ou Dr. Octávio Marques Pontes Neto (telefone 3602-1147), ou ainda, o Comitê de Ética em Pesquisa (telefone 3602-2228).

Uma via deste documento, assinada pelo pesquisador, deverá ser devolvida ao senhor (a) e uma segunda via ficará arquivada com o pesquisador.

res, deverá ser devolvida ao senhor (a) e uma segunda via ficará arquivada com a pesquisadora.

\section{Assinaturas}

Os detalhes deste estudo foram explicados a você, que teve a oportunidade de fazer todas as perguntas aos pesquisadores. Se tiver lido o consentimento livre e esclarecido (ou se ele tiver sido explicado para você), tiver entendido a informação e concordar voluntariamente em participar deste estudo, por favor, assine abaixo: 


\begin{tabular}{lcc}
\hline Nome do Voluntário & (impresso ou em letra de forma) \\
& Data: \\
\hline Nome da Testemunha & (impresso ou em letra de forma)
\end{tabular}

Data:

\section{Declaração do Pesquisador}

Declaro que revisei este estudo e o formulário de consentimento com o participante. Segundo meu entendimento, ele compreendeu os objetivos, os procedimentos, riscos e benefícios do estudo.

Nome do Pesquisador (impresso ou em letra de forma)

Assinatura do Pesquisador

Data: 